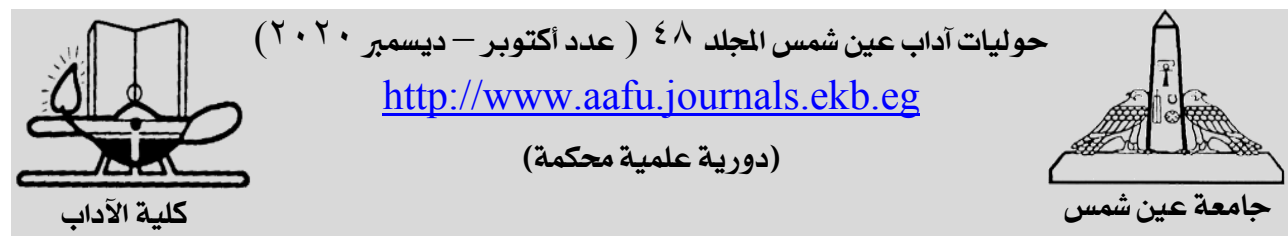

الإنسان بين الغرابة والاغتراب في الفلسفة اليونانية

"دراسة تحليلية نقدية مقارنة في مفهوم الاغتر اب الإنساني - نماذج ممثلة" الإنية

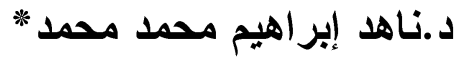

مدرس الفلسفة اليونانية- كلية التربية - جامعة الإسكندرية

المستخلص الانسان

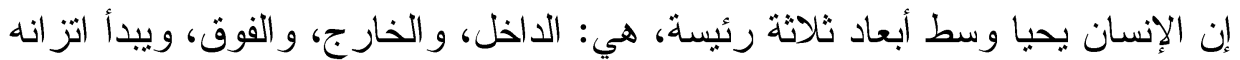

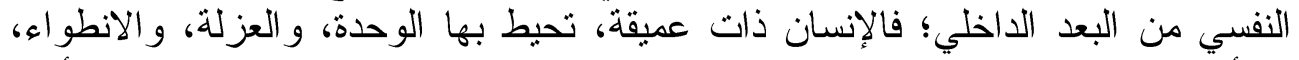

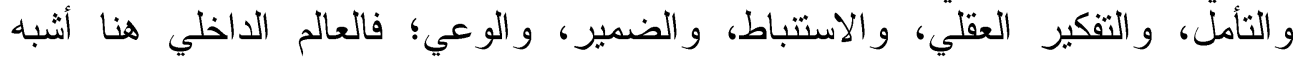

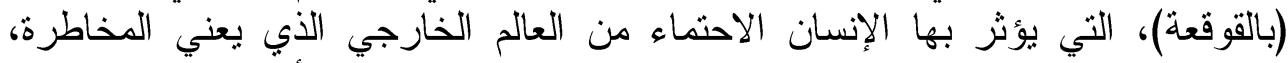

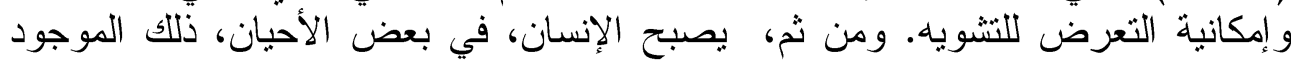

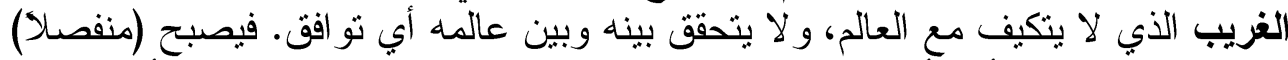

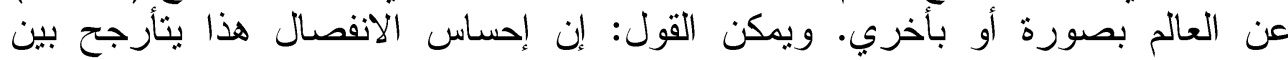
(الغزابة (Strangeness) و (الاغتراب (Alienation)؛ فيصبح الإنسان تارة (غريبا)،

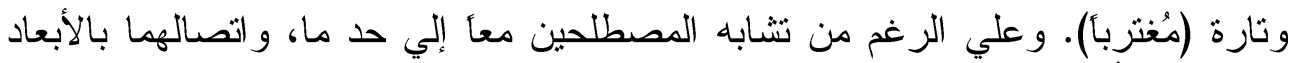

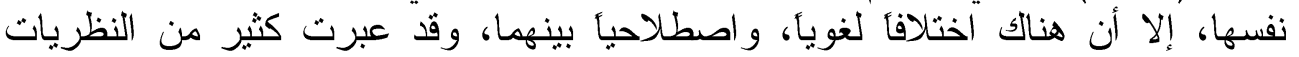

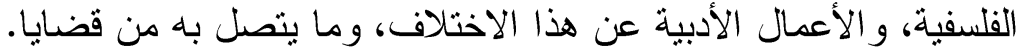

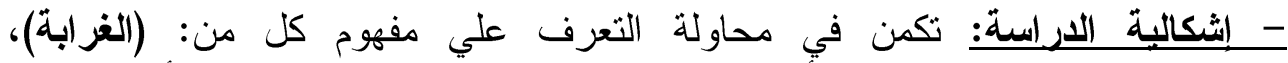
و (الاغتراب)، و الوقوف علي الأبعاد البعيدة للاغتر اب الإنساني، ومعرفة أهم النية النماذج

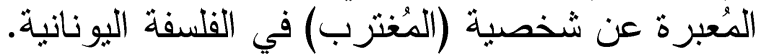

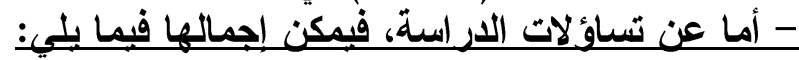

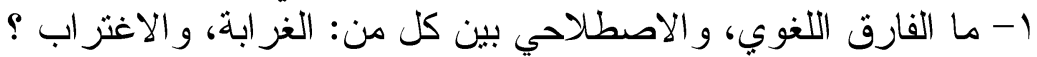

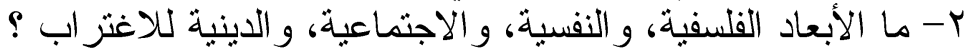

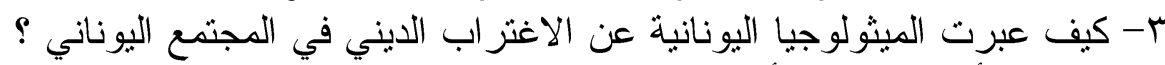

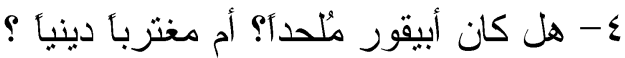

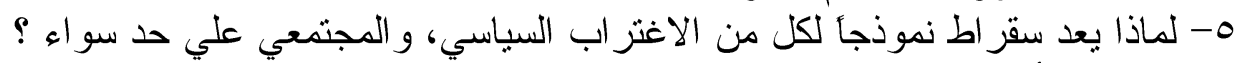

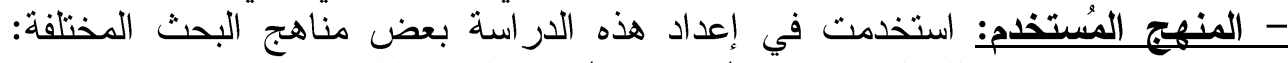

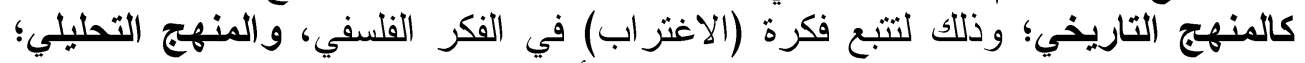

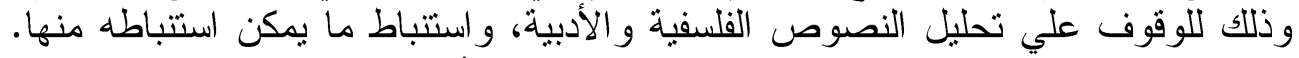

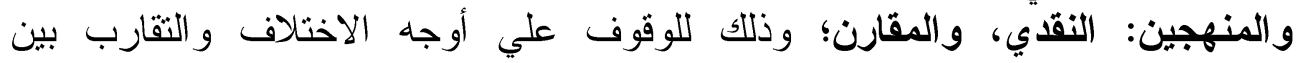
مفهومي: (الغرابة)، و (الاغتر اب) وما يتصل بهما من قُشايا مختلفة في الفلسفة اليونانية.

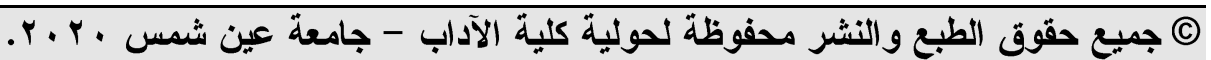


شغلت أزمة الإنسان اهتمام الفلاسفة و المفكرين علي مر العصور ؛ فمنذ بدء الخليقــة

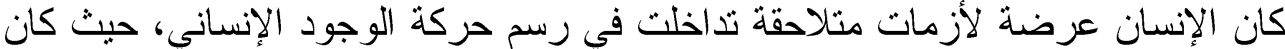

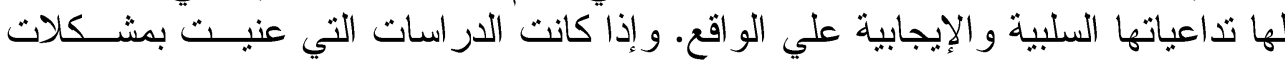

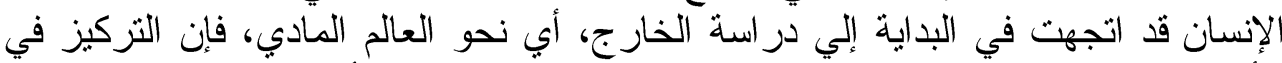

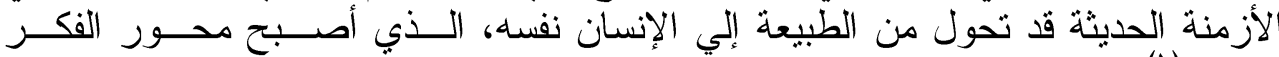

و إذا كان الإنسان بحبا وسط أبعاد ثلاثة رئيسة، هي: الداخل، و الخارج، و الفوق، فإن إنهان

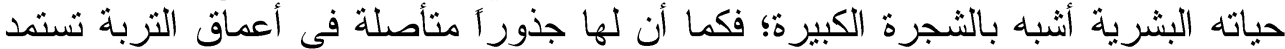

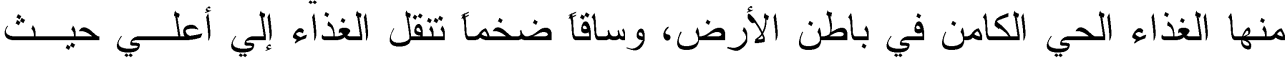

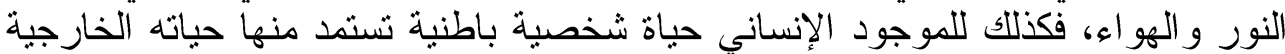

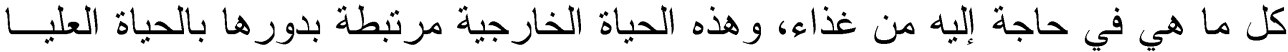

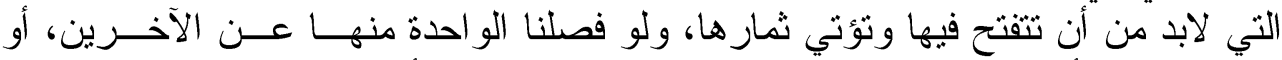

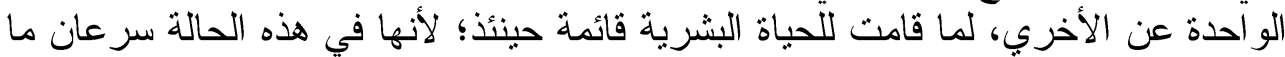

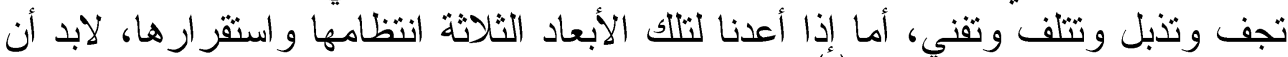

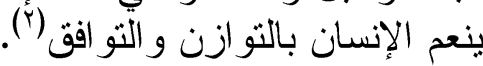

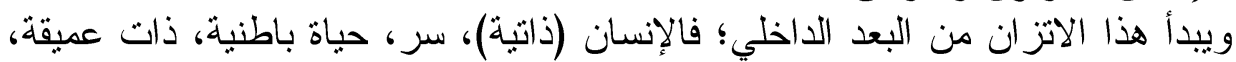

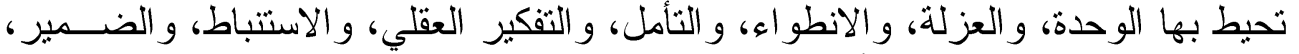

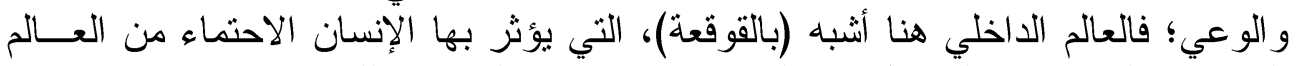

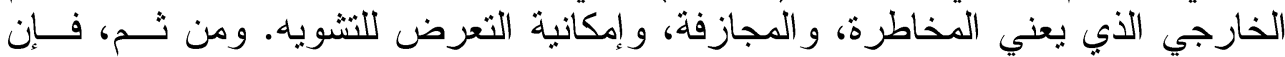

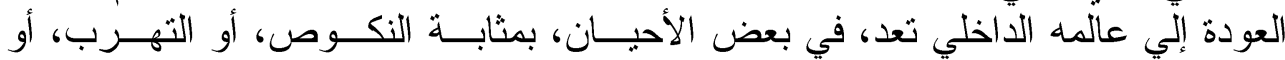

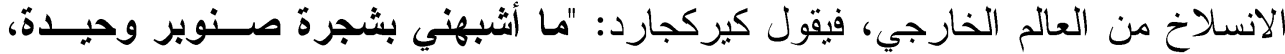

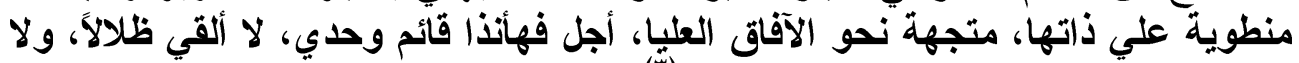

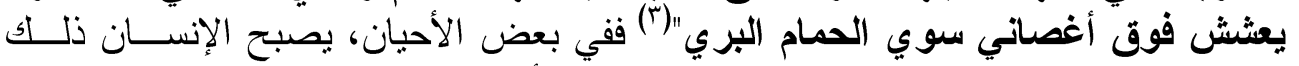

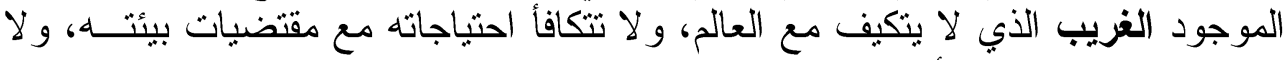

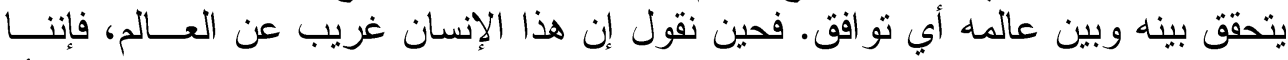

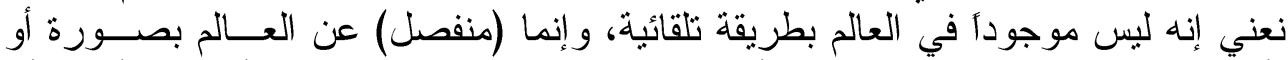

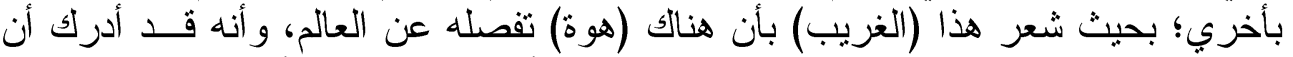

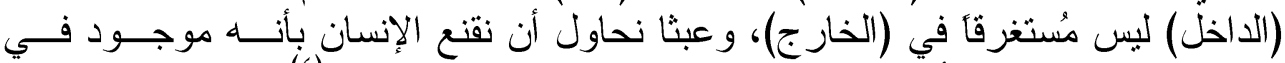

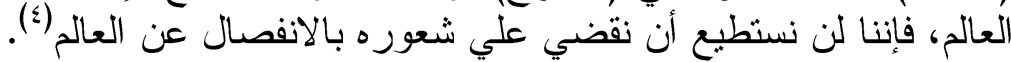

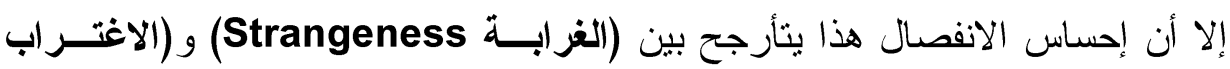

Alienation

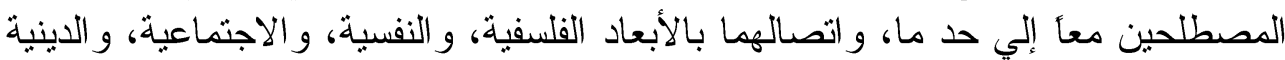

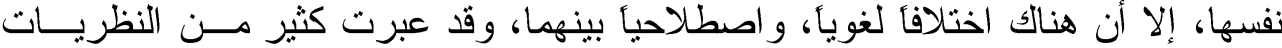
الفلسفية و الاجتماعية، و الأعمال الأدبية عن هذا الاختلاف، وما يتصل به من قضايا، مثل: الغربة، و الغر ابة، و الوحدة، و الفناء. 
- إثكالبة الار اسلة:

تكمن في محاولة التعرف علي مفهوم كل من: (الغرابة)، و (الاغتراب)، و الوقوف على الإبلي

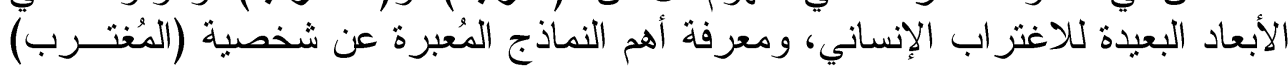
في الفلسفة اليونانية.

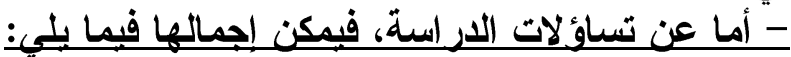

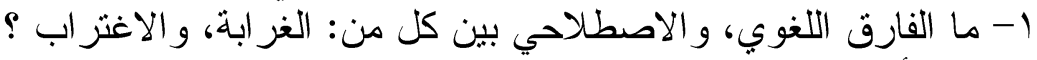

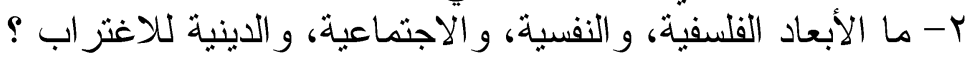

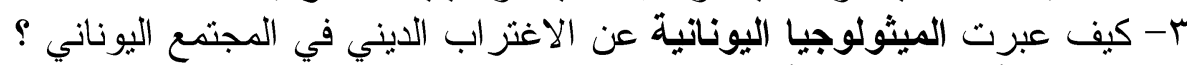

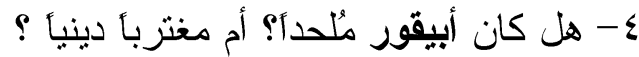
ه- لماذا يعد سقر اط نموذجأ لكل من الاغتر اب السياسي، و المجتمعي علي حد سو اء؟ - المنهُج المُستخدي:

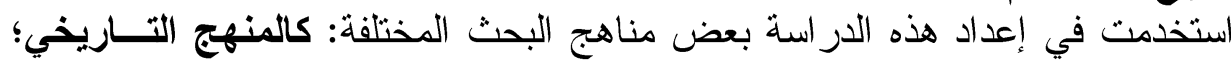

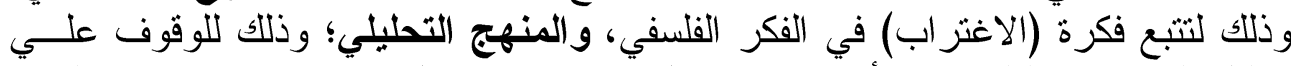

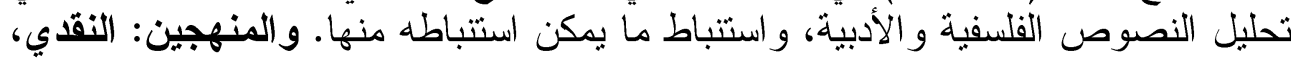

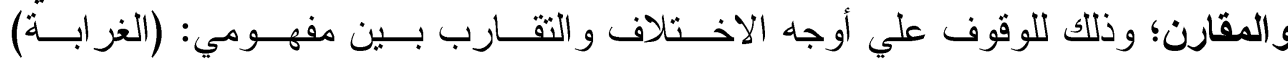

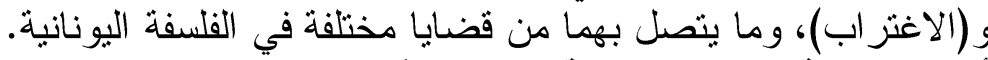

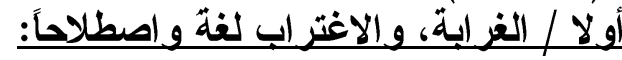

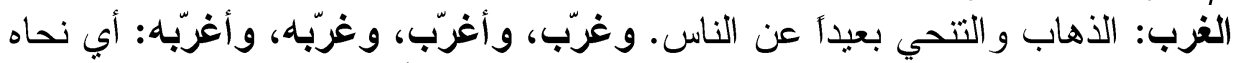

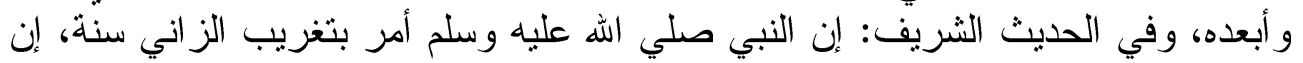

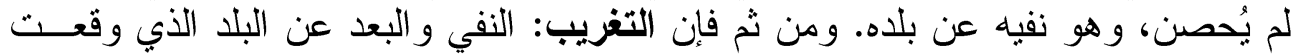

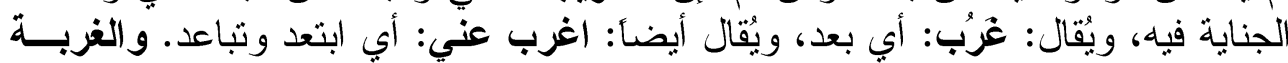

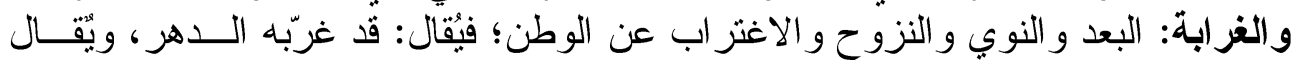

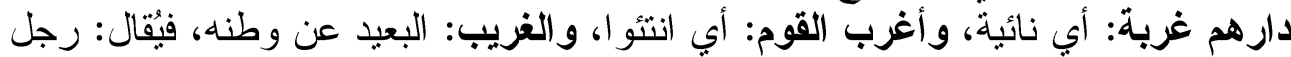

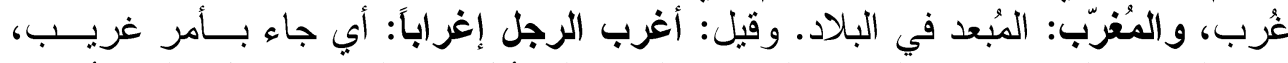

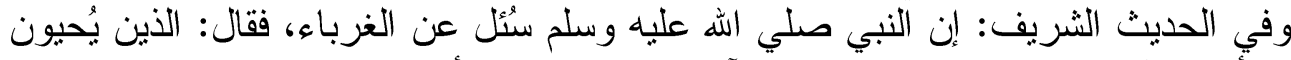

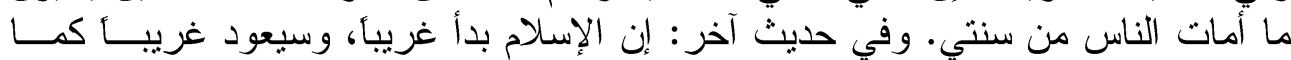

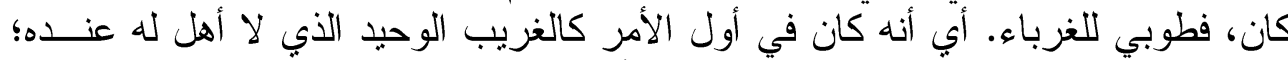

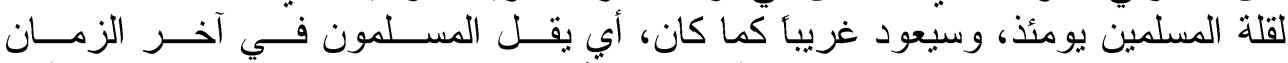

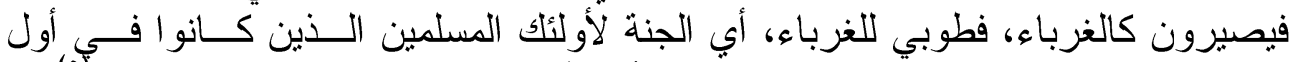

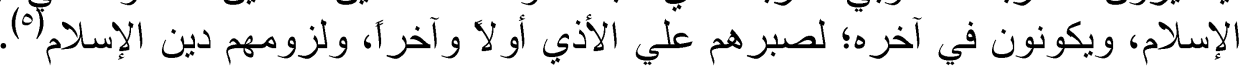

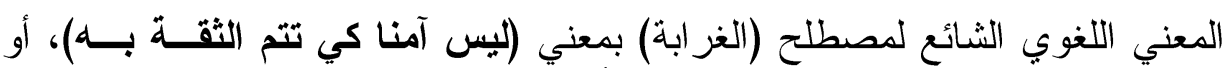

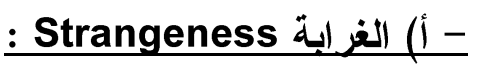

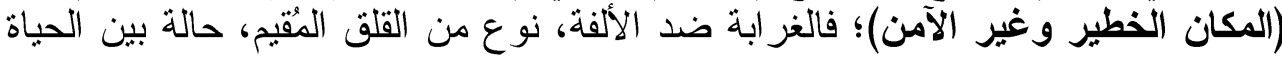

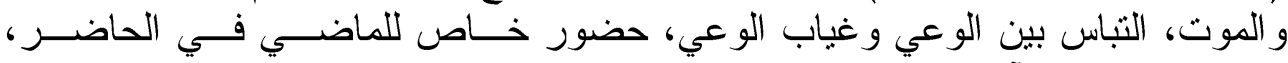

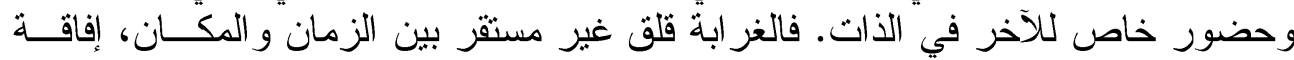

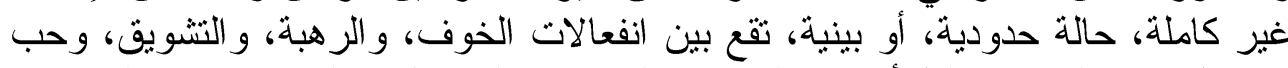

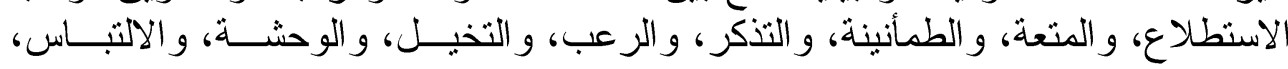


وفقدان اليقين. فالغرابة نوع من الخيال المرتبط بالخوف، و وانعدام الأمن، و التوجس، إنهــا

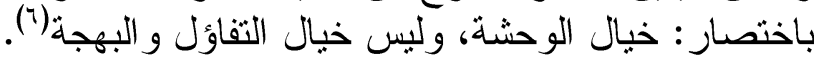

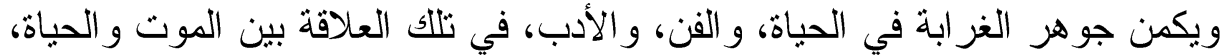

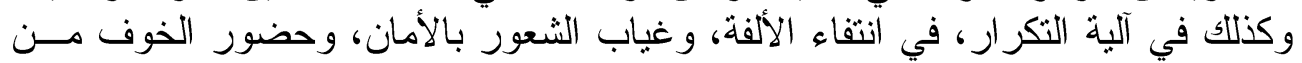

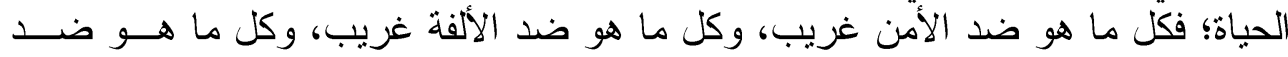

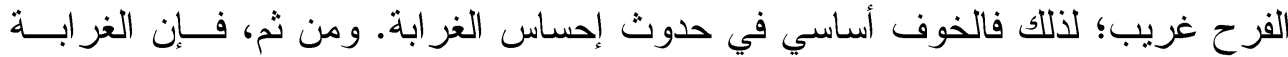

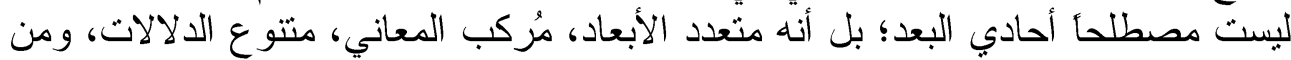

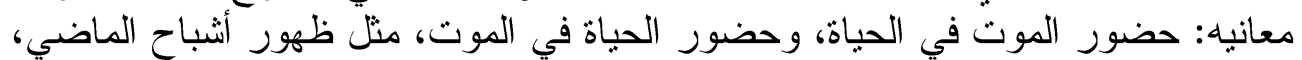

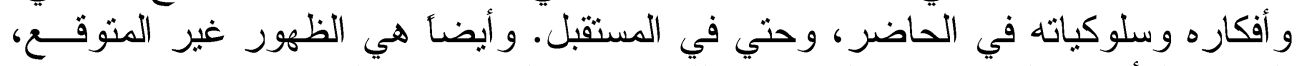

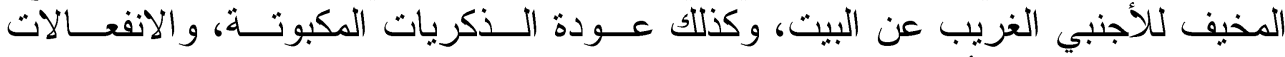

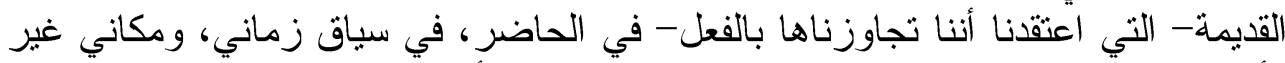

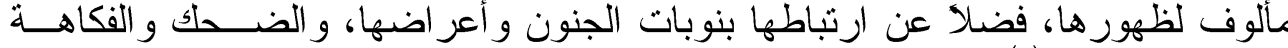

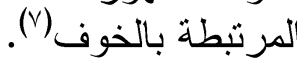

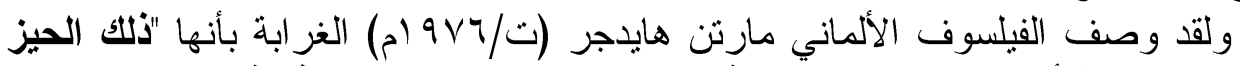

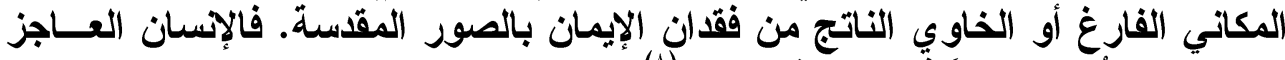

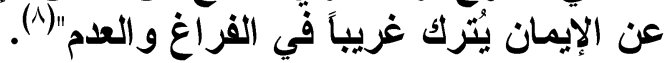

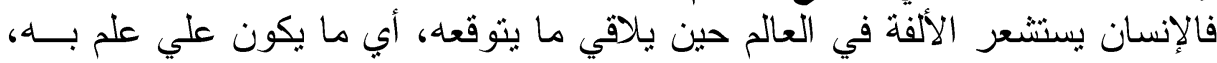

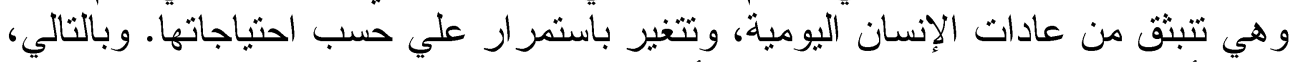

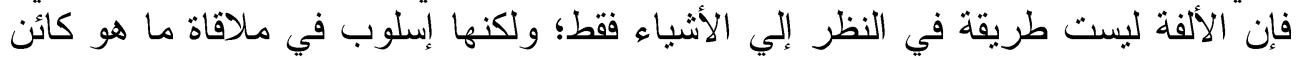

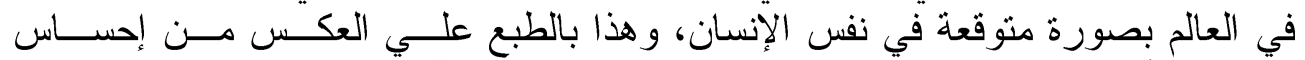

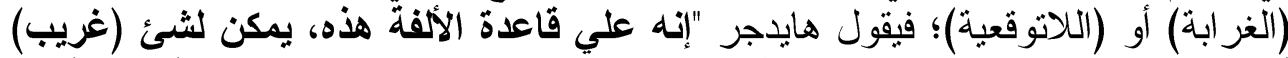

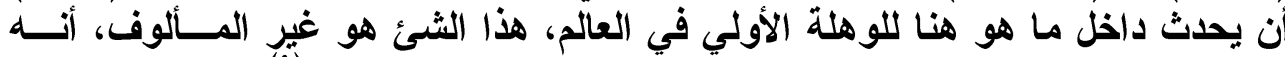

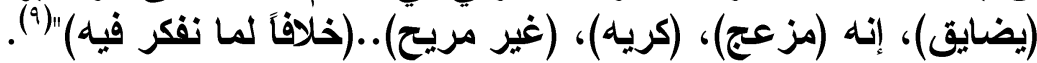

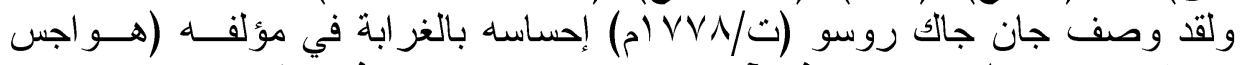

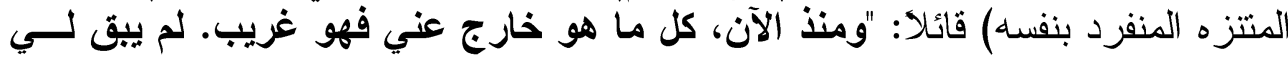

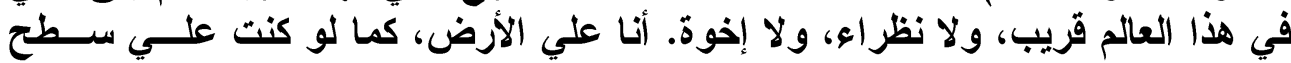

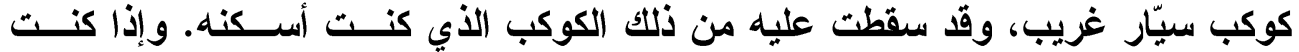

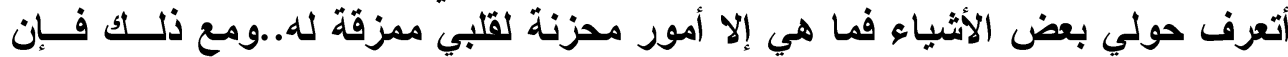

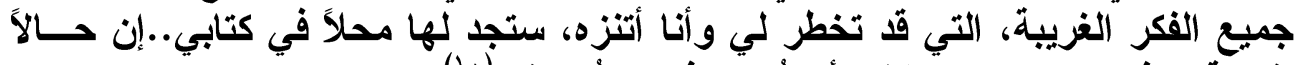

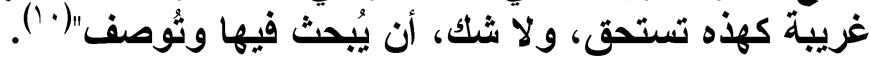

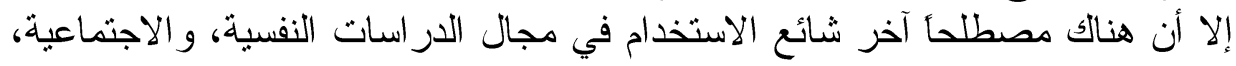
و هو مصطلح (أنومي Anomie) و هو يتداخل في معناه، كثير آ، مع مصطلح (غريــبـ)؛ فيتم ترجمته إلي مصطلح (شذوذ Anomaly) بمعني خروج علي المألوف بوجود صودات

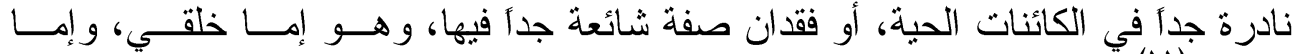

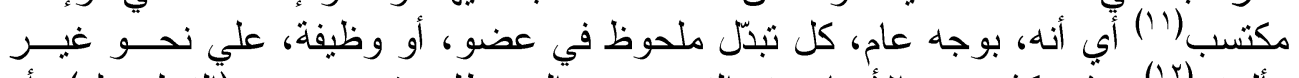

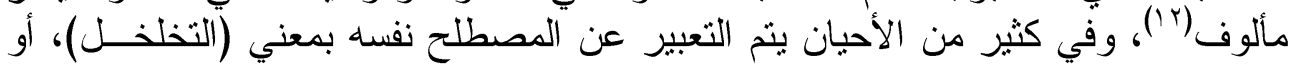

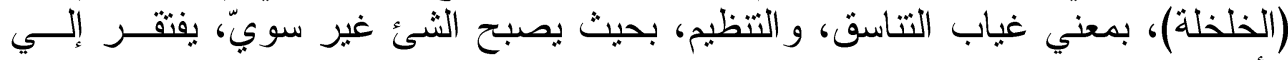

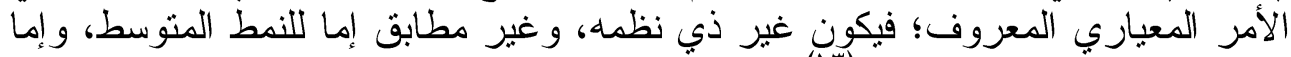

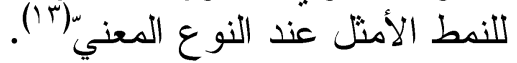




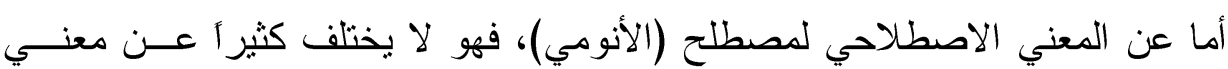

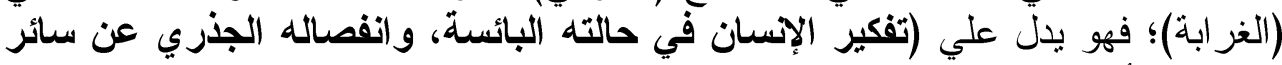

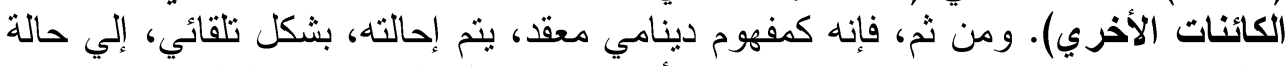

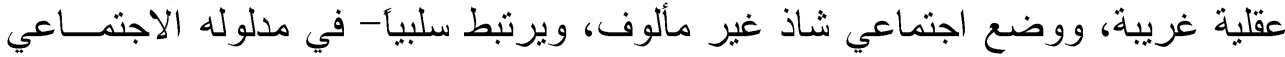

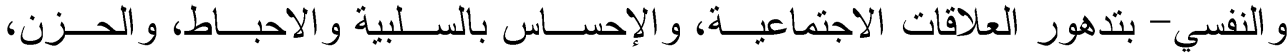
و الخسارة، و الذنب، و الغضب، أو عدم الالكز ام بالأعر اف و القو انين الاجتماعية، و الأخلاقية الأنية

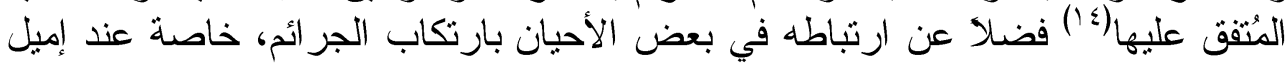

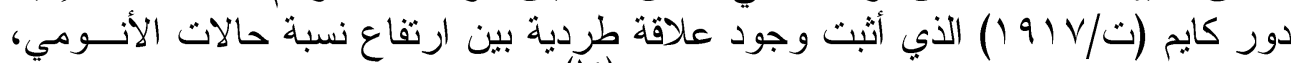

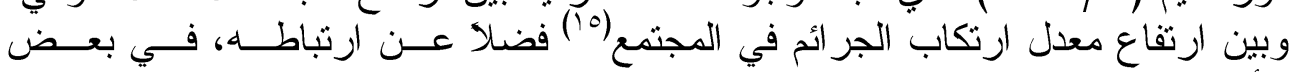

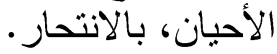

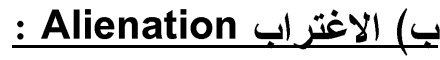

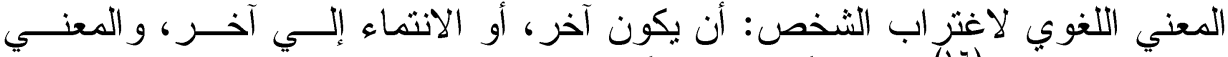

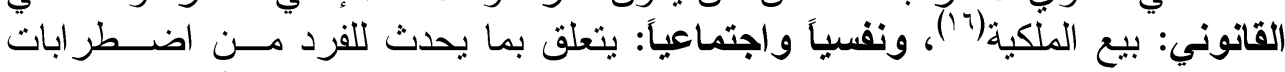

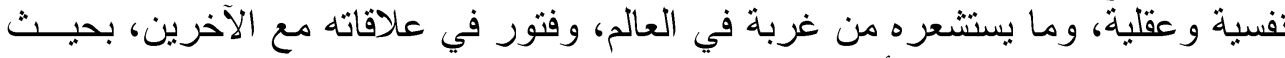

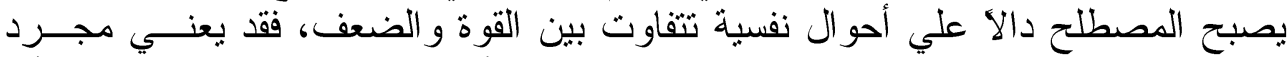

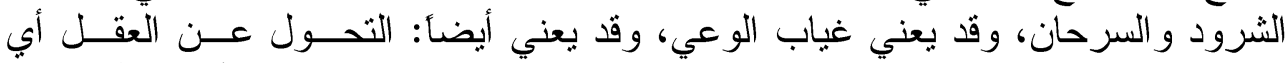

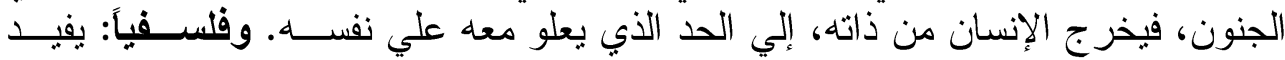

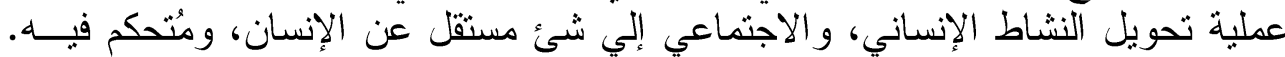

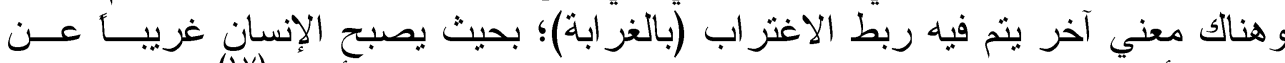

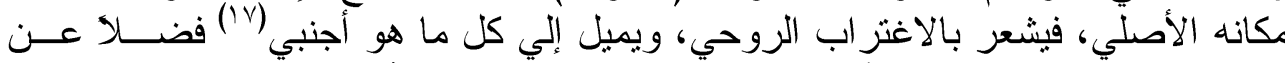

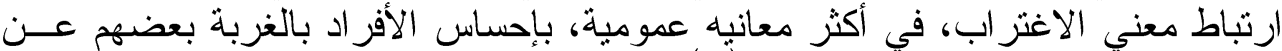

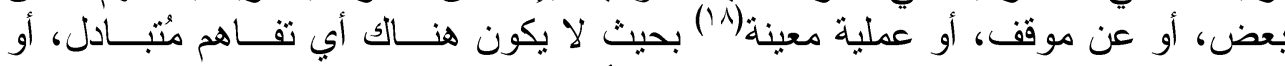

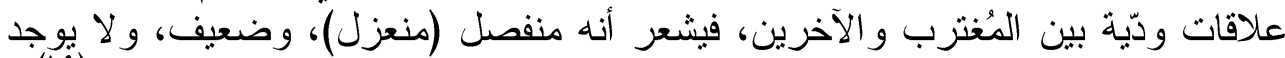

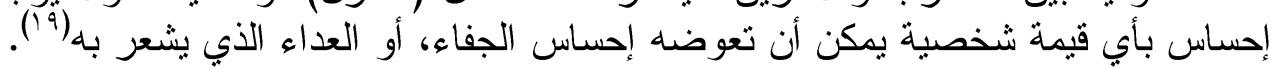

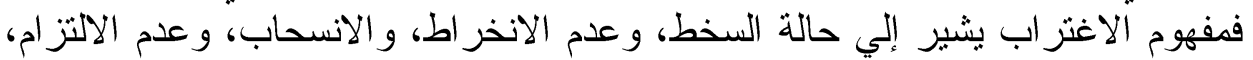

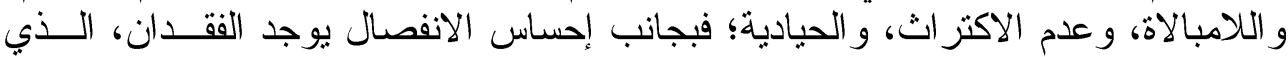

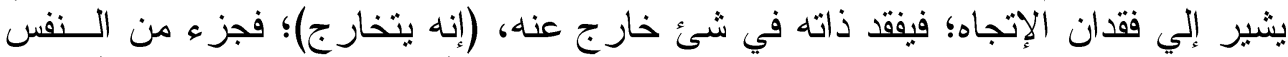

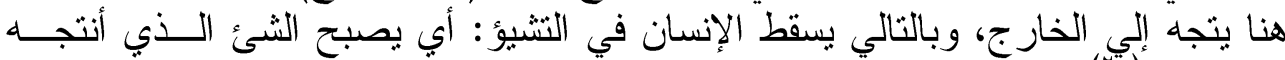

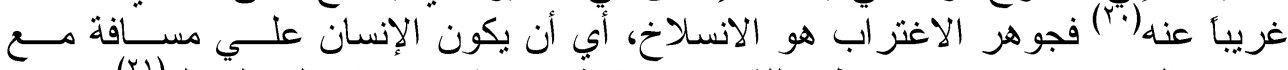

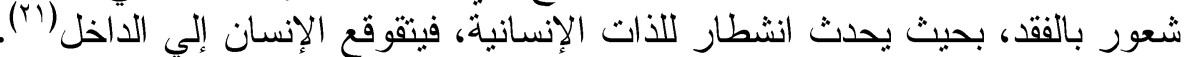

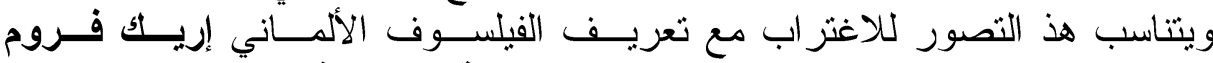

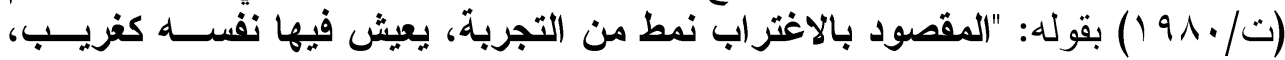

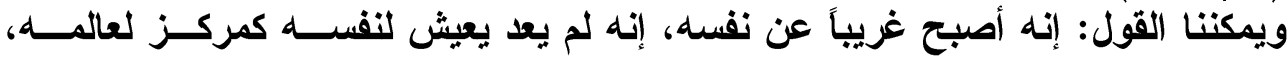

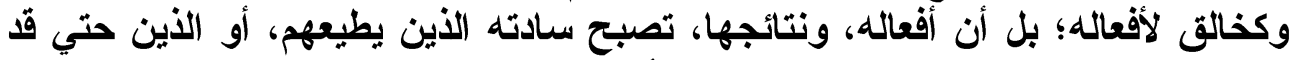

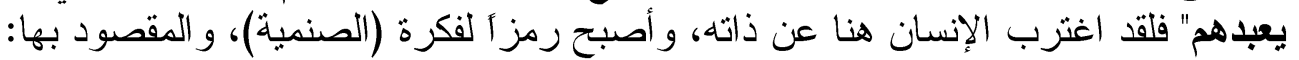

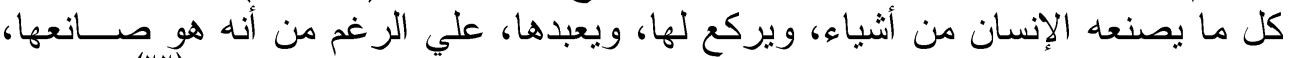

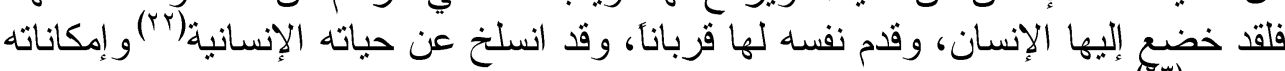




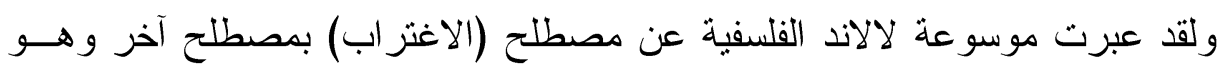

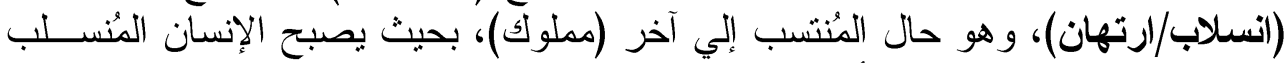

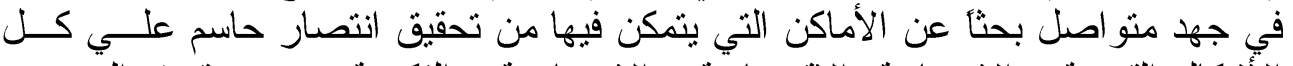

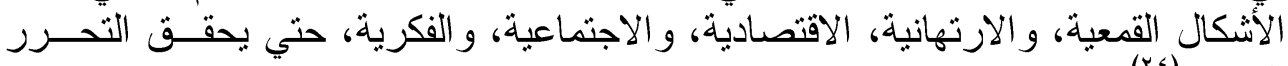

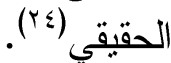

وهنالك مصطلح آخر يتداخل في معناه، إلي درجة كبيرة، مع مصطلح (المُغترب)، ألا

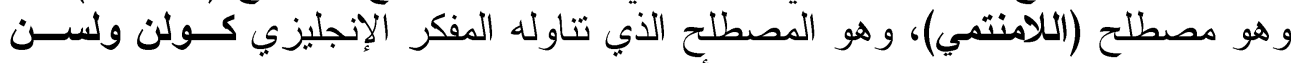

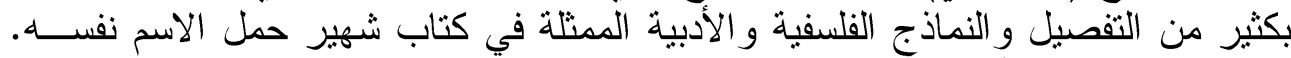

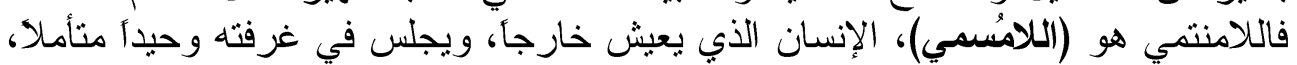

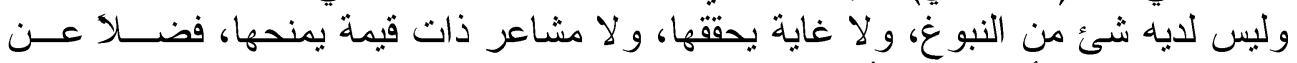

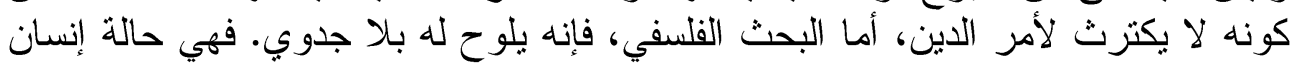

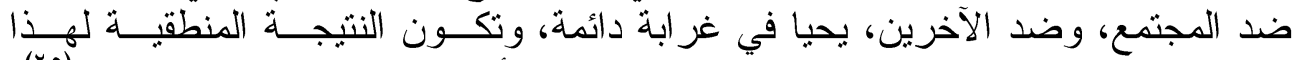

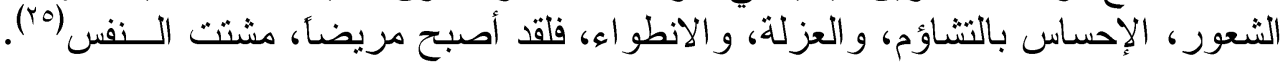

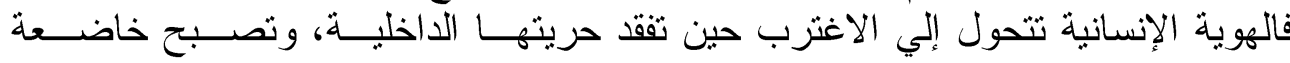

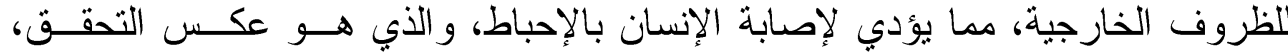

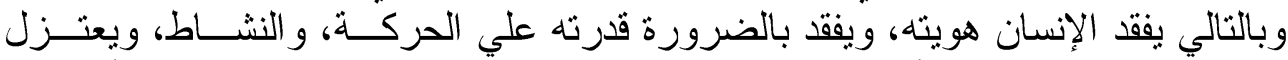

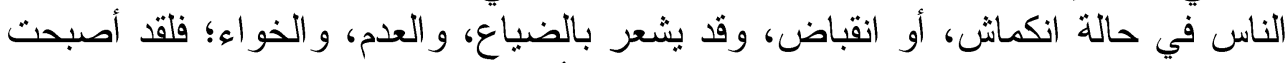

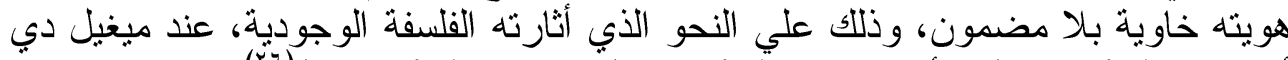

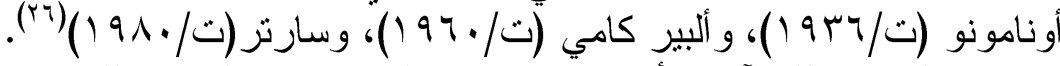

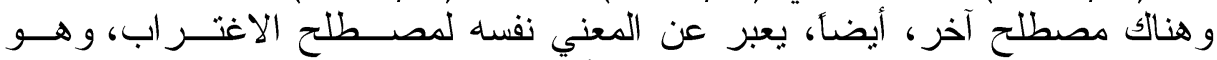

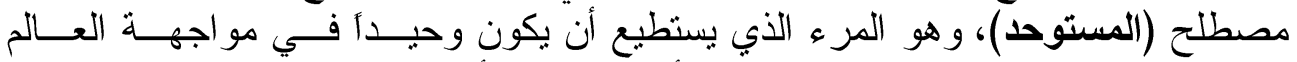

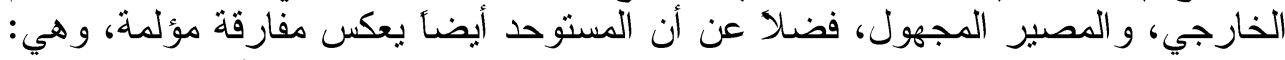

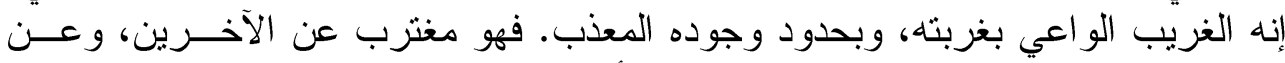

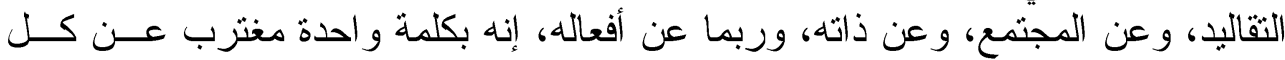

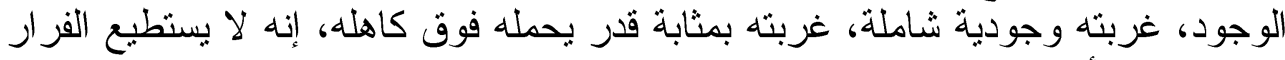

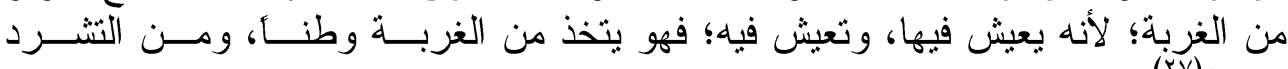
مسكنآ(rv (iv)

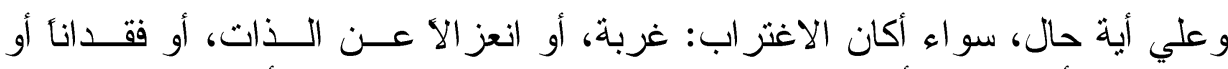

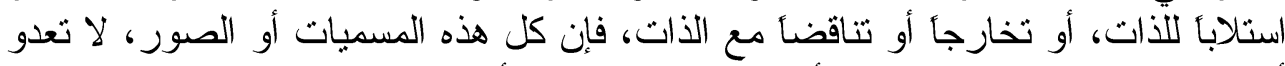

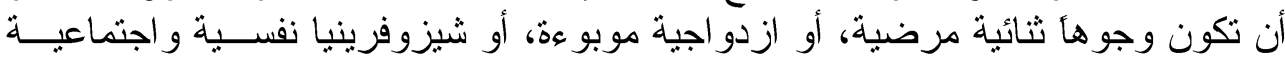

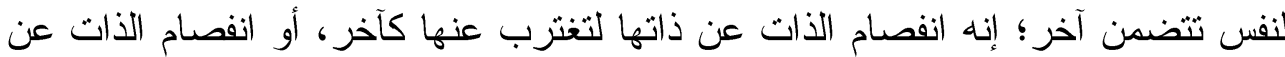

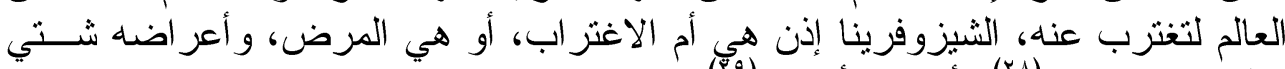

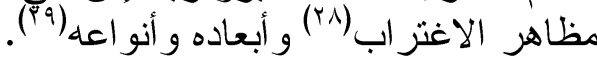

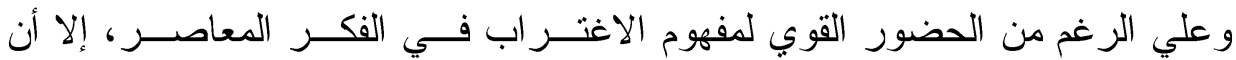

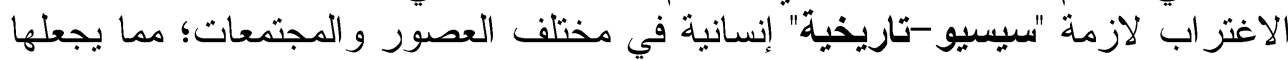

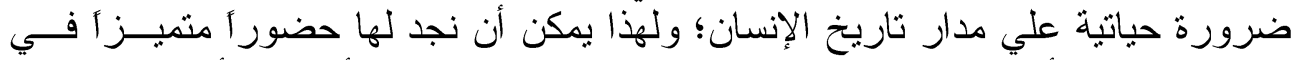

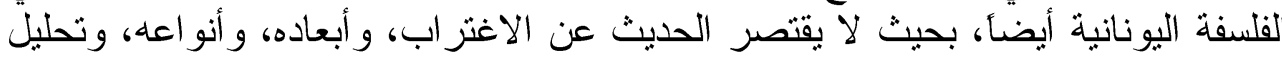

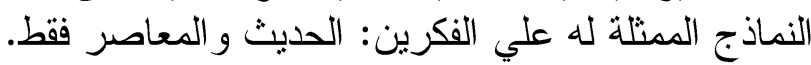


ثانباً/ الغرابة، والاغتراب في الفلسفة البيونانبة (نماذج ممثلة):

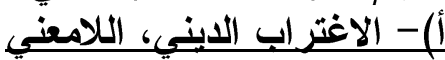
1- الميثولئوحيا اليونانية:

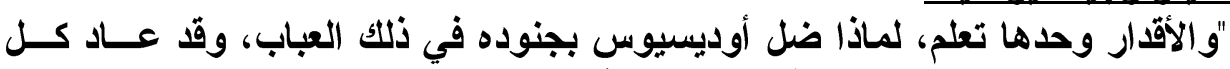

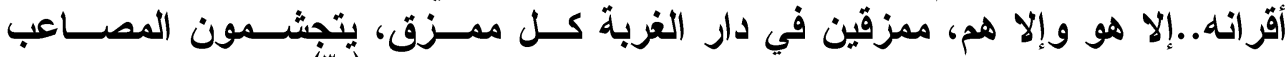

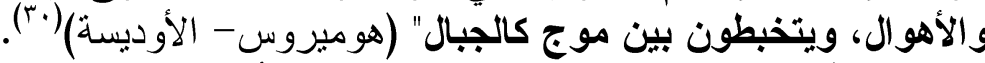

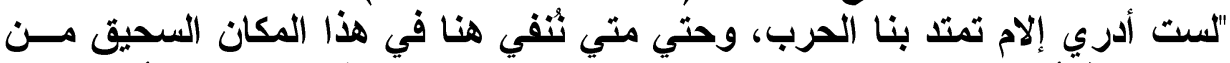

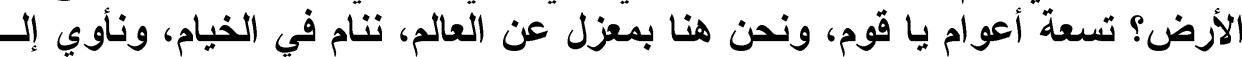

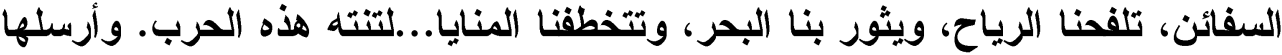

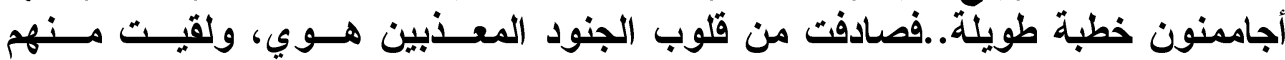

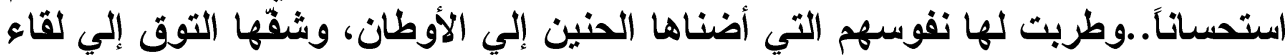

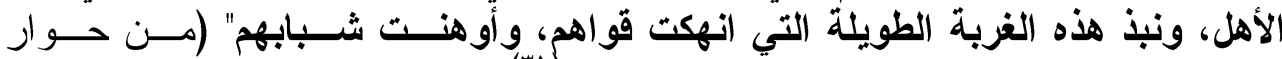

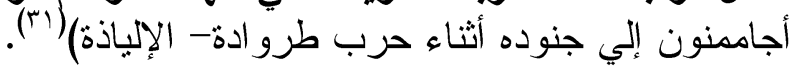

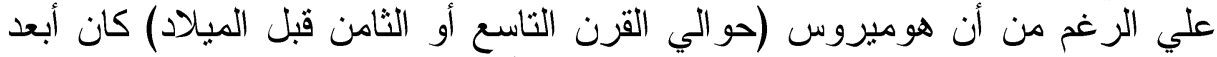

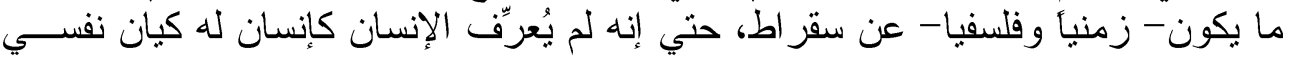

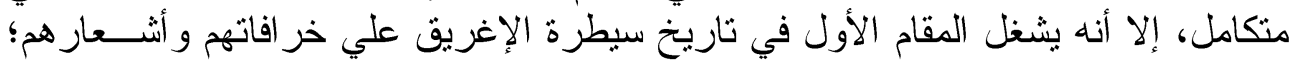

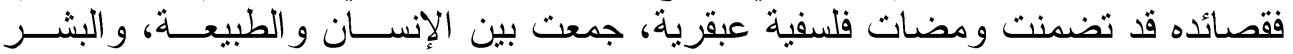

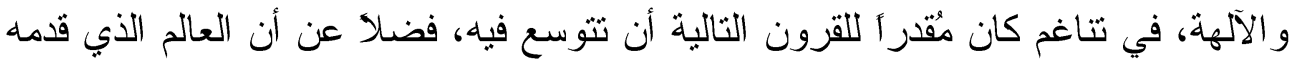

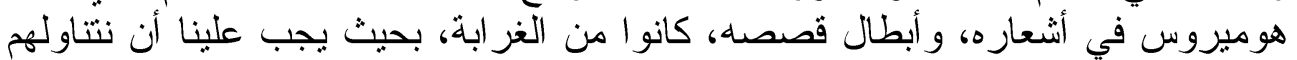

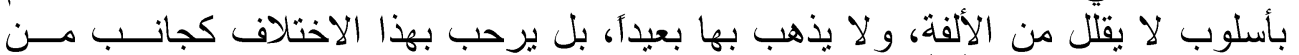

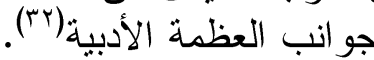

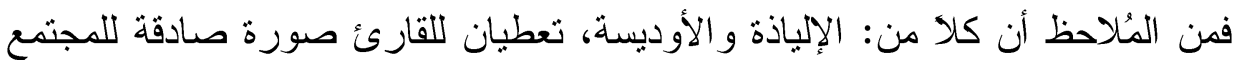

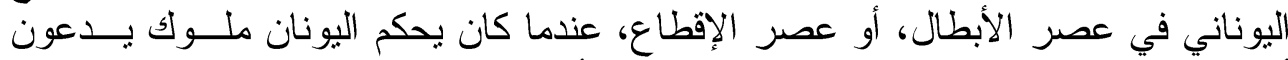

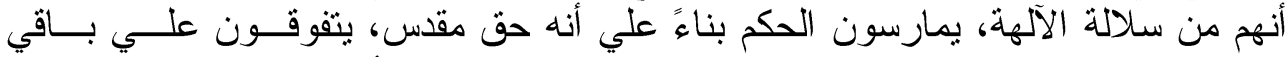

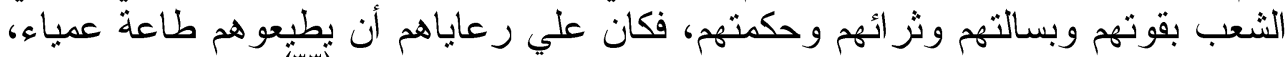

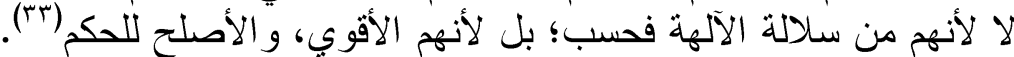

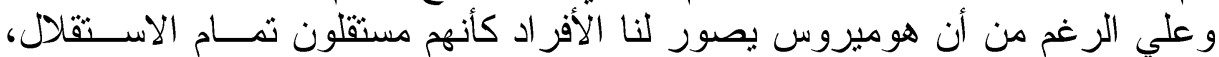

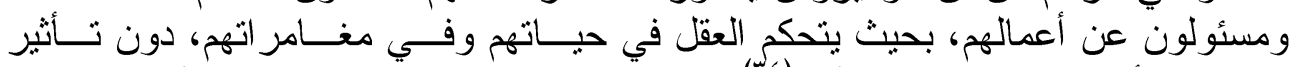

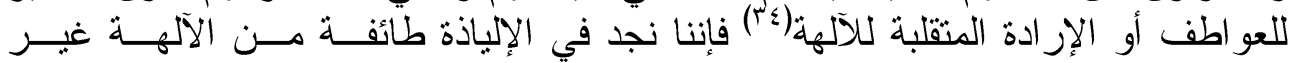

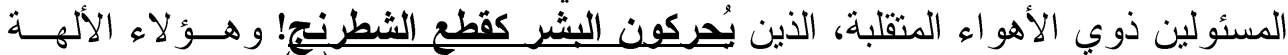

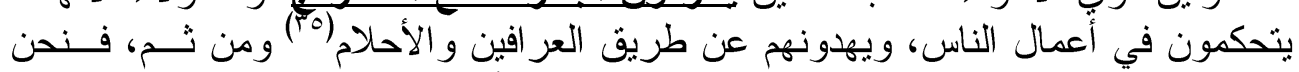

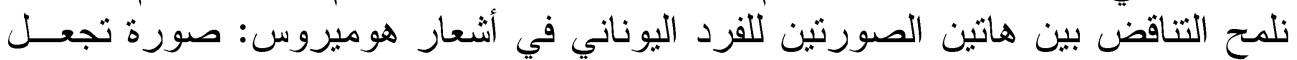

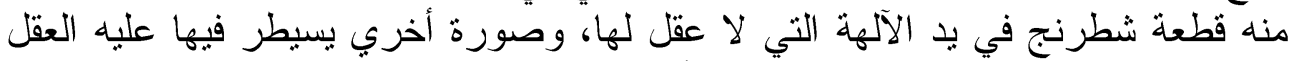

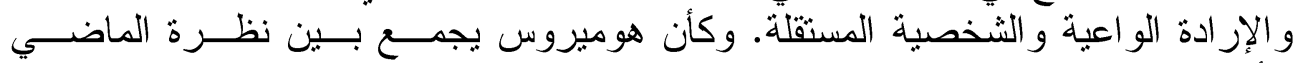

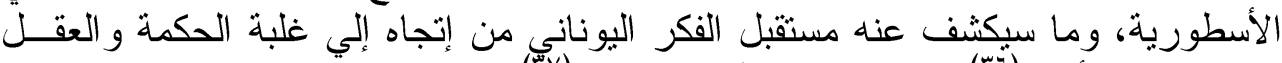

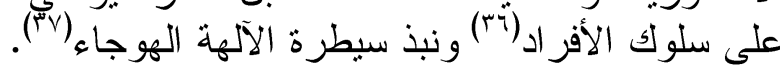

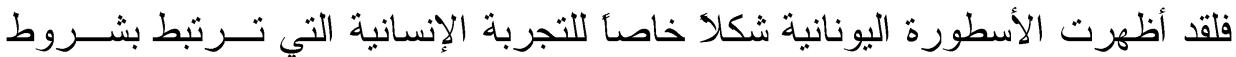

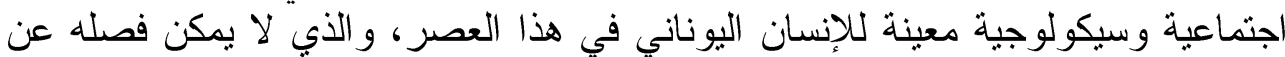

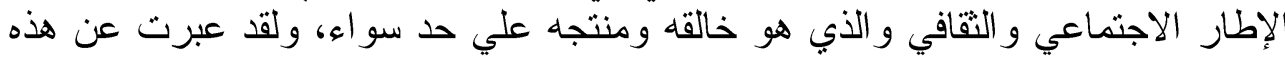




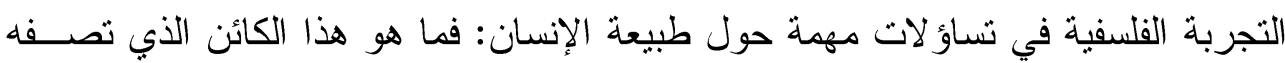

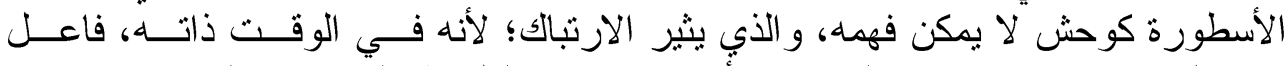

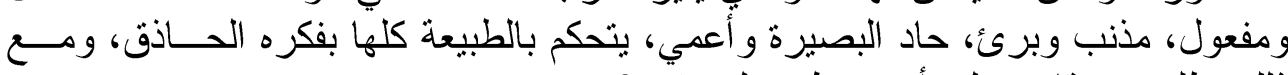

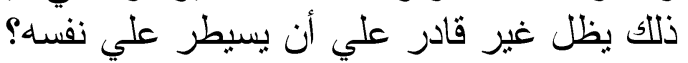

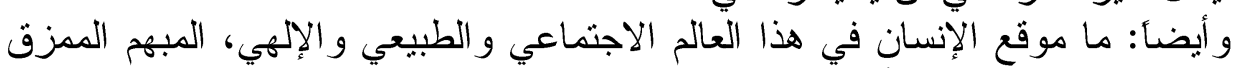

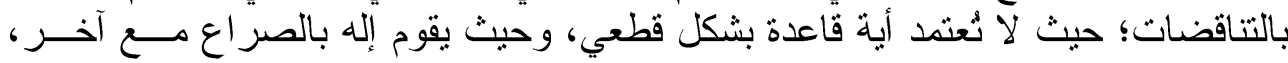

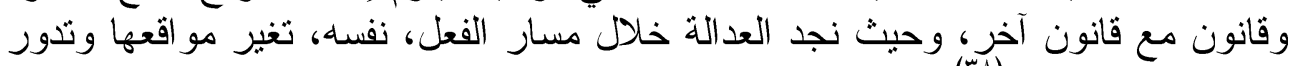

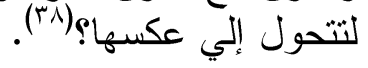

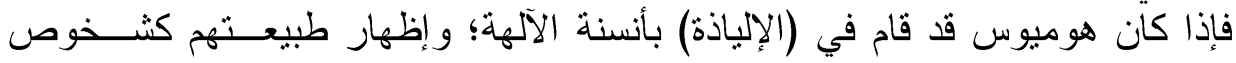

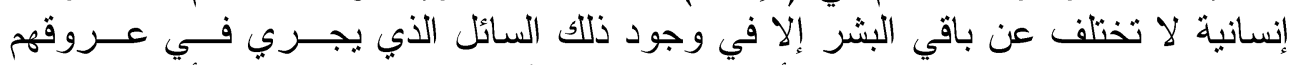

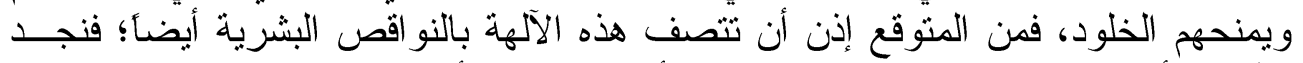

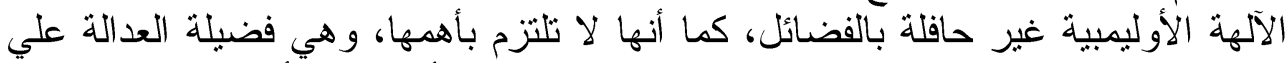

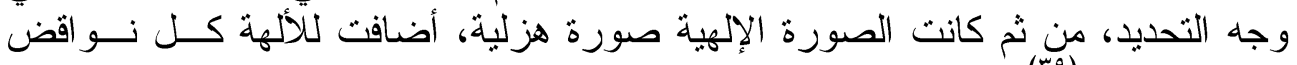

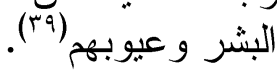

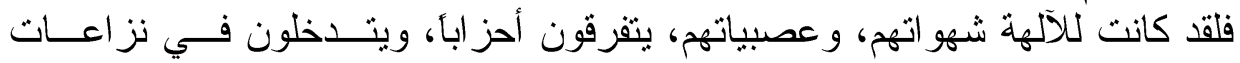

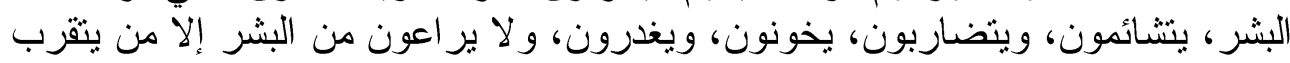

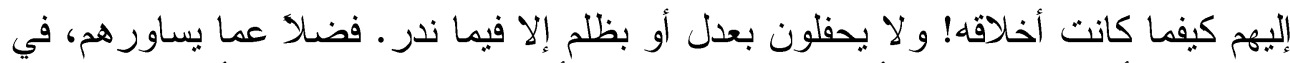

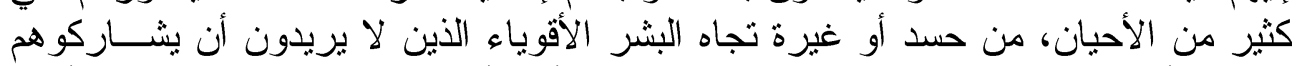

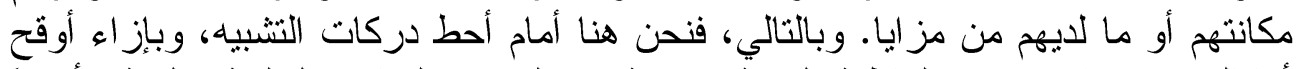

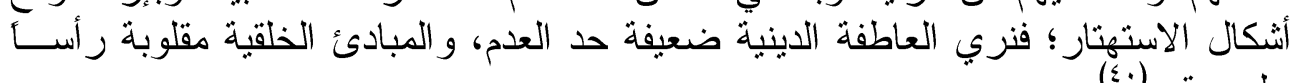

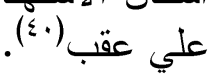

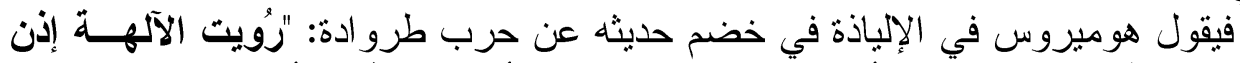

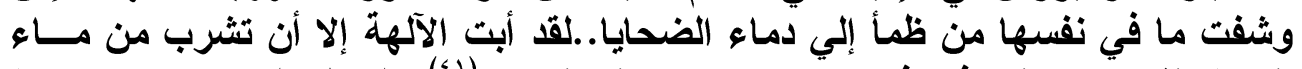

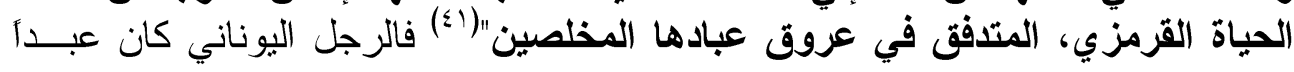

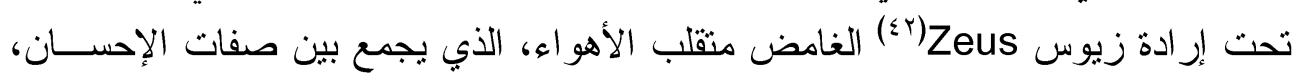

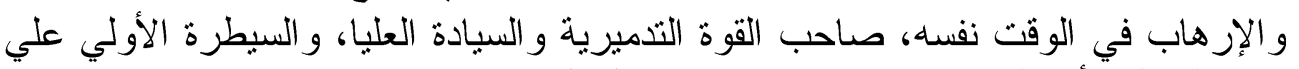

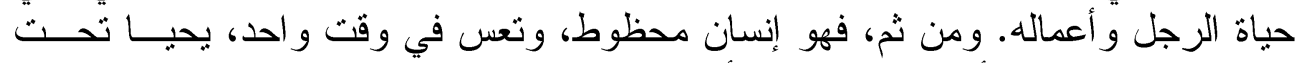

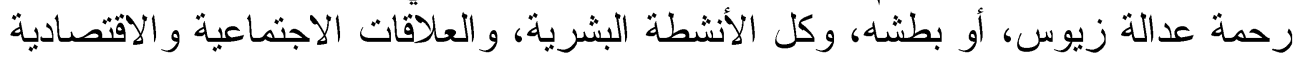

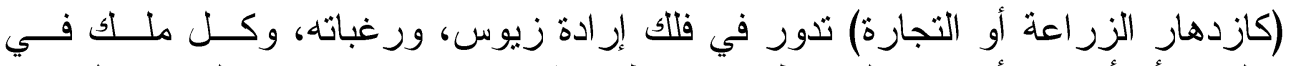

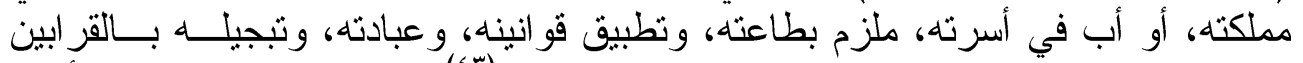

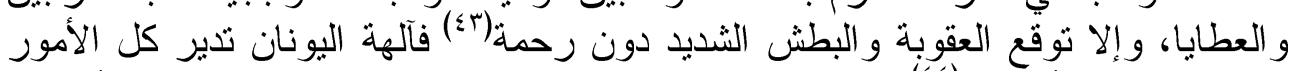

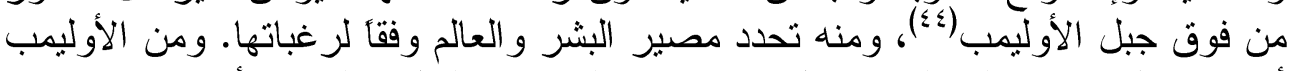

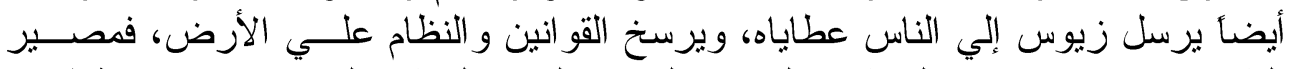

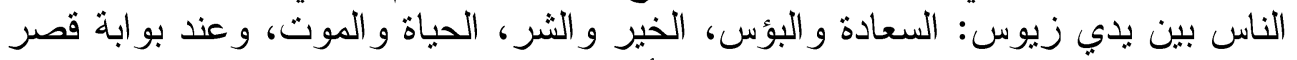

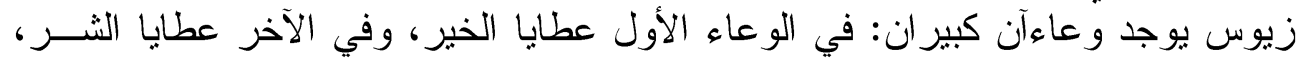

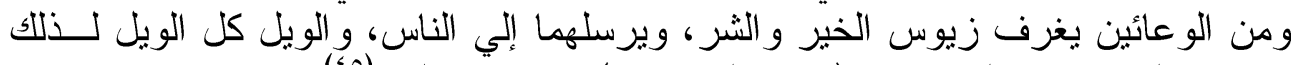

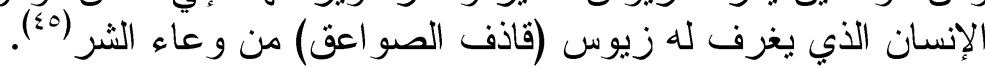

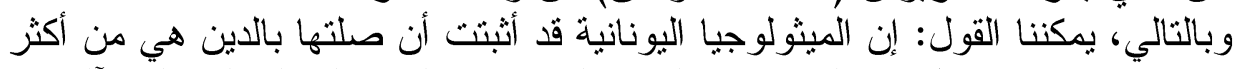

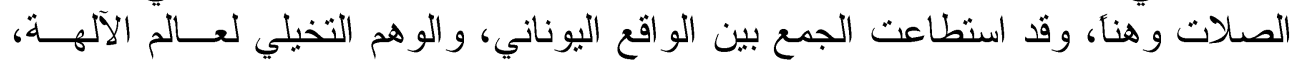


وكأنها (حافلة مليئة بالغر ائب) التي تتنمي إلي ماض مجهول، لا يُعرف عنه إلا أنه خارج

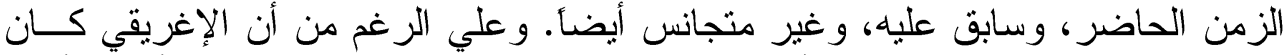

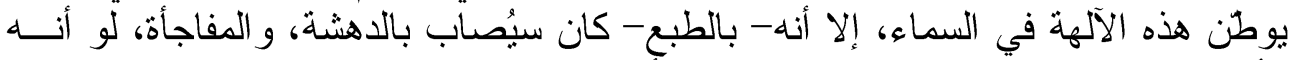

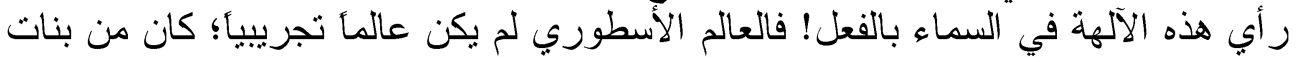

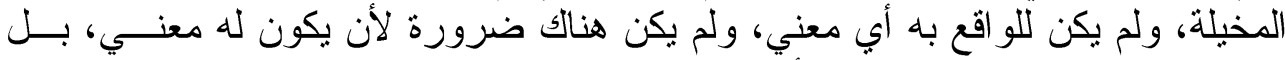

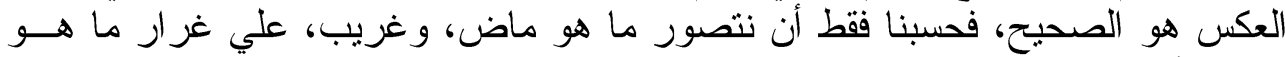

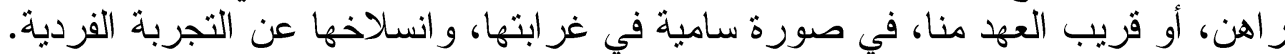

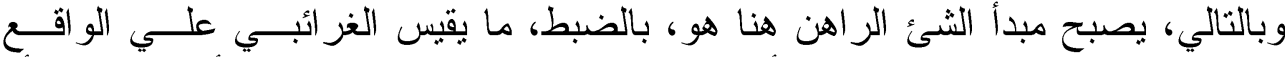

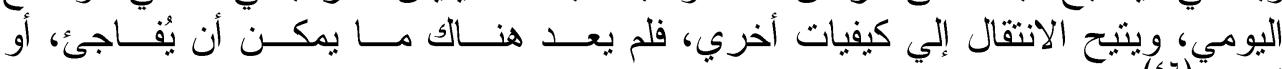

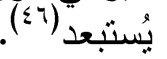

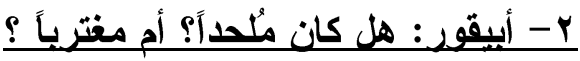
لم تبتعد العقلية اليونانية عن الفكر الديني الذي تبني عقيدة معينة، ألا وهي أن اقتران

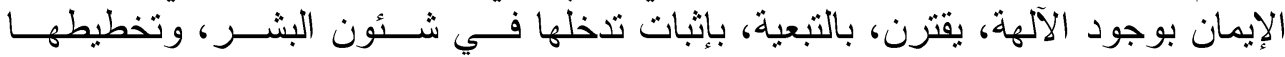

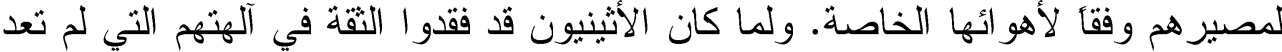

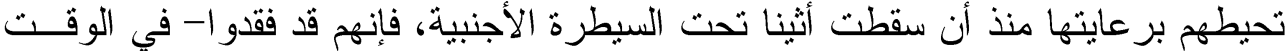

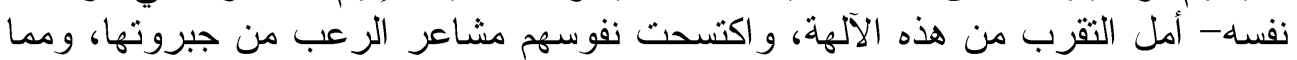
عسي أن تسلطه عليهم من عقاب في الدنيا و الآخرة، ولذلك أضحت حياتهم قلقأ و اضطر ابأ منو أصلين (أن)

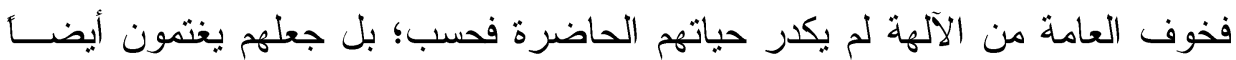

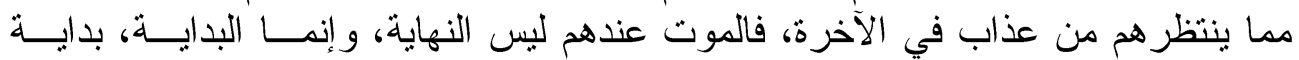

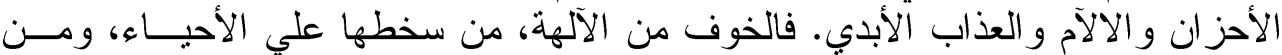

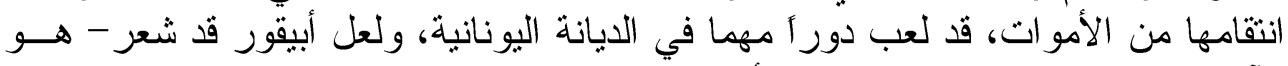

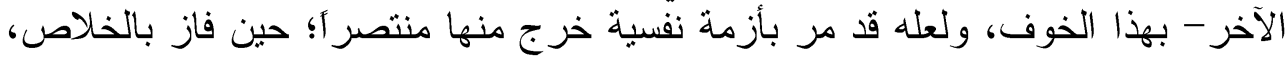
ويريد بدافع شعور العطف الشامل مساعدة بقية الناس علي الفوز بدور هم علي الخدان الخلاص.

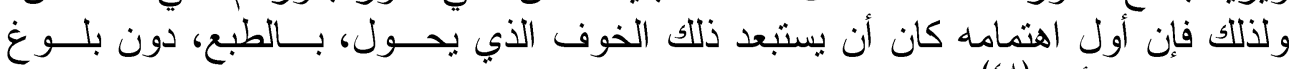

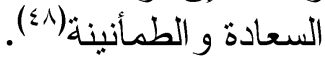

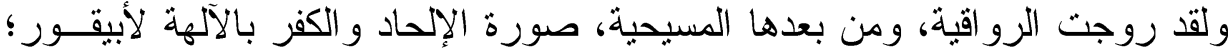

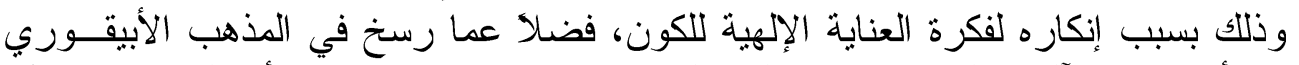

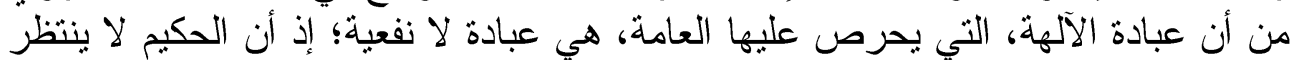

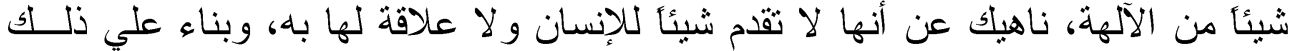

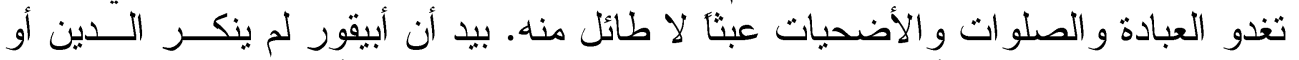

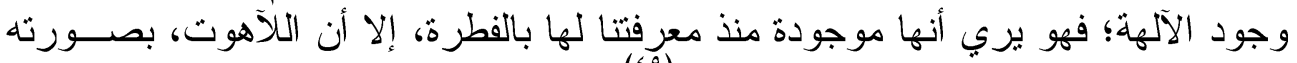

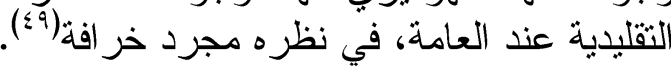

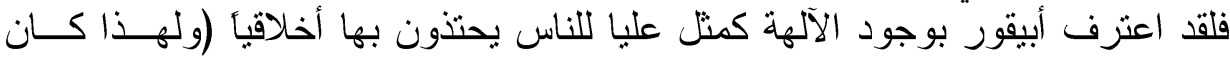

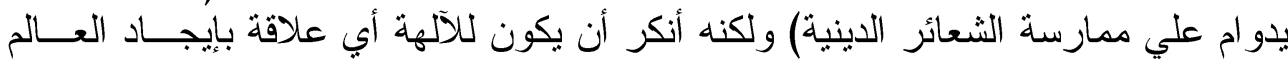

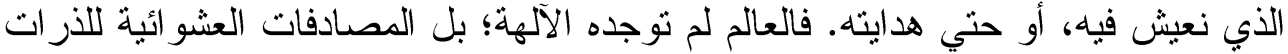

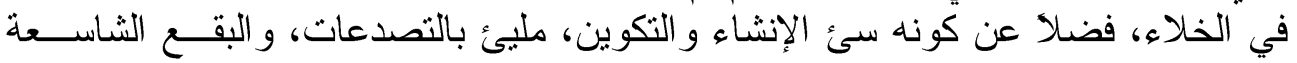

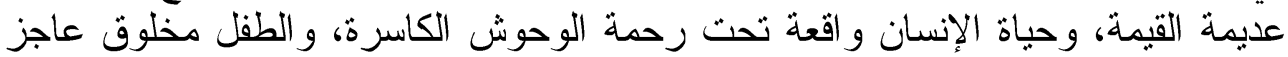
تعس إذا ما قورن بالحيو انات في سن الطفولة. ومن ثم، فلا وجود لأي عناية إلهية للكون، 


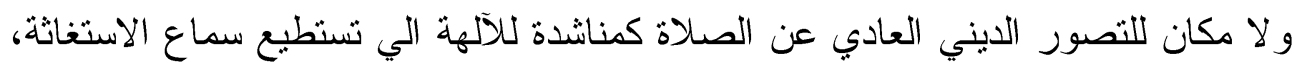

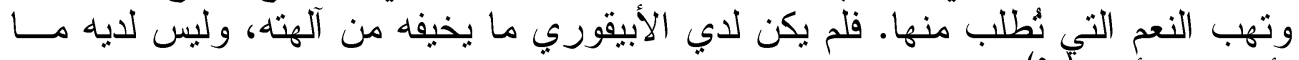

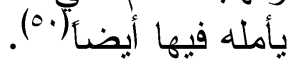

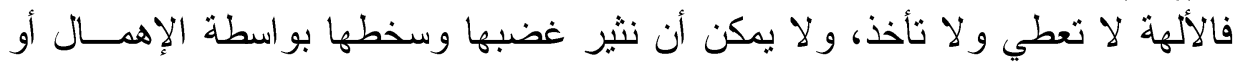

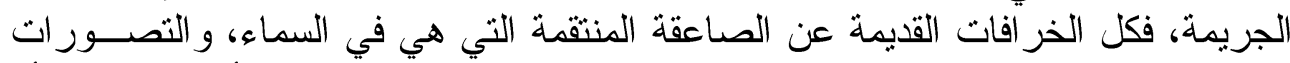

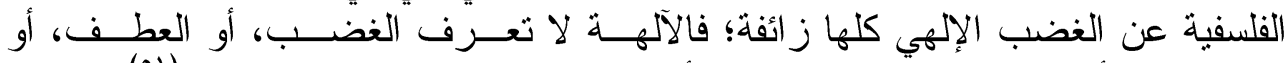

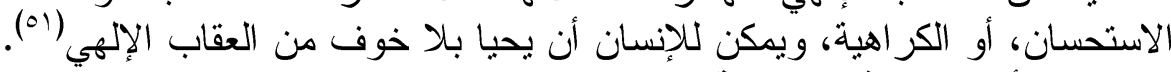

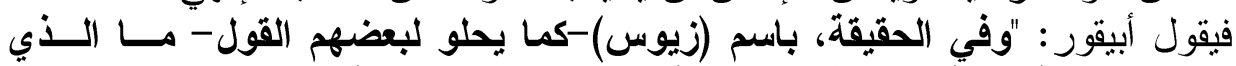

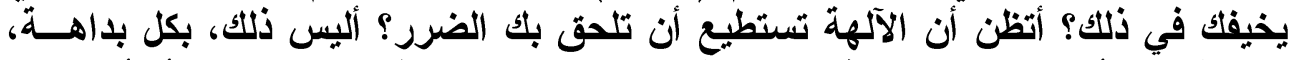

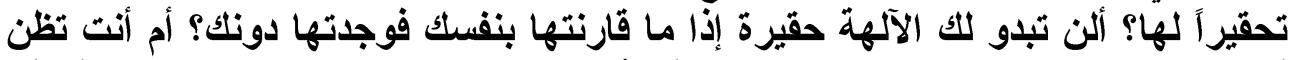

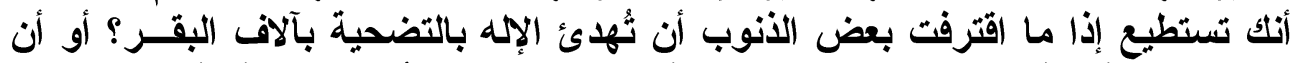

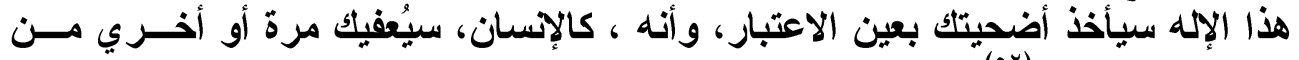

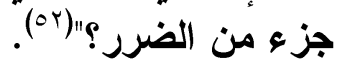

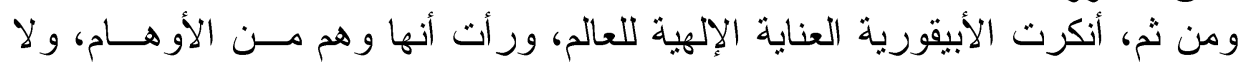

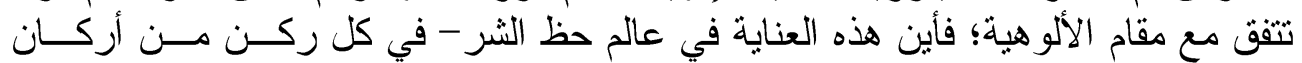

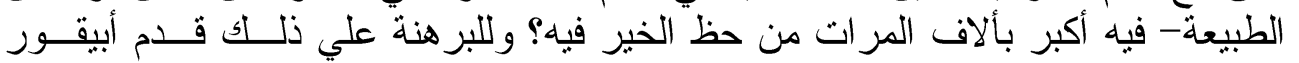

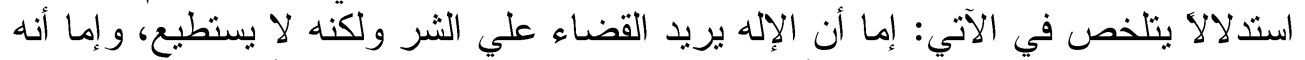

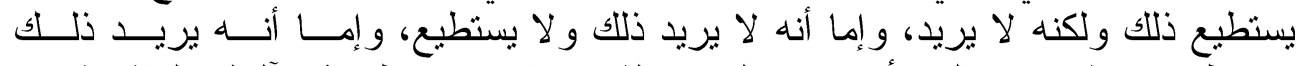

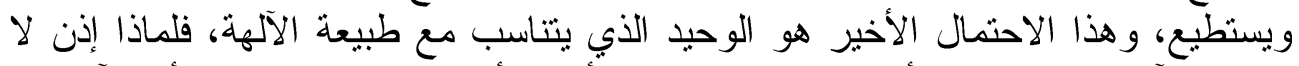

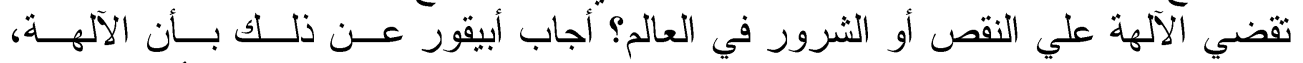

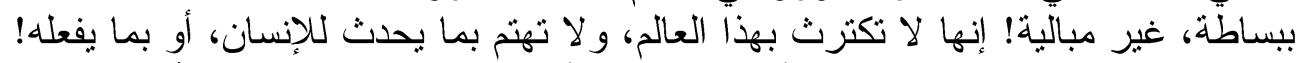

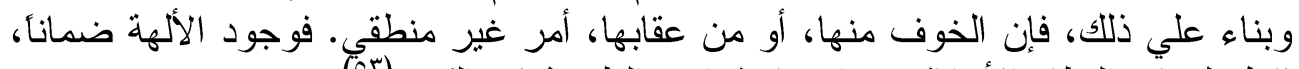

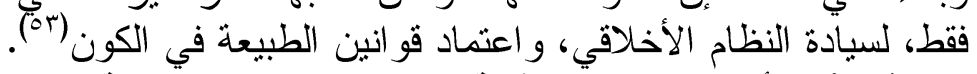

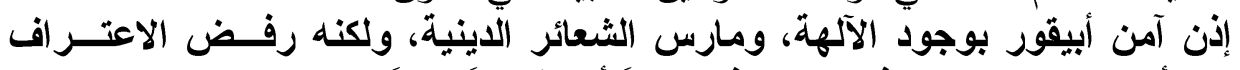

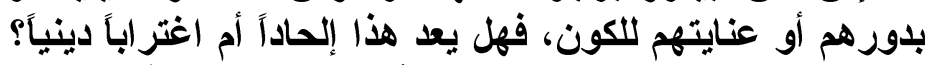

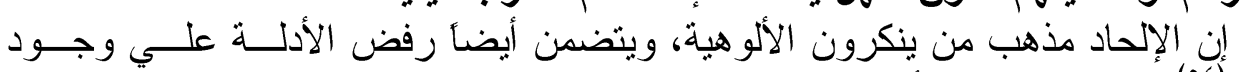

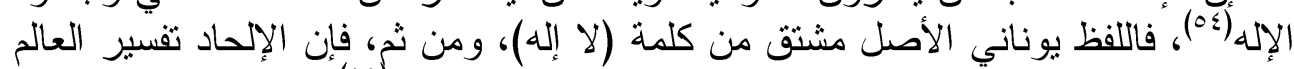

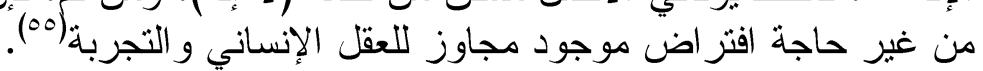

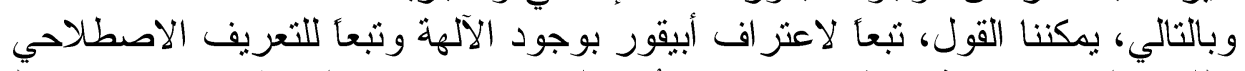

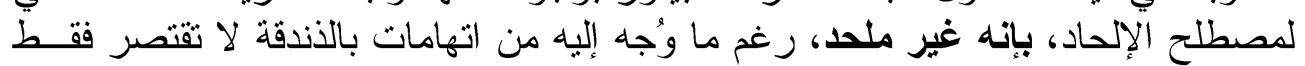

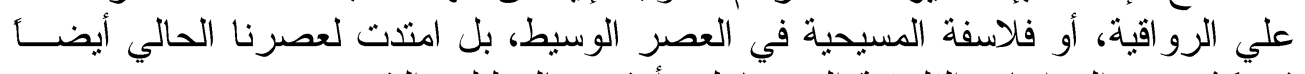

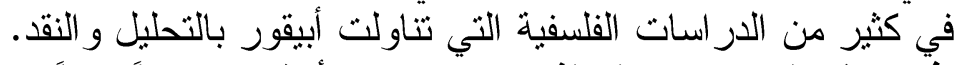

إذن يتبقي لدينا الاحتمال الثاني، وهو كون أبيقور البئن مغترباً دينياً.

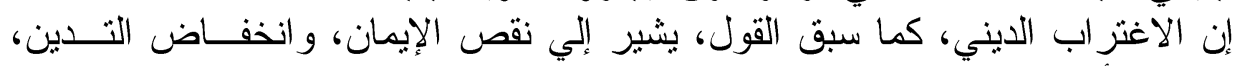

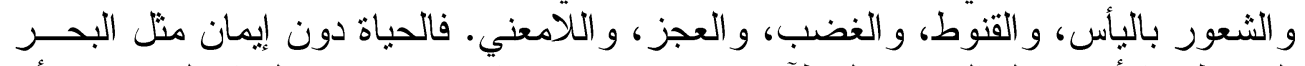

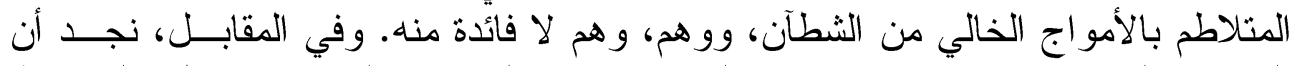

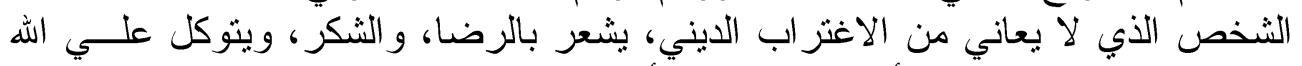

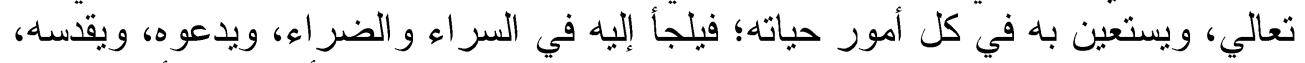

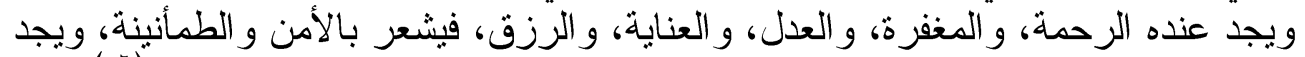

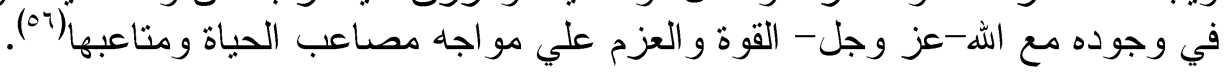


إذن أساس الابتعاد عن الاغتر اب الديني الإيمان بحول الله وقوته، و الاستعانة به عــز الإنه

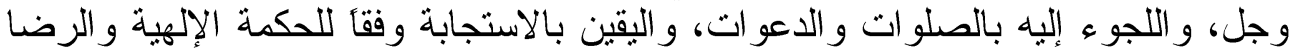

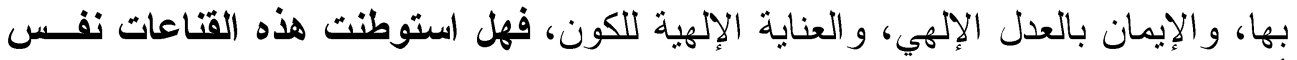

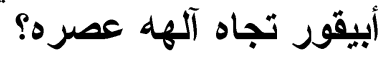

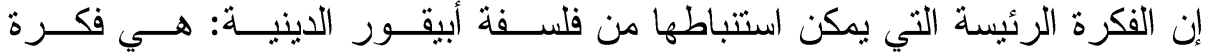

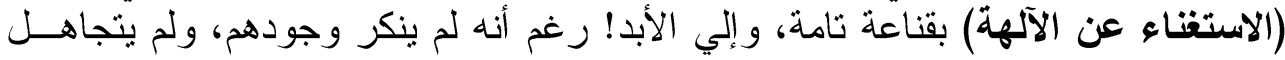

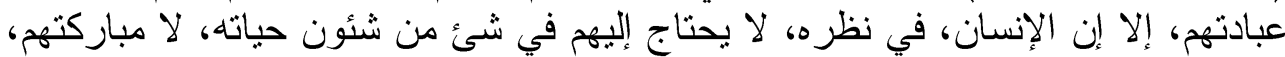

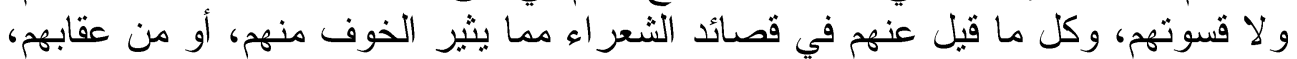

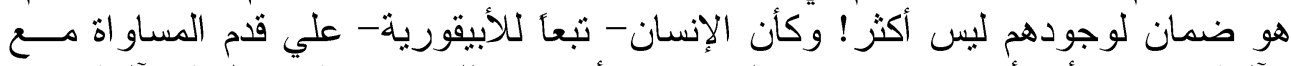

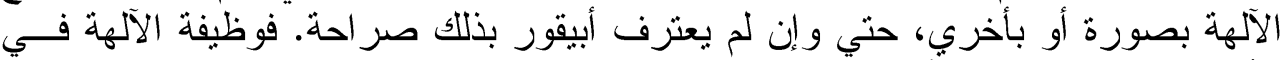
الأبيقورية وظيفة ثقافية أخلاقية، وليست لانهية لهوتية، بحيث يتم النظر إليها كمثل عليا، فقط، يُحتذي بها قدر الإمكان (ov)

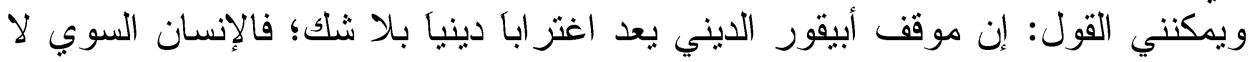

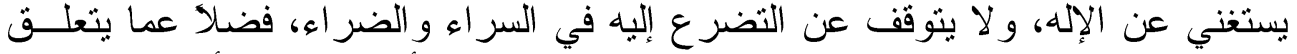

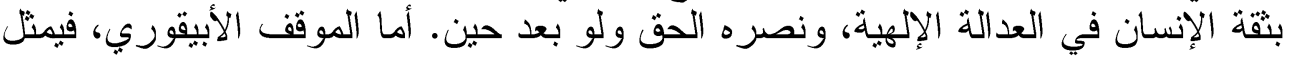

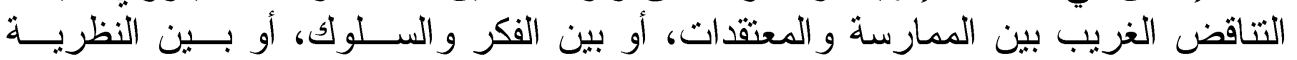

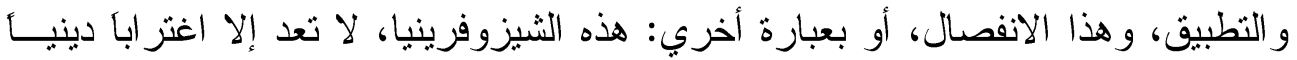

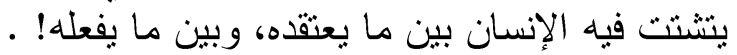

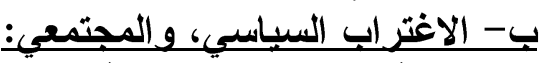

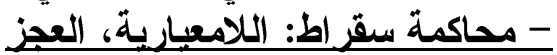

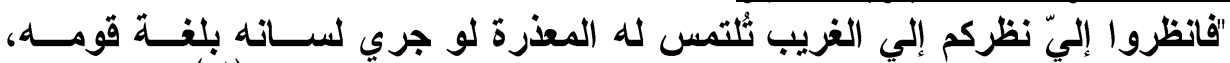

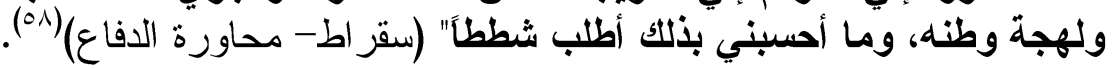

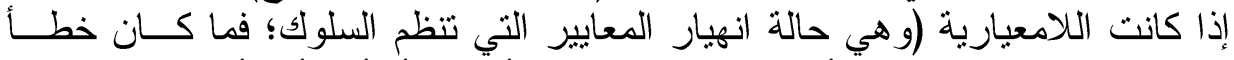

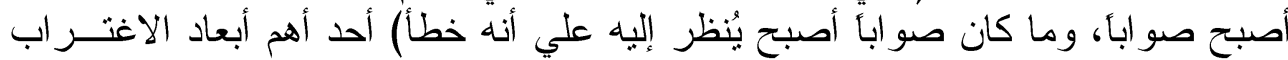

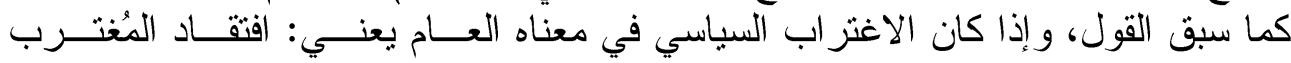

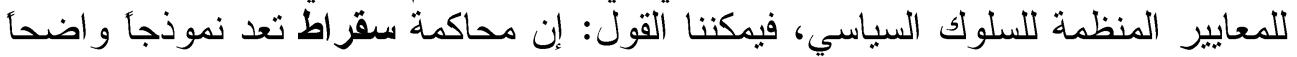

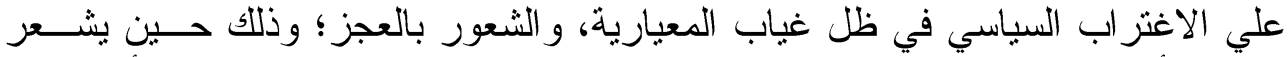

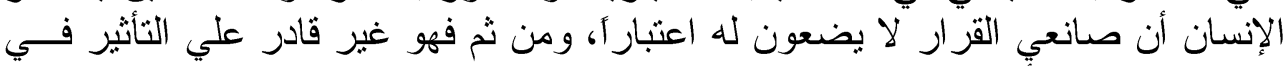

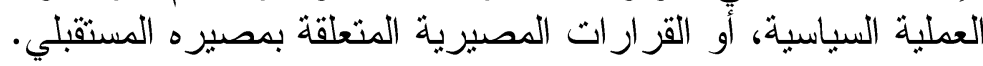

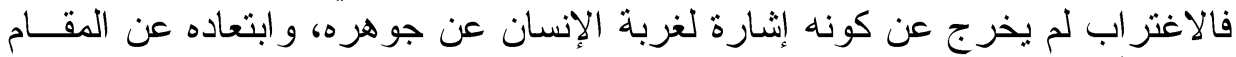

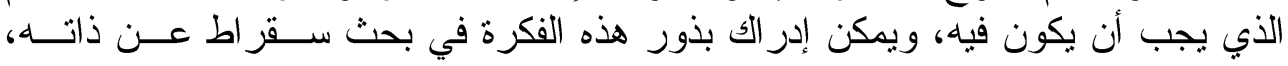

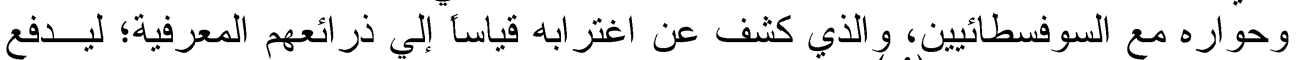

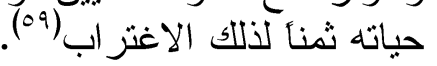

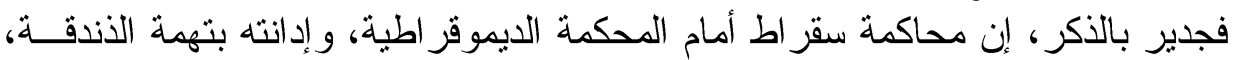

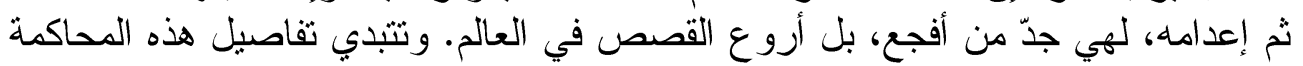

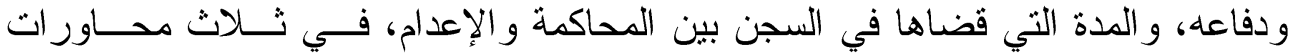

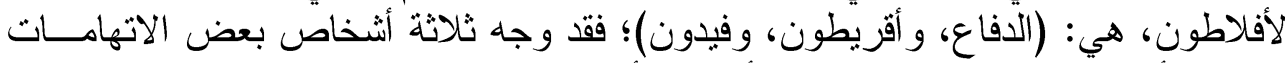

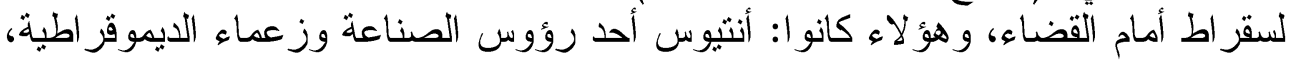

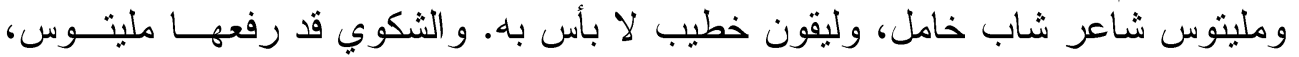


ونصها ما يلي: إن سقر اط منهم بإنكار الآلهة القومية (آلهة المدينة)، ومحاولة إدخال عقائد

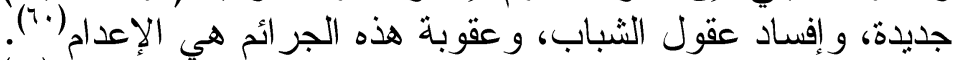

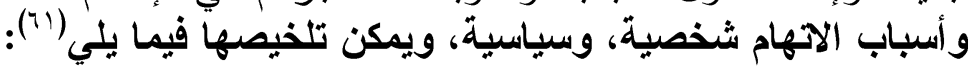

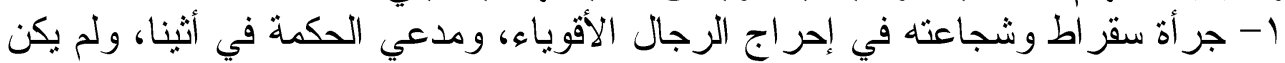

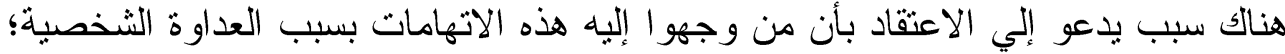

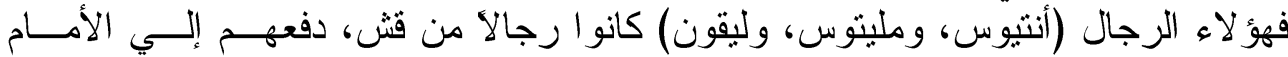
أشخاص أقوياء ظلاء الر الفي الساحة الخلفية.

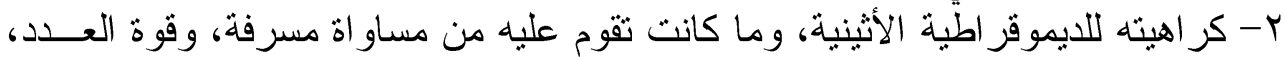

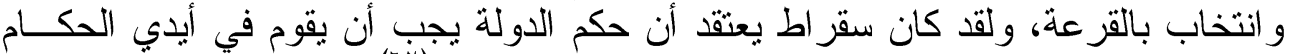

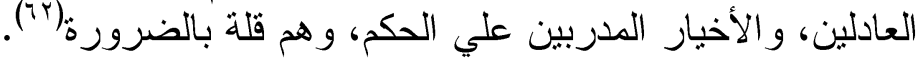

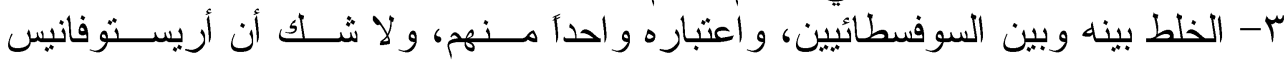

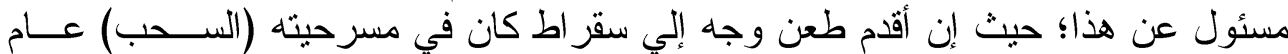

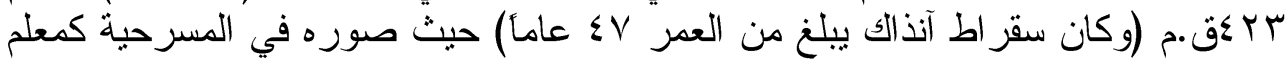

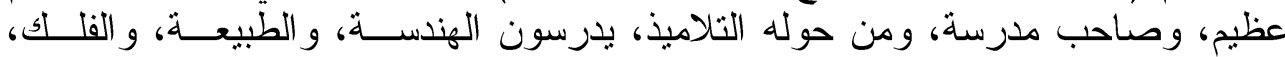

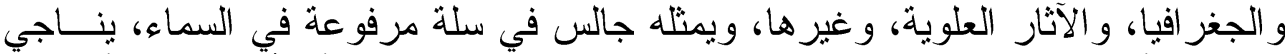

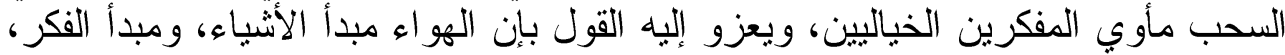

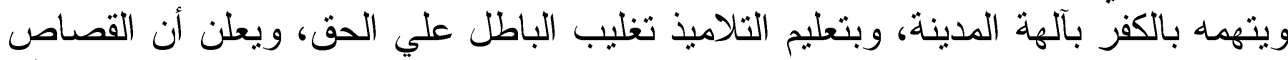

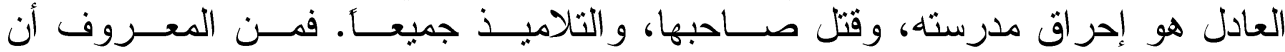

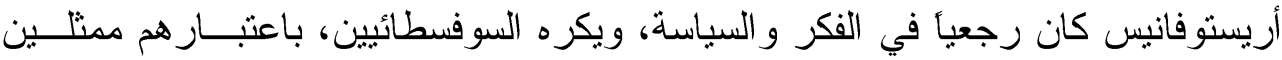

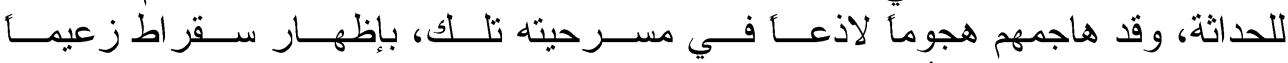
للسوفسطائيين، ولم بكن أريستوفانيس ليخاطر بإير اد هذا في مسرحيته لو لم يكن جمهوره يشاركه هذا الظن (7)

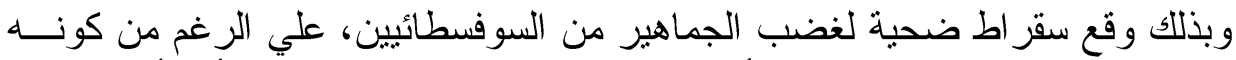

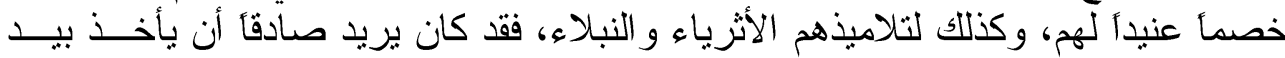

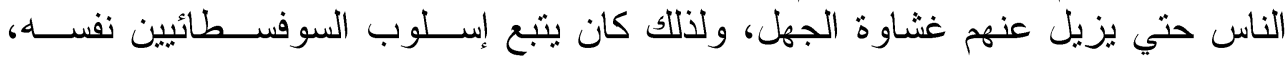

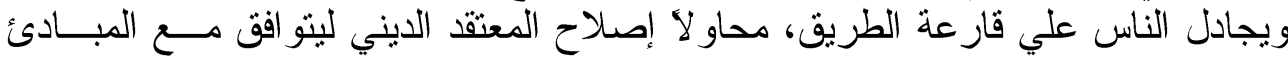

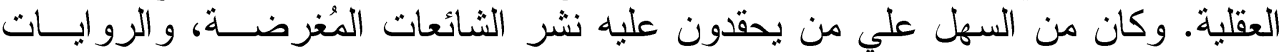

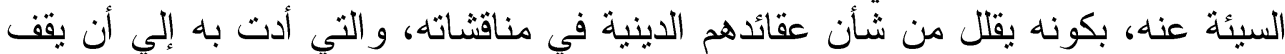

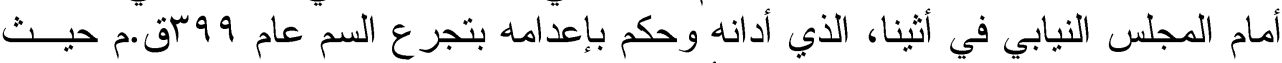

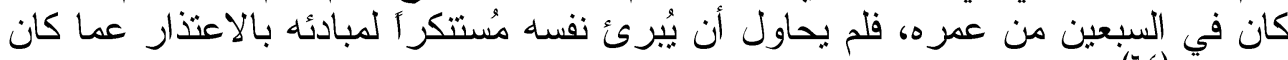

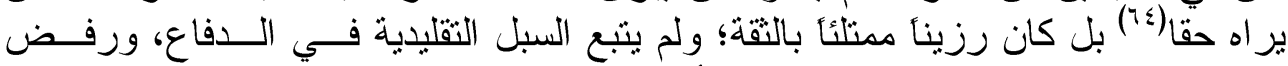

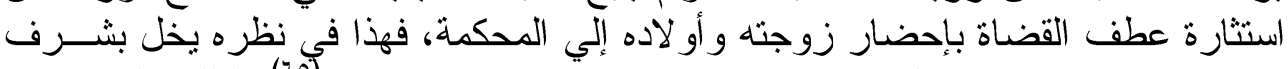

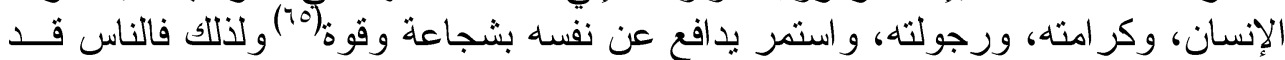

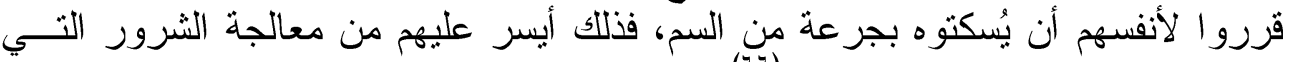

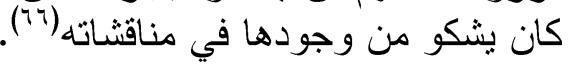

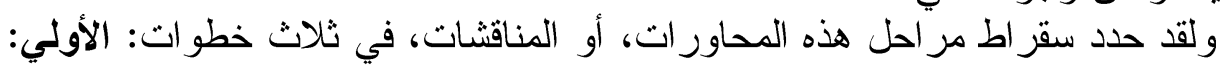

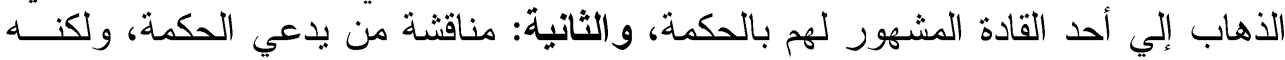

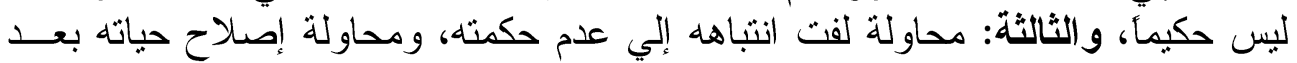

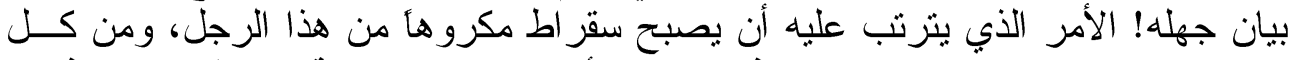
من حضر المناقشة؛ فيقول سقر اط: "فإن وجلت الن أنه لا يمتلك الحكمة، ويتظاهر بمعرفتها، 


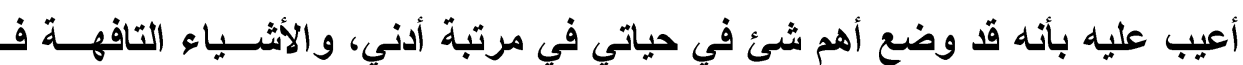

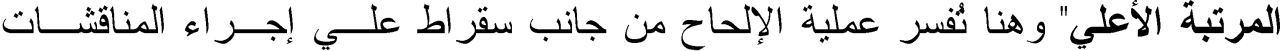

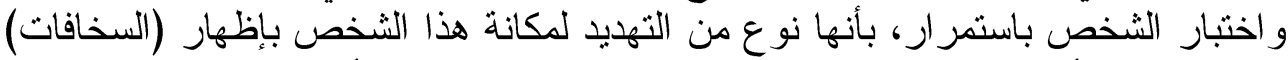

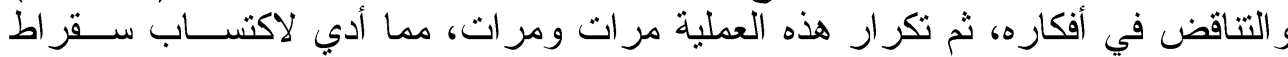

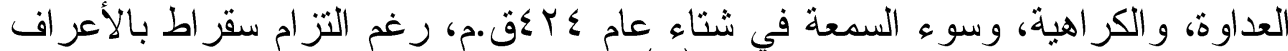

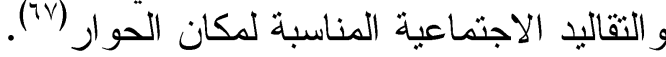

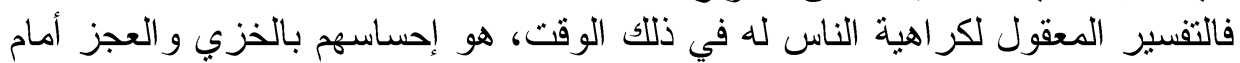

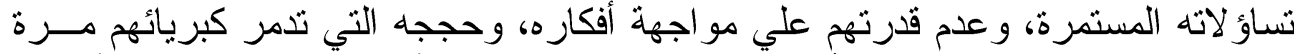

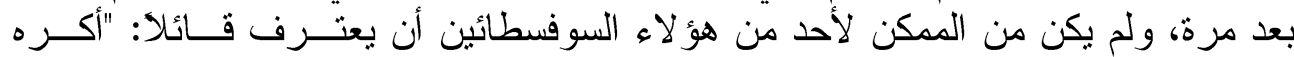

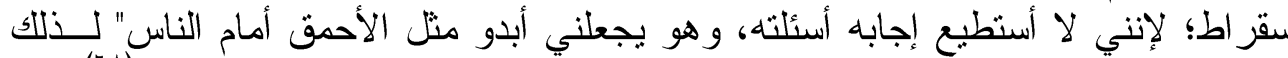

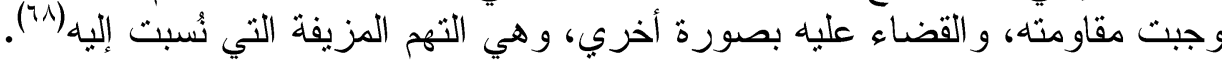

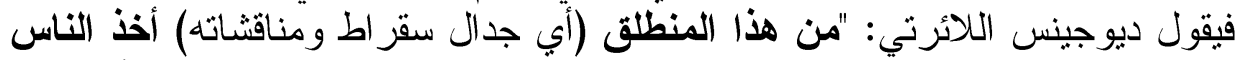

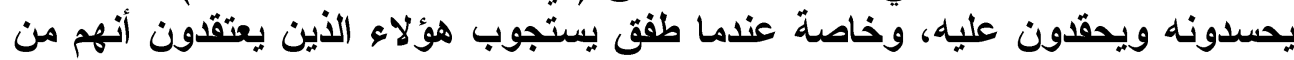

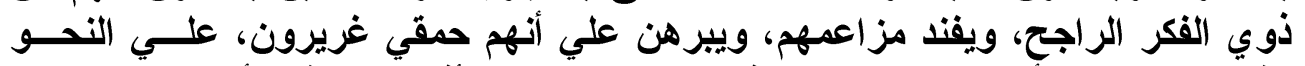

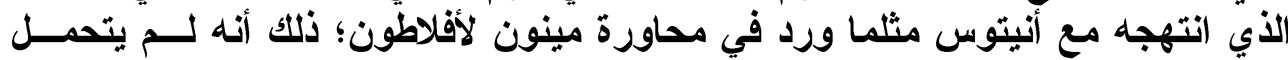

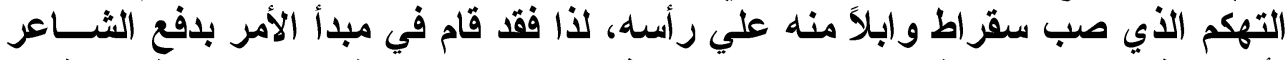

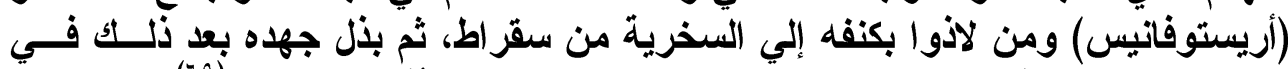

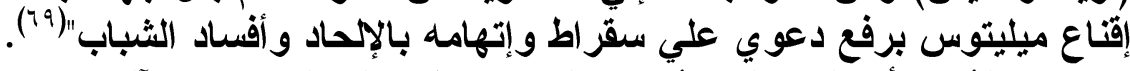

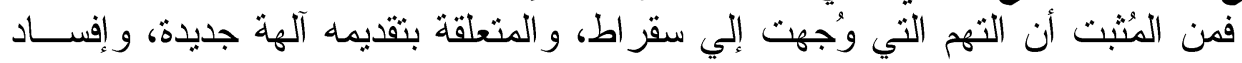

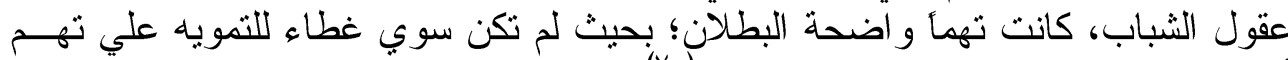

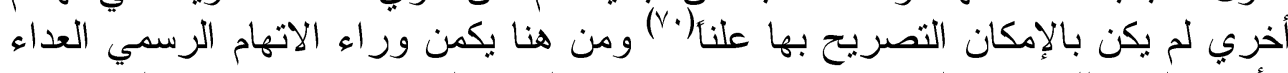

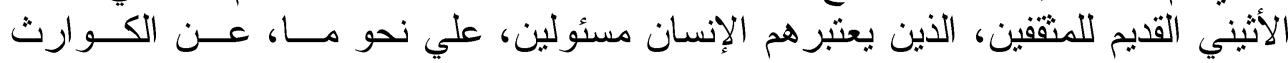

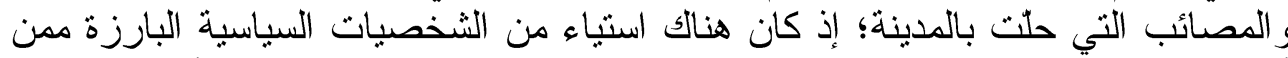

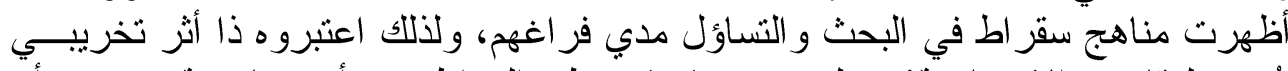

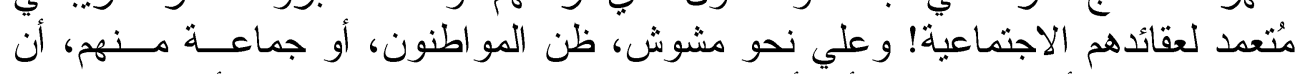

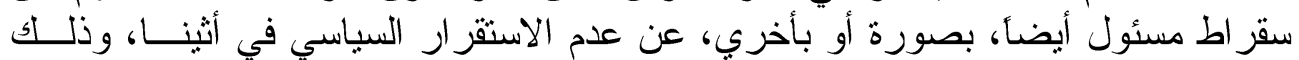

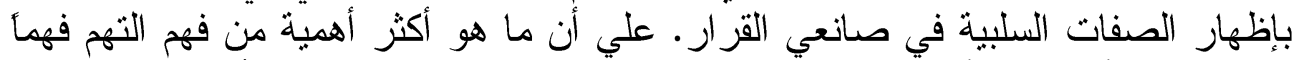

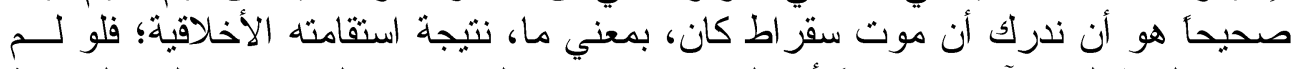

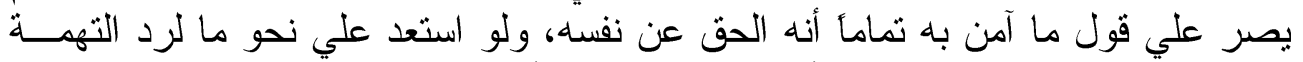

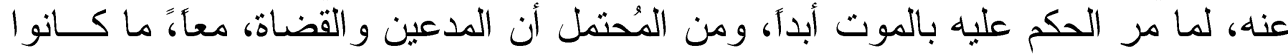

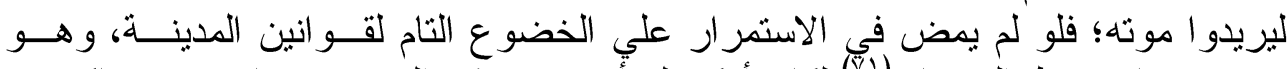

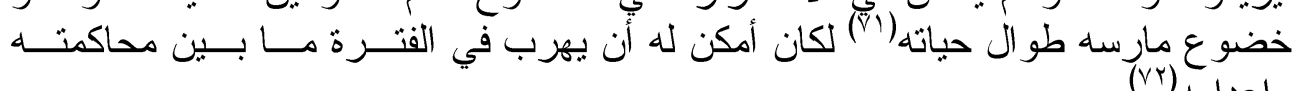

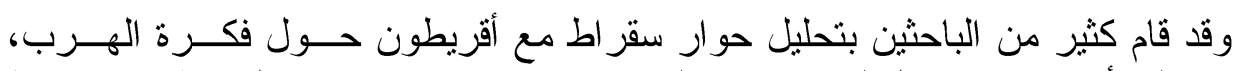

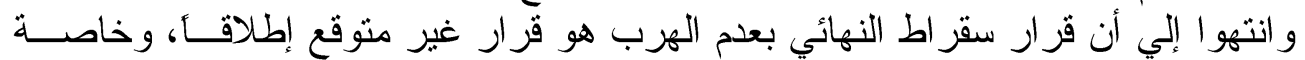

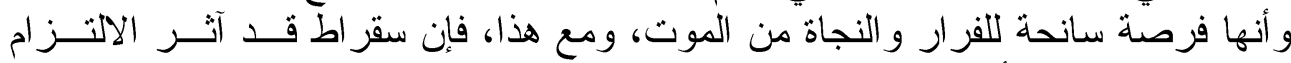

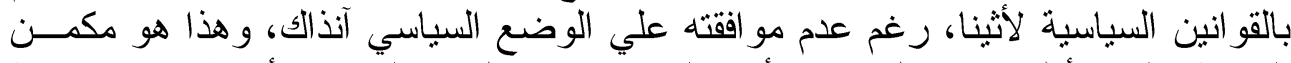

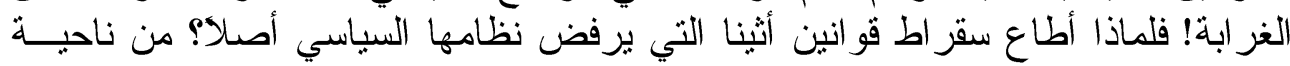


أخري، سقر اط قد التزم بالطاعة لقو انين غير عادلة، فهل يتماشي هذا مع فكره الأخلاقي،

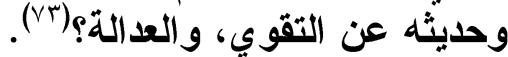

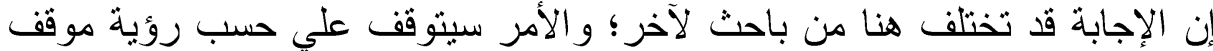

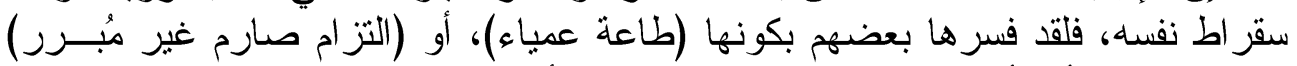

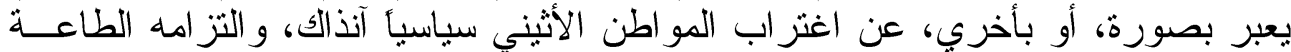

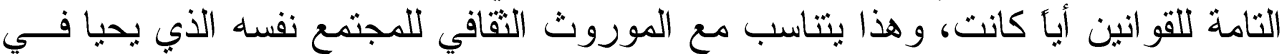

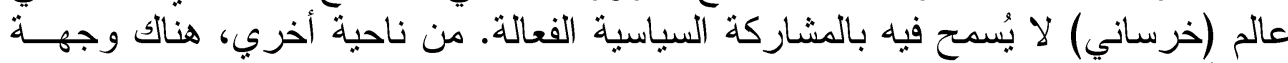

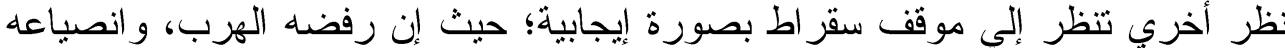

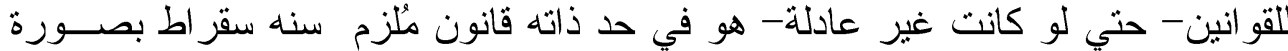

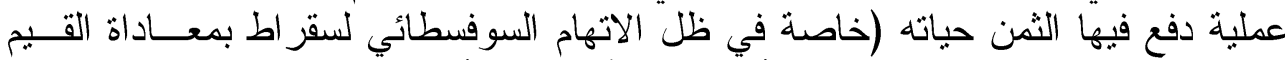

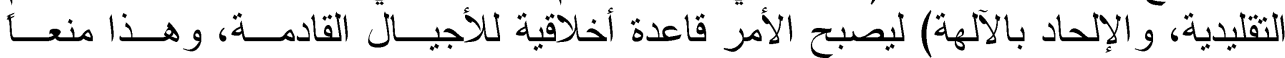

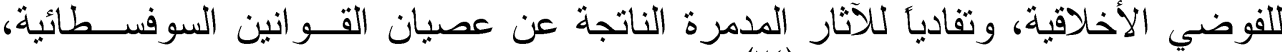

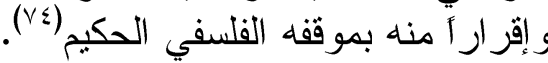

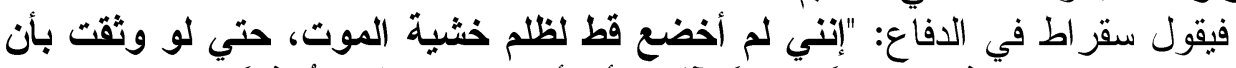

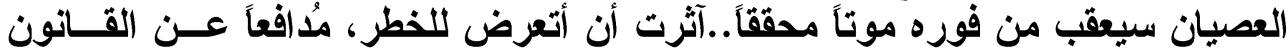

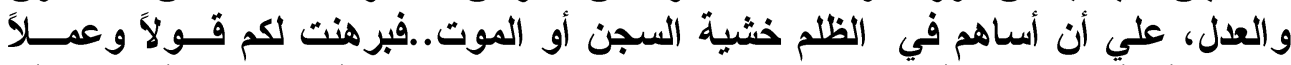

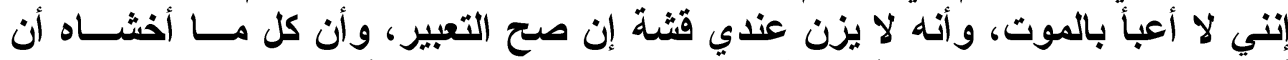

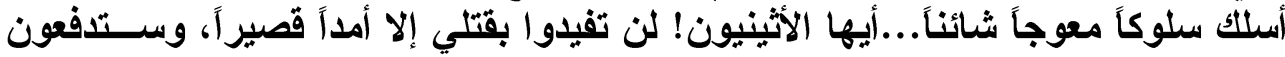

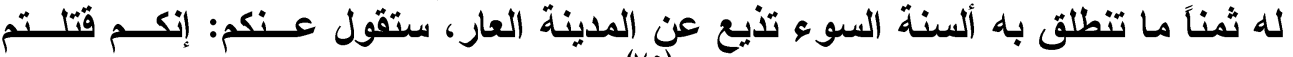

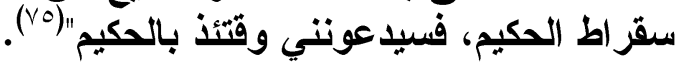

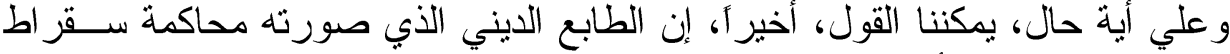

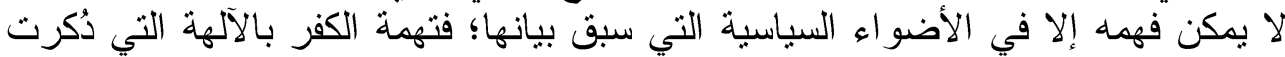

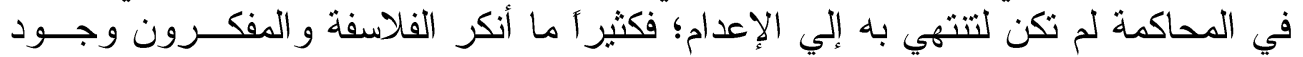

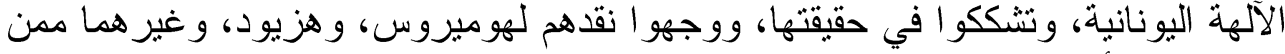

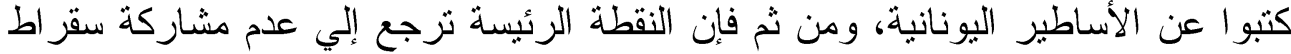

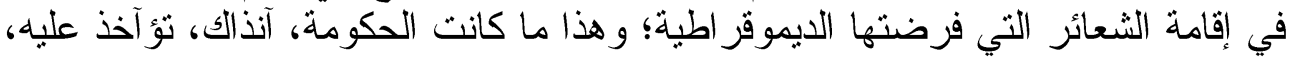

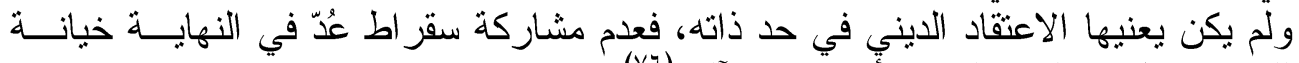

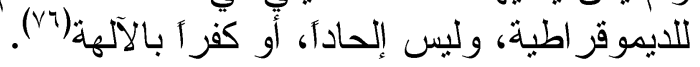

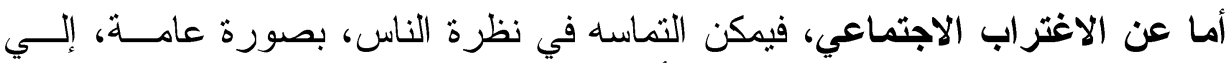

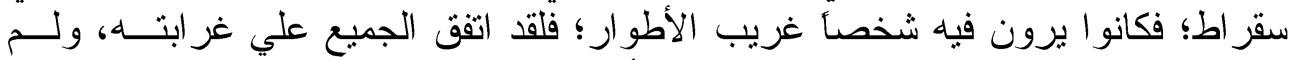

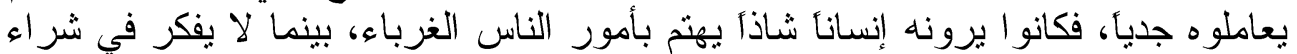

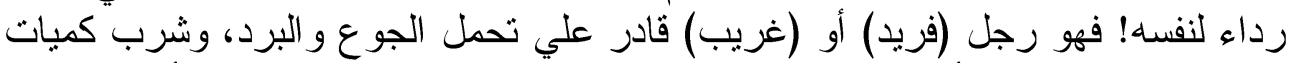

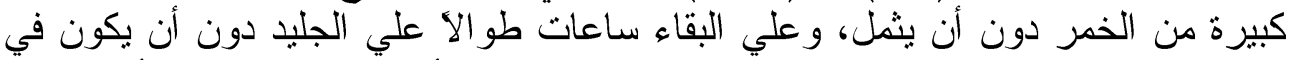

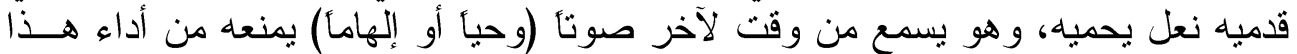

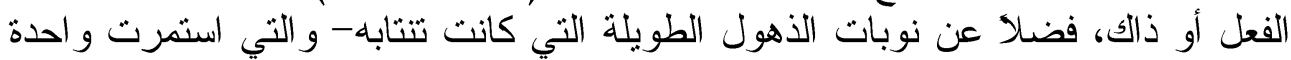

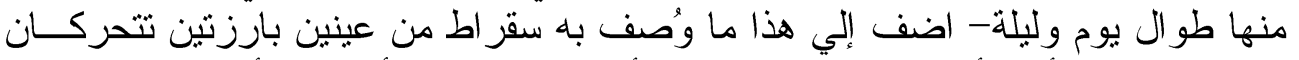

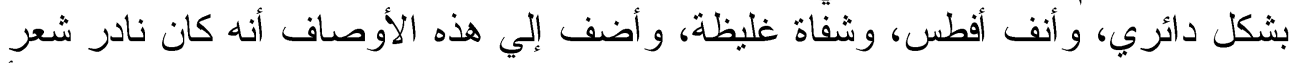

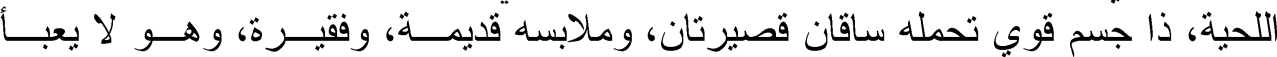

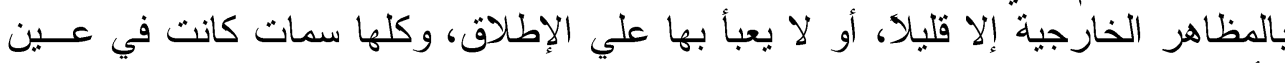

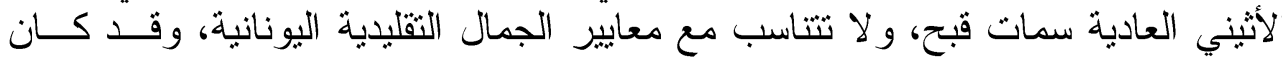




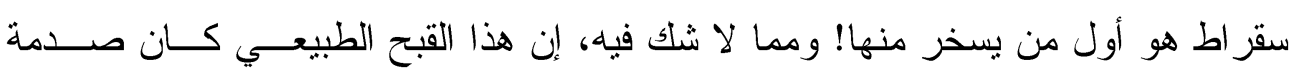

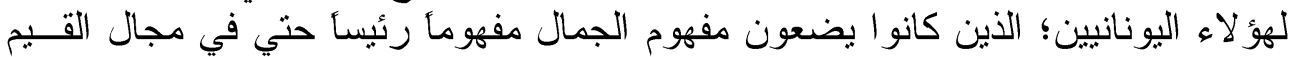

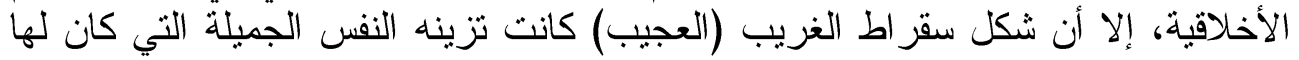

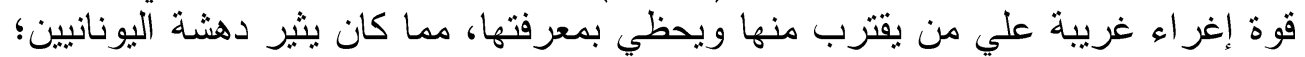

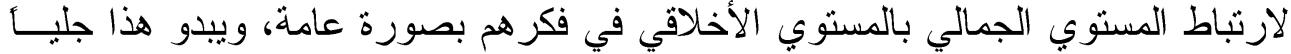

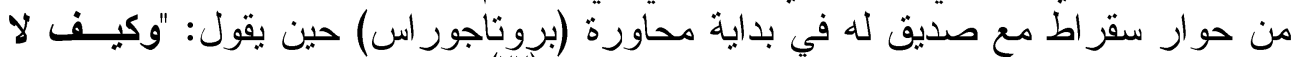

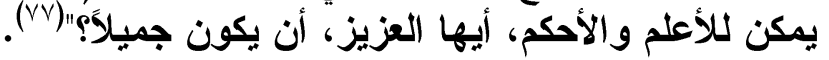

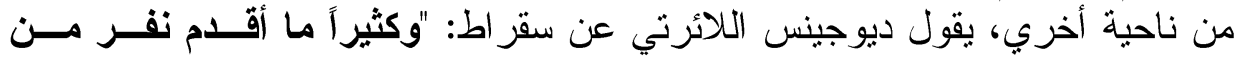

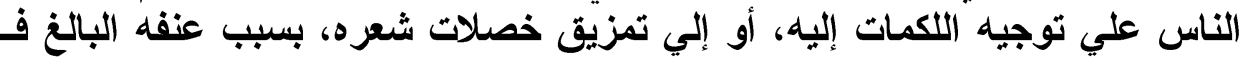

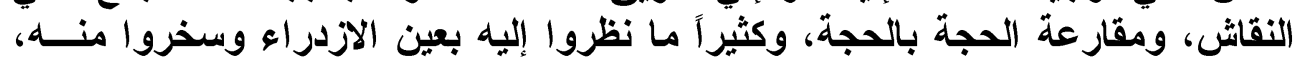

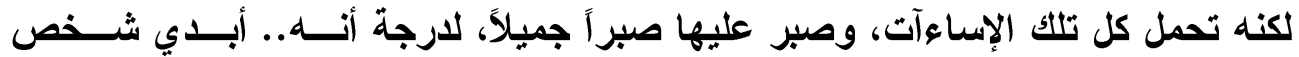

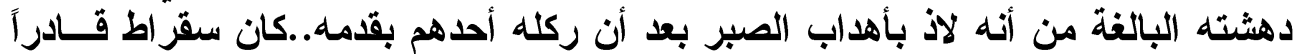

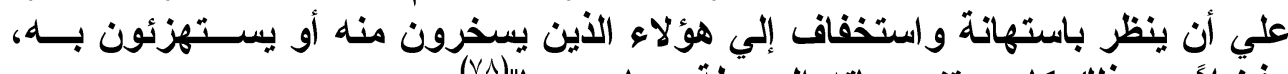

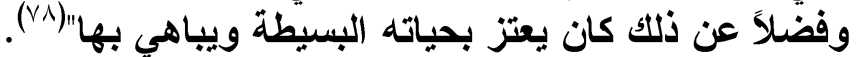

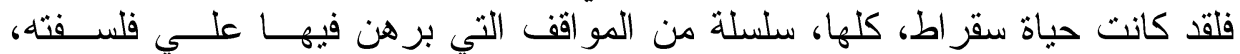

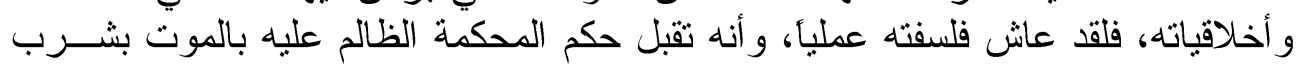

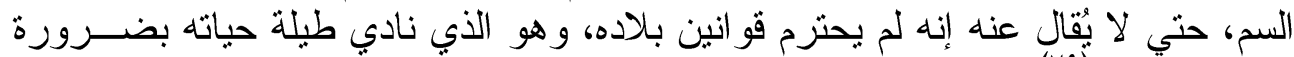

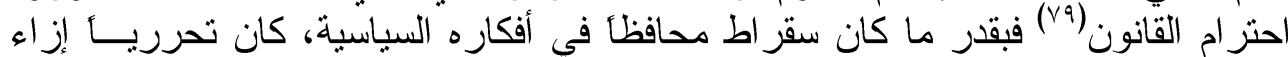

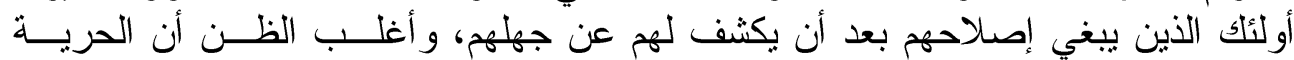

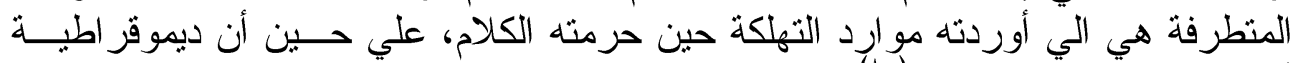

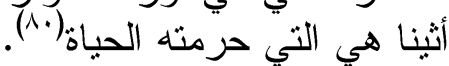

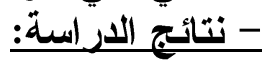

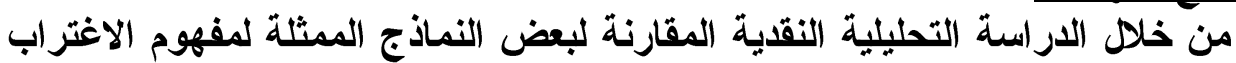

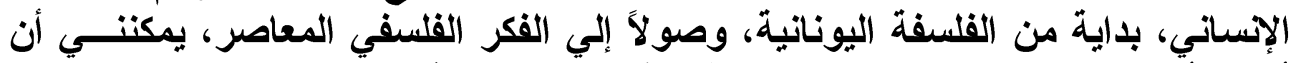

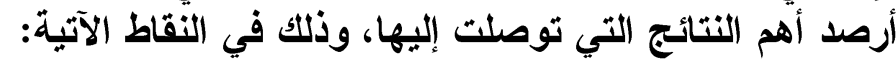

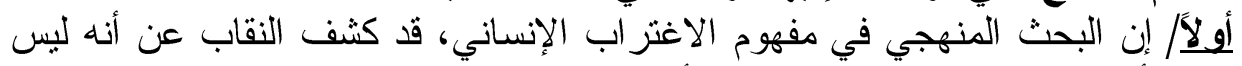

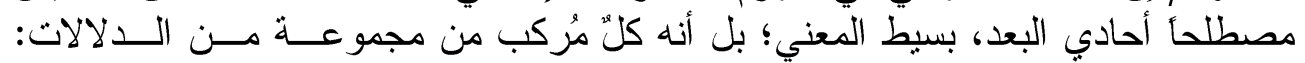

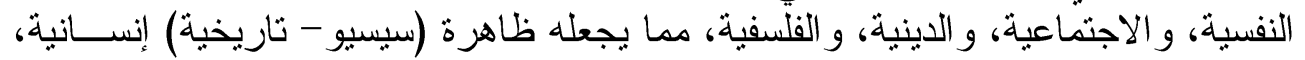

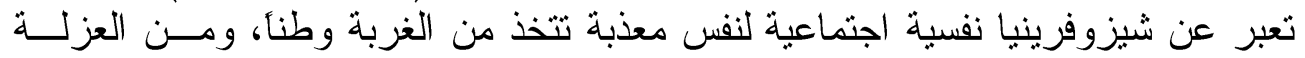

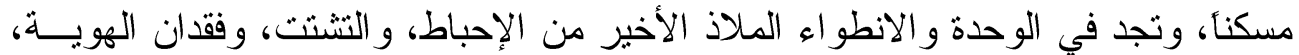
و هشاشه الحياة.

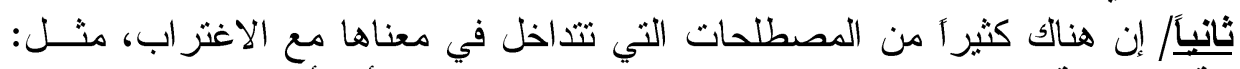

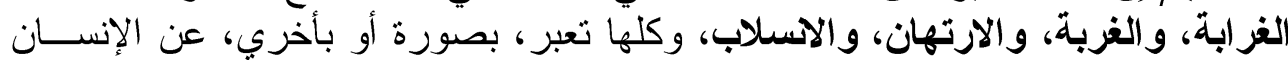

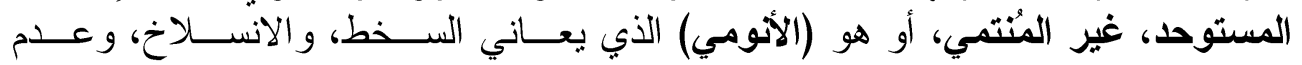

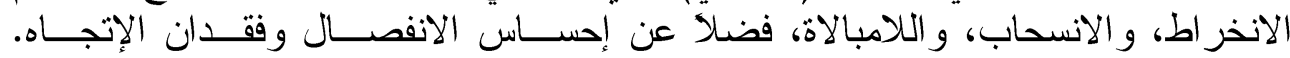

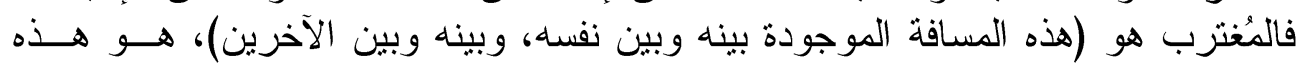

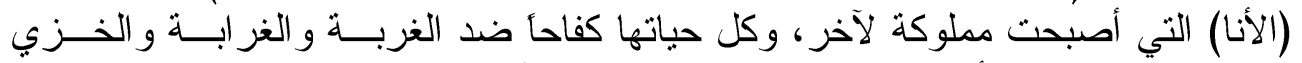

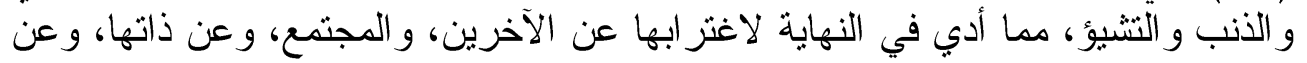


الإله أيضاً ! فلقد أصبحت غربتها الوجودية الثاملة، بمثابة القدر الذي لا يمكـن الفــرار

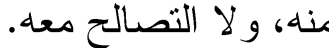

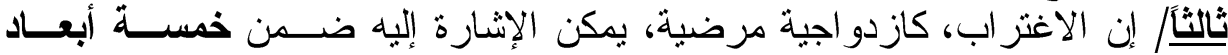

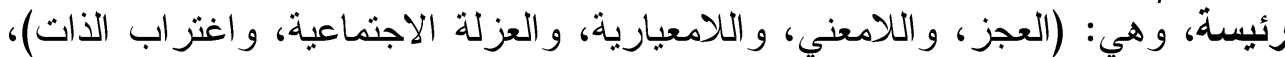

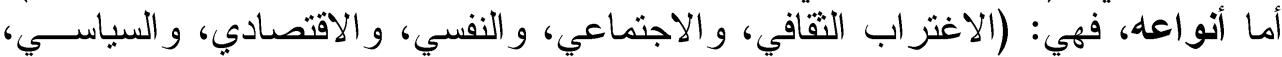

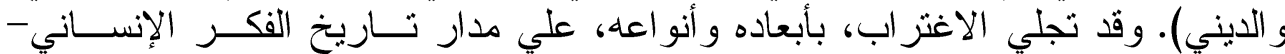

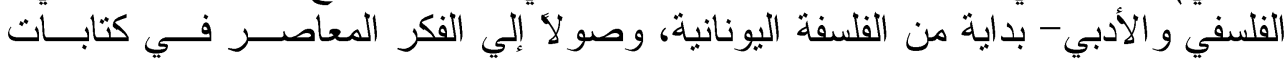

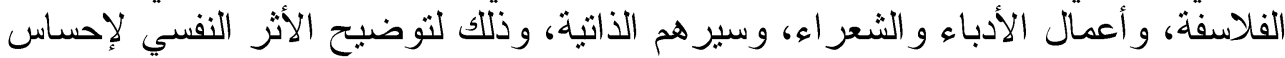

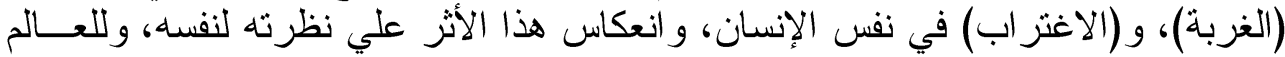

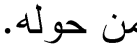

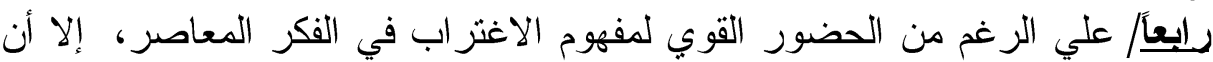

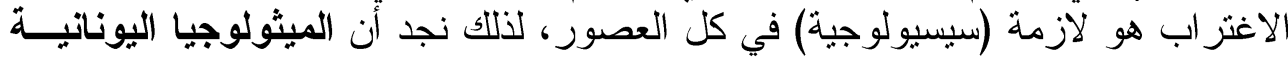

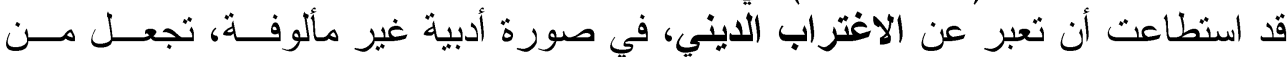
الغر ابة عنو انأ للإبداع الفني، الأبي يعد نبعاً لا ينضب، فئ لكثير من الأفكار الفلسفية.

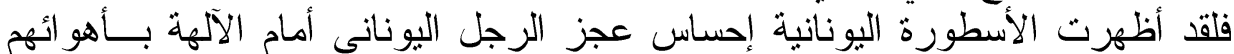

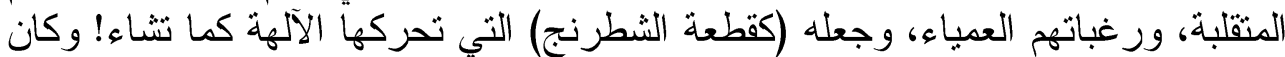

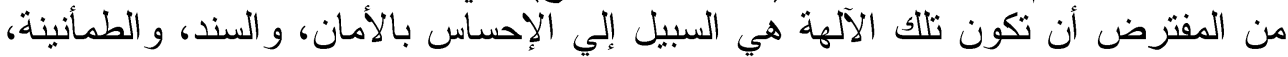

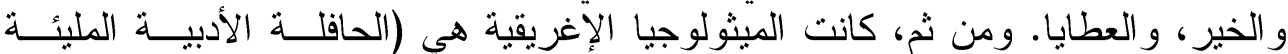

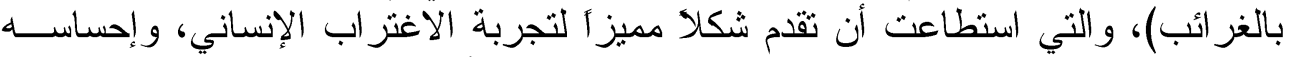

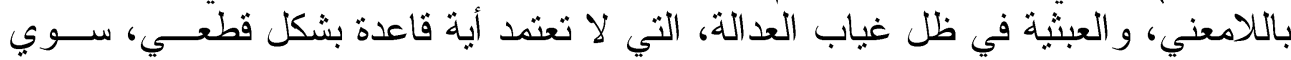

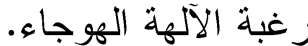

خامساً/ يعد أبيقور، وفقأ لفكره الديني، مغتربأ دينيأ، ويمكن التماس هذا الاغتر اب في

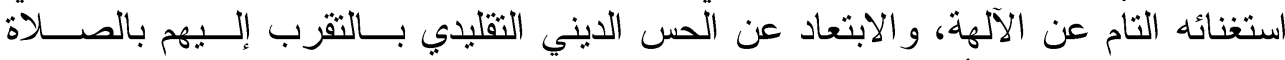

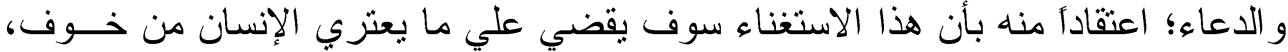
وقلق، وتزقب للعقاب الإلهي، في الدنبا أو بعد الموت، ومن ثم يصل الإنسان إنسان إلي السعادة

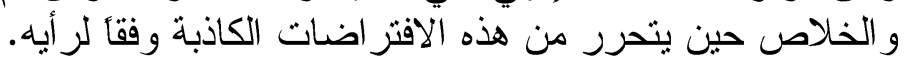

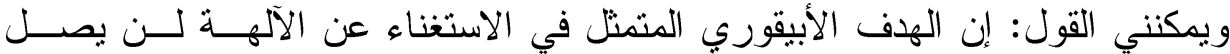

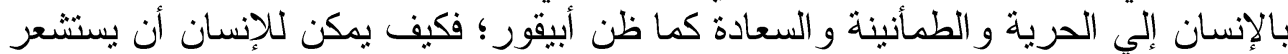

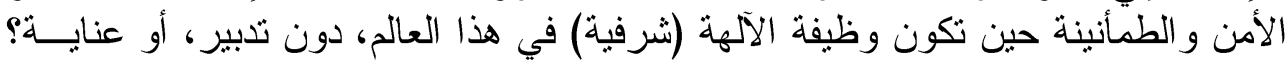

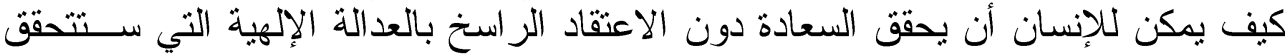

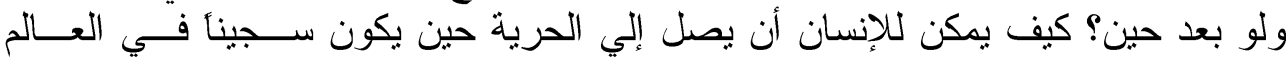

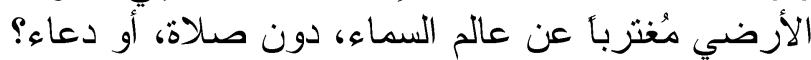

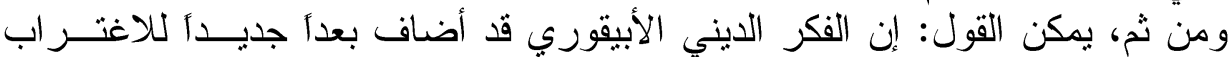

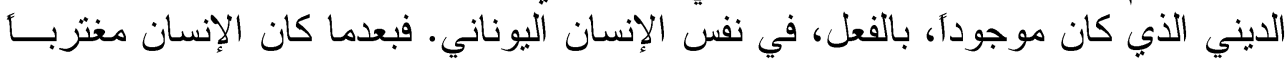

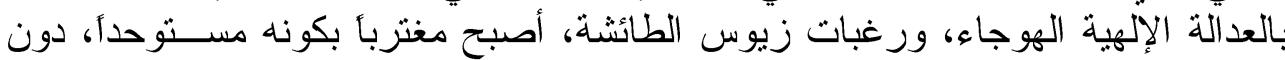

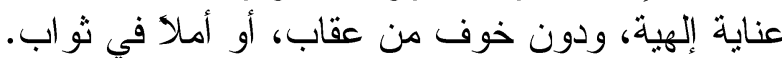

سيادساً لقد كان سقراط نموذجأ للاغتراب السياسي المجتمعي؛ فمحاكمته الثــــيرة

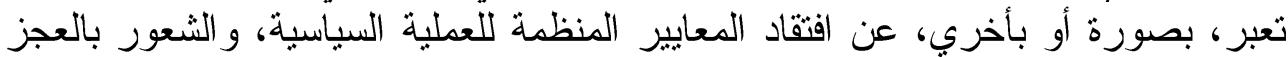

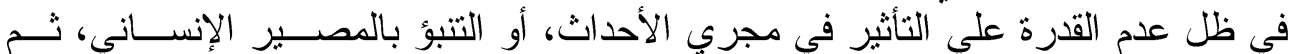

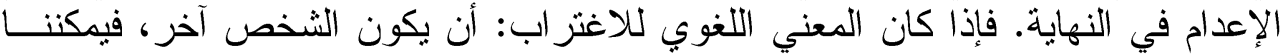


القول: إن سقر اط كان، فعلا، شخصأ آخر في نظر الآخرين، الذين أضمروا لــهـ العــــاء

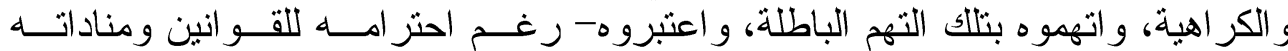

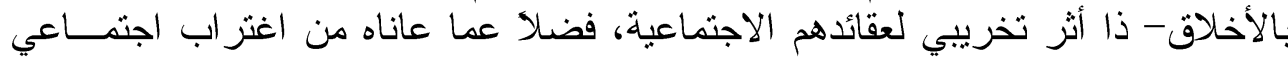

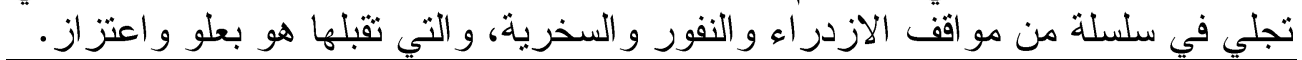

Abstract

Man Between Strangeness and Alienation In Greek Philosophy

"'A Comparative Analytical Study in The Concept of Human Alienation - Representative Models" By Nahed Ebrahim Mohamed Mohamed

Man lives within three main dimensions: the interior, the outside, and the top, and his psychological balance begins from the internal dimension; Man is deep, surrounded by loneliness, isolation, Introverted, meditation, mental reasoning, deduction, conscience and consciousness; The inner world here is more like (with a snail), in which a person influences the protection from the outside world, which means risk, and the possibility of deformation. Hence, man becomes, at times, the strange existence that does not adapt to the world and does not achieve any compatibility between it and its world. So it becomes (separate) from the world in one way or another. It can be said: This sense of separation oscillates between (Strangeness) and (Alienation). Then the person becomes (strange) at times, and at times (Alienated). In spite of the two terms being somewhat similar and related to the philosophical, psychological, social, and religious dimensions themselves, there is a linguistic and idiomatic difference between them, and many philosophical and social theories and literary works have expressed this difference, and related issues .

\section{-The problem of the study:}

to try to identify the concept of (Strangeness) and (Alienation), and stand on the remote dimensions of human alienation, and know the most important expressions of personality (alienated) In the Greek philosophy.

\section{- Approach used:}

Some different research approaches was used in this research: the historical approach; which is used to follow the idea of the (Alienation) in philosophical thought, and the analytical approach; This is to find out the analysis of philosophical texts, and critical and comparative; to find out the differences and convergence between the concepts of (Strangeness) and (Alienation) and the various related philosophical issues, In Greek philosophy . 


$$
\begin{aligned}
& \text { حوليات آداب عين شمس - المجلد ^^ } \\
& \text { التهو امش } \\
& \text { ' يحبي سليم البشتاوي: أزمة الإنسان في الأدب المعاصر، دار ومكتبة الكندي للنشر و التوزيع، عمان، } \\
& \text { ( }
\end{aligned}
$$

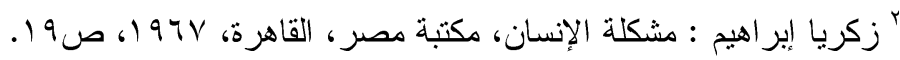

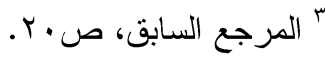

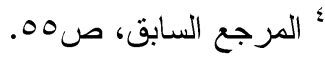

$$
\begin{aligned}
& \text { هُ ابن منظور : لسان العرب، تحقيق: عبد الله علي الكبير، محمد أحمد حسب الله، هاشم محمد الثاذلي، دار }
\end{aligned}
$$

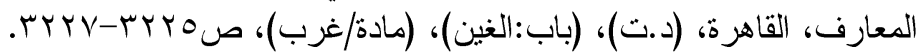

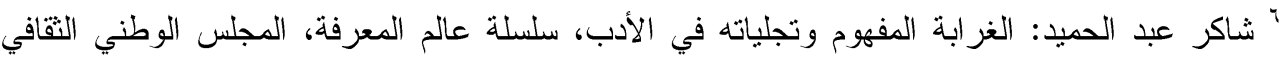

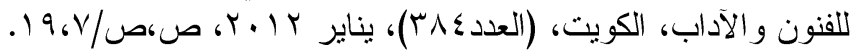

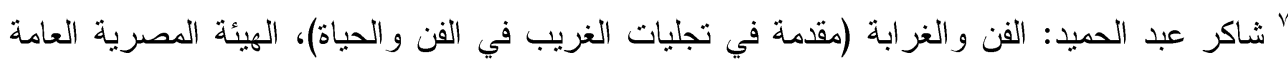

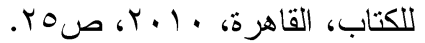

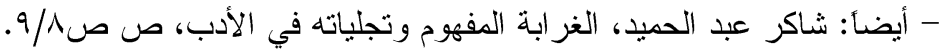

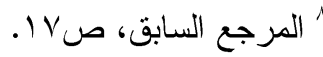

$$
\begin{aligned}
& \text { 9 هايدجر .مارتن: الأنطولوجيا هيرمينوطيقا الو اقعانية، ترجمة: عمارة الناصر ، منشور ات الجمل، بيروت، }
\end{aligned}
$$

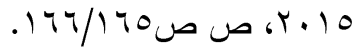

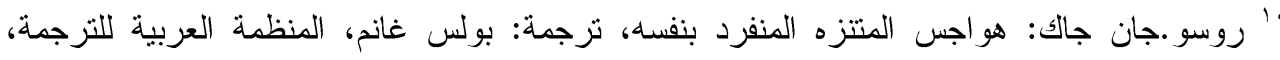

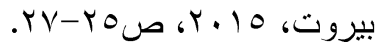

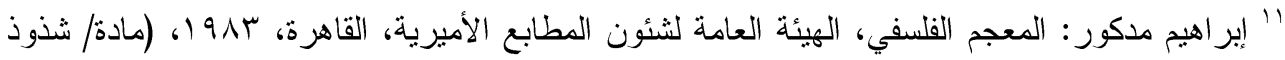

$$
\begin{aligned}
& \text { (Anomaly }
\end{aligned}
$$

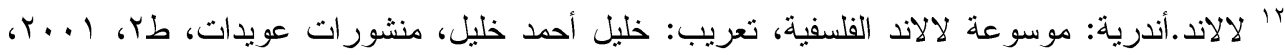

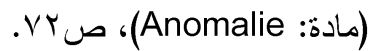

"' لالاند، موسوعة لالاند الفلسفية، (مادة/ تخلخل Anomie، متخلخل Anomique، لا سوي/ شاذ

(Anormal

'\& Bjarnason.Thoroddur: Anomie Among European Adolescents (Conceptual and Empirical Clarification of a Multilevel Sociological Concept), Published in: Sociological Forum, Vol. Y $\leqslant$, No.', March Y.. 9, P. I ro-I rV.

- Bernburg.Jon: Anomie, Social Change and Crime. A Theoretical Examination of Institutional-Anomie Theory, British Journal of Criminology, september $r \ldots r$, P. $\vee r \cdot$.

- Mukherjee.S.R: On violence as the negativity of the Durkheimian: between anomie, sacrifice and effervescence, Blackwell Publishing, Oxford, r.. 9, P. ${ }^{\circ}$.

${ }^{10}$ Dicristin.Bruce: Durkheim's theory of anomie and crime: A clarification and elaboration (Article), Anzsoc (Australian and New Zealand Journal of Criminology), Vol. ¿q, r.17, PP. rII/TIr.

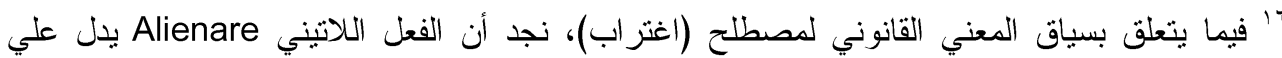

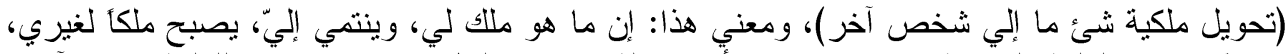

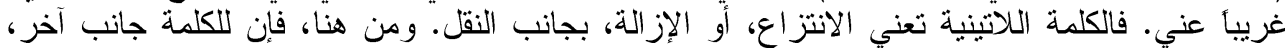

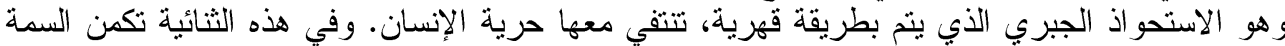

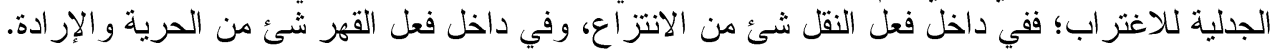




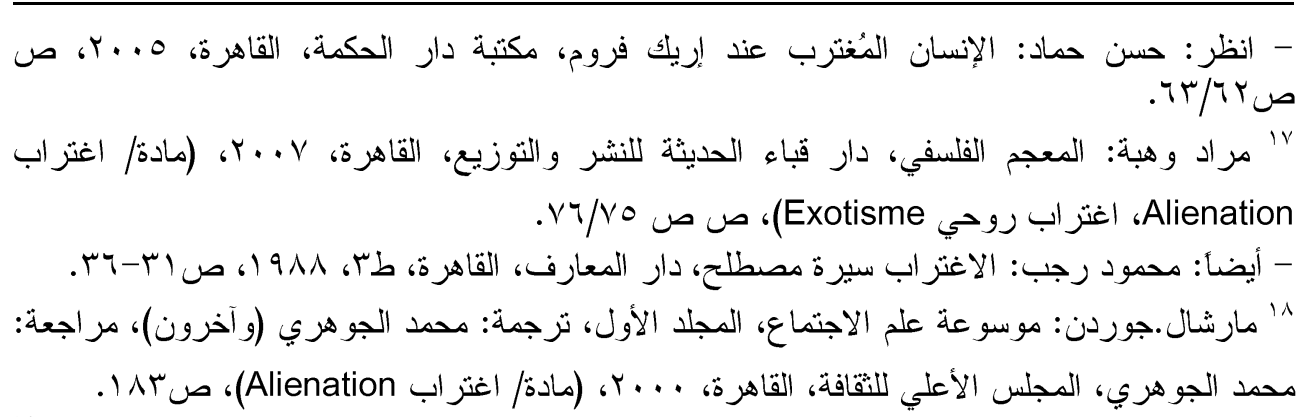
19 Wood.Aleen: Alienation, Published in: Routledge Encyclopedia of Philosophy, Routledge, London and NewYork, 1991, P. r r 7.

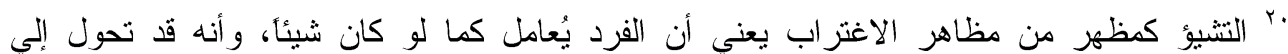
موضوع، وفقد هويته، أي فقد شخصيته التي هي مركز إنسانيته ولبها، وقد ظهر هذا هذا المفهوم في فلسفة

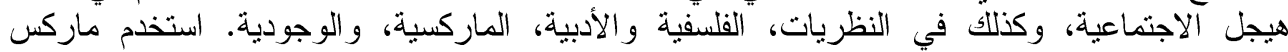

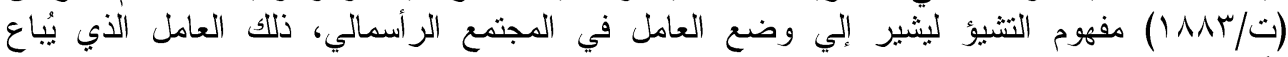

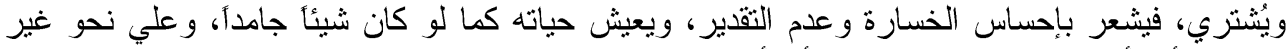

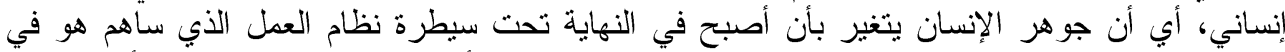

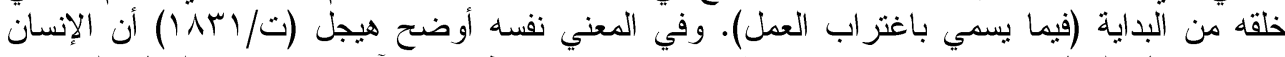

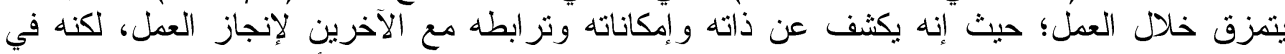

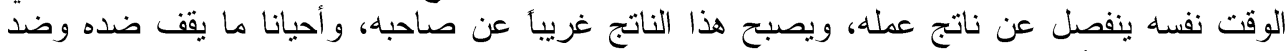

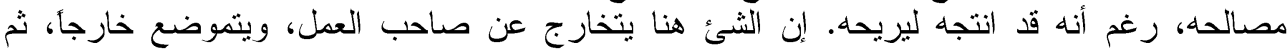

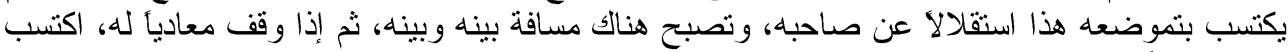

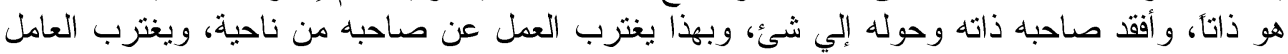

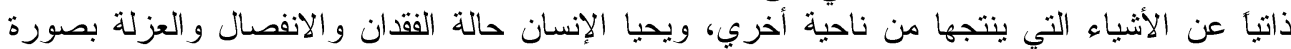

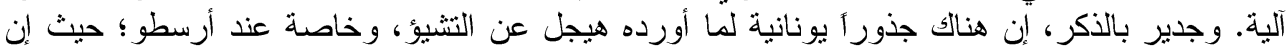

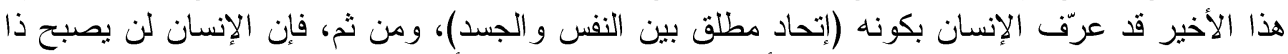

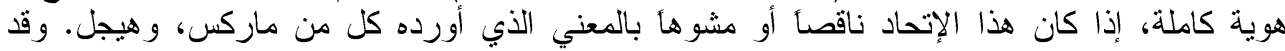

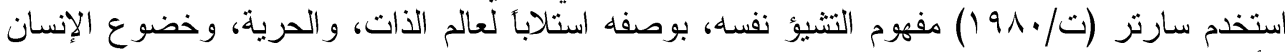
للأساليب المبتذلة في الحياة اليومية. - انظر

- Hatley.Kathleen: The Development of the Concept of Alienation from Hegel to Marx (Its Relationship to the Perennial Philosophy), Thesis Submitted to the requirements for the Degree of Master of Science, Stilwell University, Oklahoma, I $9 \vee r$, PP. $\vee / \wedge$.

- Chooback.Nima: Marx's Theory of Alienation and the Capability Approach (A Comparative Study), Thesis Submitted to the requirements for the Degree of Master of Arts, The University of Western Ontario, Canada, $r \cdot 1 \cdot$, PP. $11 / 19$.

- Farahbod.Farzin: Work Alienation, Historical Backgrounds, Concepts, Reasons and Effects (Article), Published in: ISSN(Journal of Basic and Applied Scientific Research),

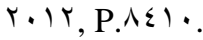

-Brownlee.Timothy.L: Alienation and Recognition in Hegel's Phenomenology of Spirit (Article),Published in: Philosophical Forum, Y.10, P.'.

-Sayers.Sean: Marx and Alienation (Essays on Hegelian Themes), Palgrave Macmillan, UK, Y. II, P.'.

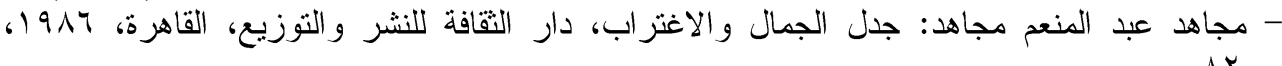


ـ محمد عباس يوسف: الاغنر اب و الإبداع الفني، دار غريب للطباعة و النشر و التوزيع، القاهرة، ع ...؟،

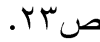
- لافين.ت.ز : من سقراط إلي سارتز (البحث الفلسفي)، ترجمة: أشرف محمد كيلاني، المركز القومي

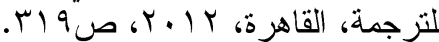

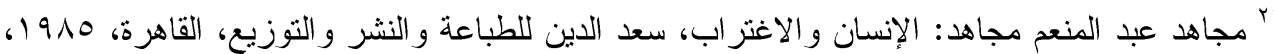

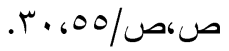
بو إن فعل الانسلاخ هنا يعبر عن تقهقر الذات الأصلية إلي الوراء، مُخلية الساحة لو لادة ذات أخري

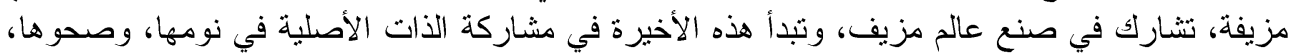

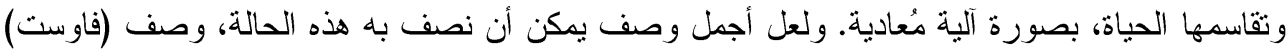

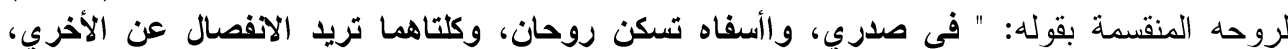

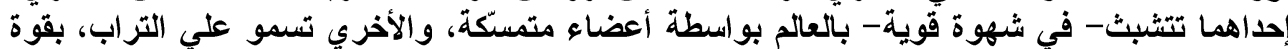
صاعدة إلي ساحات الأجداد".

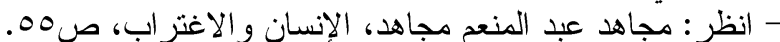

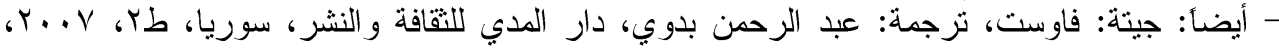
. rAN ص

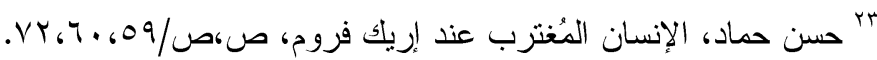

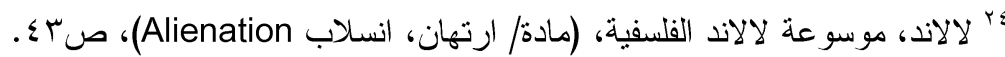

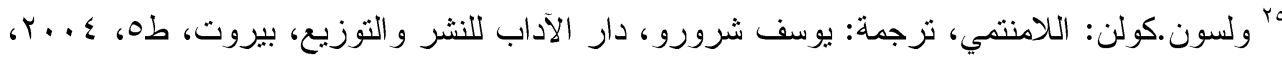

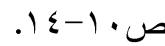

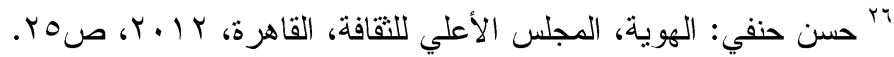

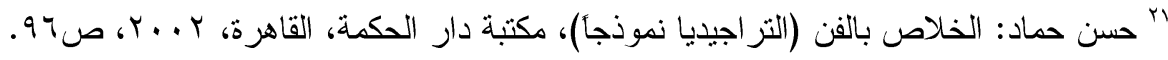

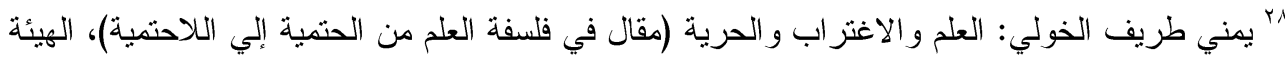

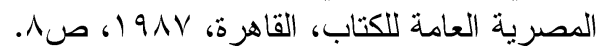
-Leopold.David: Alienation, Published online in: Stanford Encyclopedia of Philosophy, r.l1.

بو علي الرغم من أنه لا يوجد اتفاق تام بين الباحثين علي معني محدد لمفهوم الاغتر اب، فإن هناك اتفاقاً

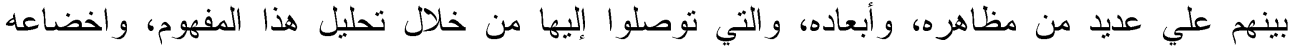

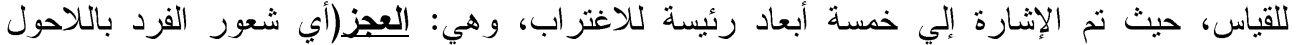

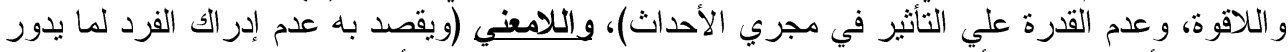

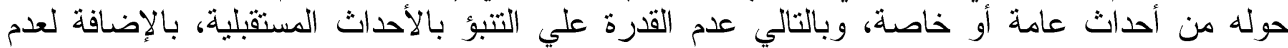

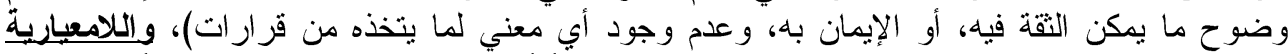

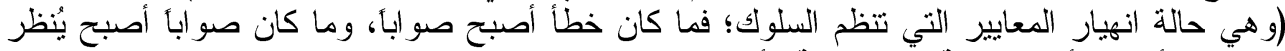

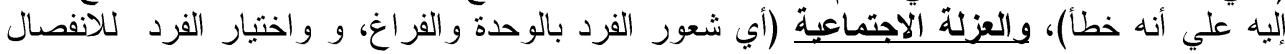

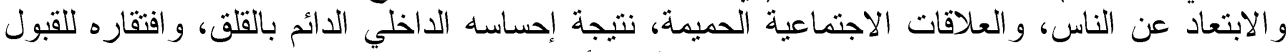

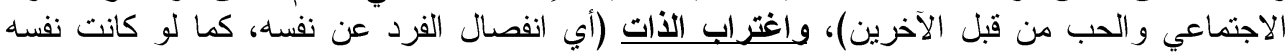

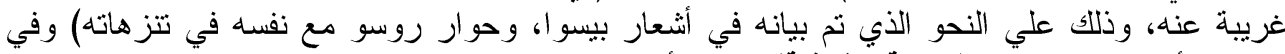

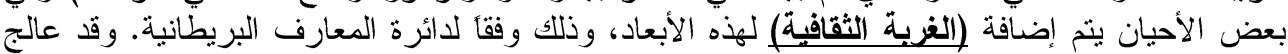

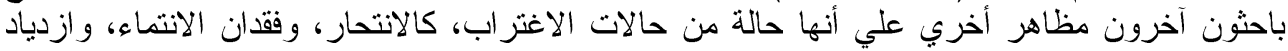

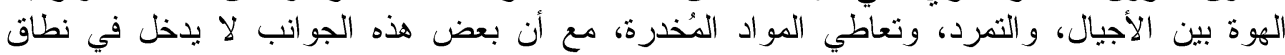

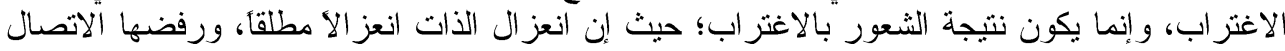

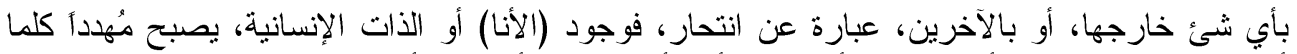

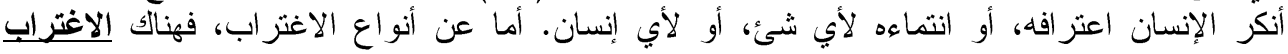




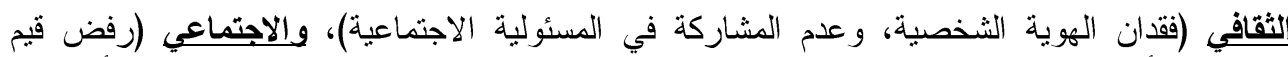

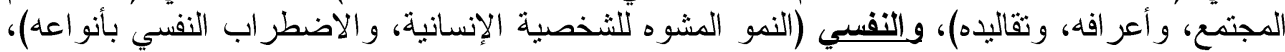

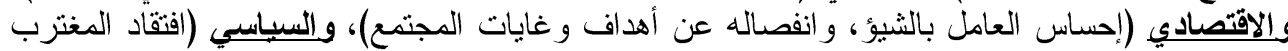

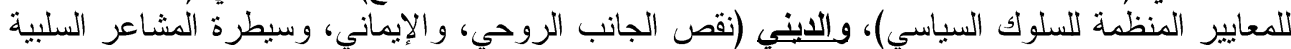

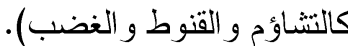
: - انظر

- Jackson.Sidney.J: The alienation of the individual from society: A social-psychological theory and cross-cultural comparison, Theses Submitted to the Requirements for the Degree of Doctor of PHILOSOPHY (Published), Iowa State University, Iowa, 19^r,P. 1 1 9 .

- أيضأ: عبد اللطيف محمد خليفة: دراسات في سيكولوجية الاغتراب، دار غريب للطباعة والنشر،

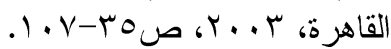

- برديائيف.نيقو لاي: العزلة والمجتمع، ترجمة: فؤاد كامل، مكتبة النهضة المصرية، القاهرة، .9719،

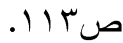

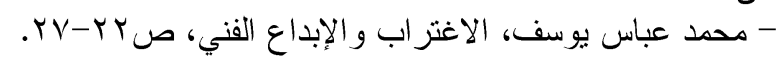

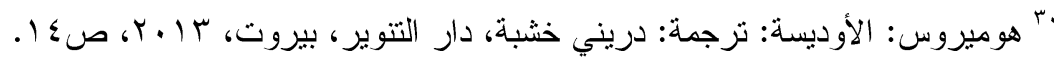

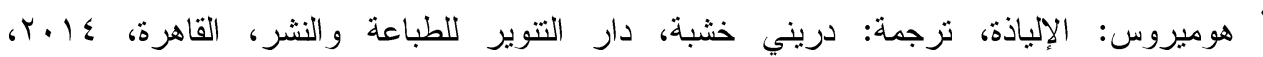

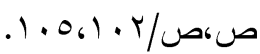
كَّ" فينلي.م.آي: عالم أوديسيوس، ترجمة: محمد عبودي إبراهيم، المركز القومي للترجمة، القاهرة،

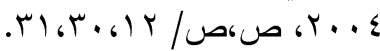

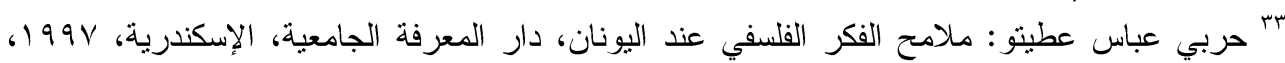

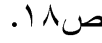

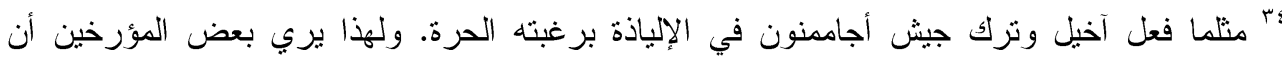

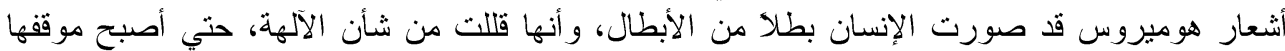

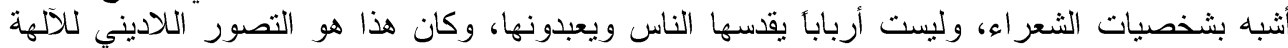
في المرحلة الأسطورية اليونانية. - انظر: جعفر أل يس: فجر الفلسفة اليونانية قبل سقراط، دار إحباء الكتب العربية، القاهرة، ع901، ص ro طب محمد علي أبو ريان: تاريخ الفكر الفلسفي (الفلسفة اليونانية)، دار الجامعات المصرية، الإسكندرية،

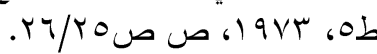

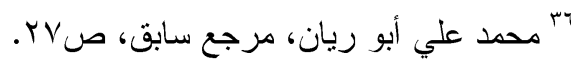

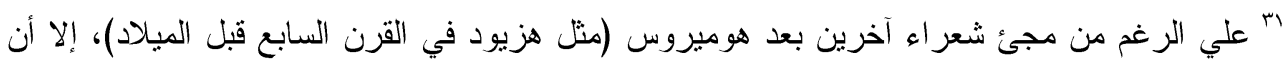

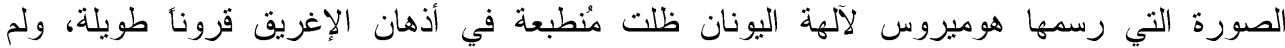

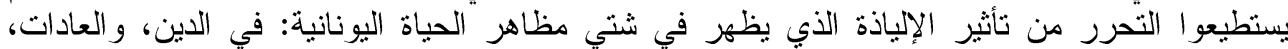

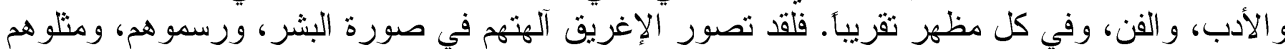

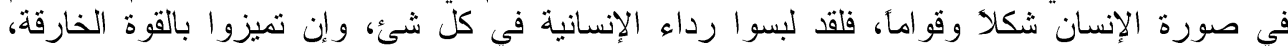

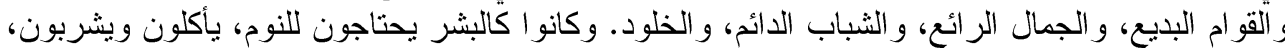

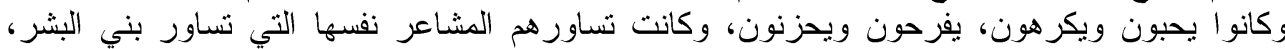

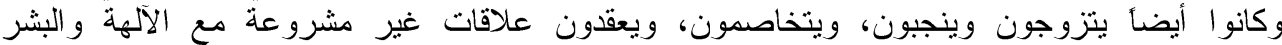

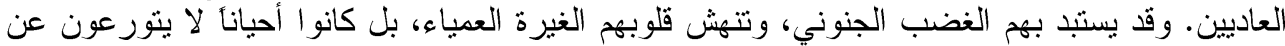

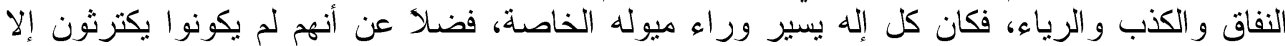

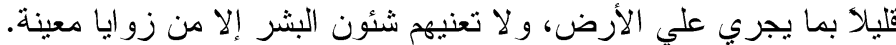

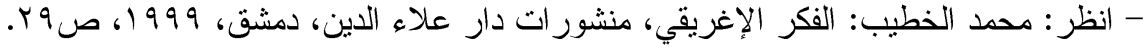


- أيضاً: أمبرة حلمي مطر: الفلسفة اليونانية تاريخها ومشكلاتها، دار قباء للطباعة والنشر و التوزيع،

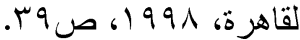

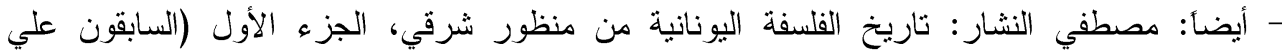

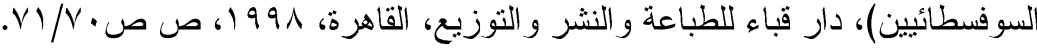

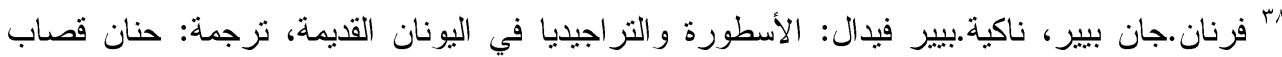

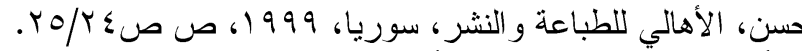
- أيضأ: فرنان.جان بيير: الأسطورة و الفكر عند اليورة اليونان (دراسات في علم النفس التاريخي)، ترجمة:

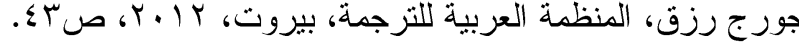

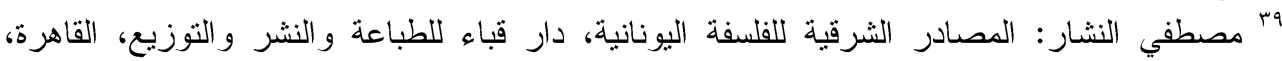
(199V

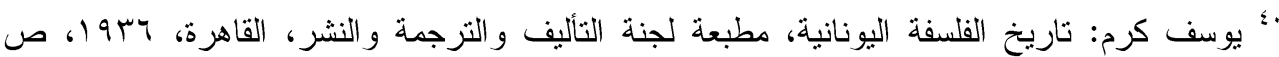
ص 0/5.

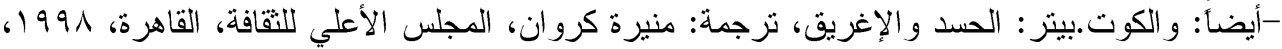

$$
\begin{aligned}
& \text { صهץ. } \\
& \text { " هو ميروس، الإلياذة، صلون. }
\end{aligned}
$$

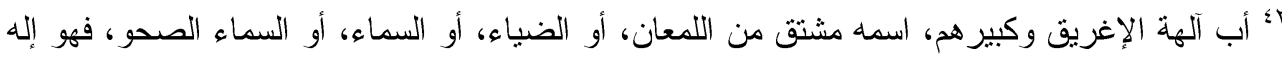

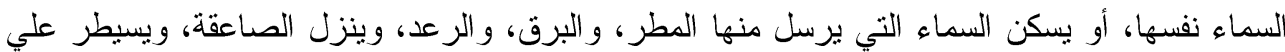

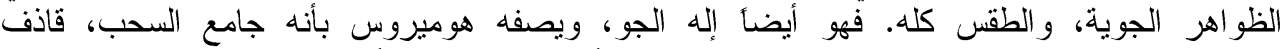

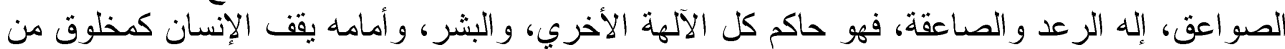
طبقة أدني، كائن عاجز، الرع ل ال حيلة له.

- Bonnerjet,Biren: A Dictionary of Superstitions and Mythology, Folk Press, London, $19 \mathrm{rv}$, (Art:Zeus), P.rr.

- Harrington.K.P,Herbert.C.T: Greek and Roman Mythology, Leach-Shewell and Sonborn Press, NewYork, । $९ \vee$, PP. । $/ / 19$.

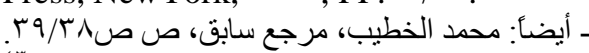

" Vernant.J.P: Myth and Society in Ancient Greece, Zone Book, NewYork, 199., P. . • _ $1 \cdot v$.

؛؛ جبل الأوليمب المشار إليه هنا، ليس جبلا فعليا يمكن زيارته أو رؤيته، علي الرغم من وجود جبل الربل

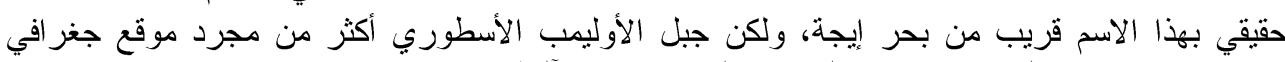

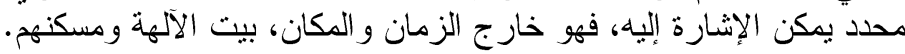

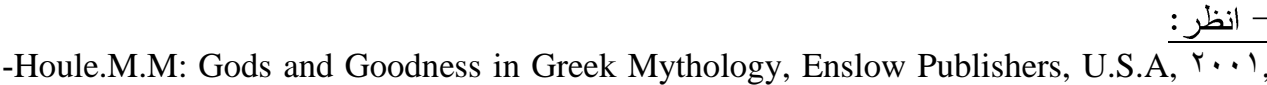
P.rv.

ه؛ نيهاردت.أ.أ: الآلهة والأبطال في اليونان القديمة، نرجمة: هاشم حمادي، الأهالي للطباعة والنشر

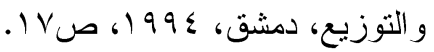
ب؛ فاين.بول: هل اعتقد الإغريق بأساطيرهو هُ (بحث في الخيال المُكّون)، ترجمة: جورج سليمان، هيئة

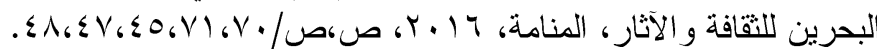
لأ أبيقور الرسائل و الحكم، دراسة وترجمة: جلال الدين سعيد، الدار العربية للكتاب، (د.م)، (د.ت)، . $\wedge V$

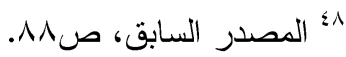




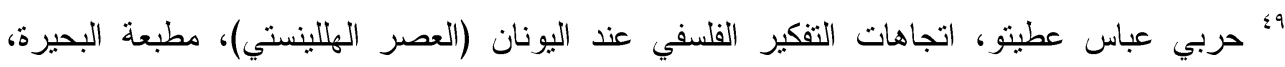

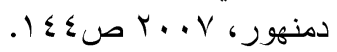

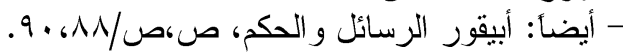

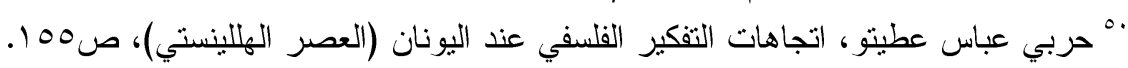

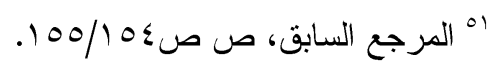

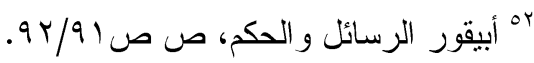

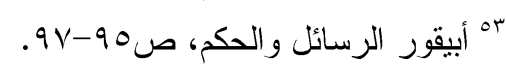
- أيضاً: عبد الرحمن بدوي: خريف الفكر اليوناني، مكتبة النهضة المصرية، القاهرة، طء، • لو 1، ص $.01 / 0 \mathrm{~V}$

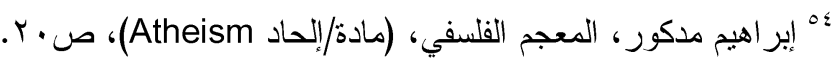

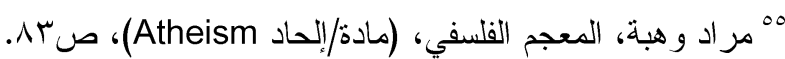

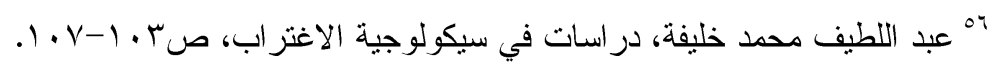

ov Obbink.Dirk: The Atheism of Epicurus(Paper), Barnard College, Columbia University, 1919, P,P/111, 19.,190,199, r.0.

زه أفلاطون: محاورة الدفاع، نشر في: محاورات أفلاطون(أوطيفرون، الدفاع، أقريطون، فيدون)، ترجمة:

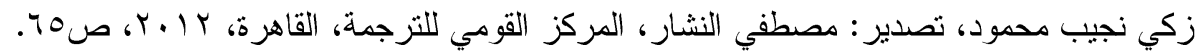

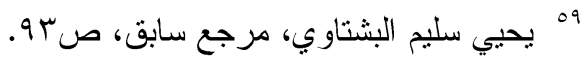

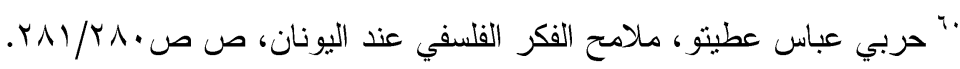

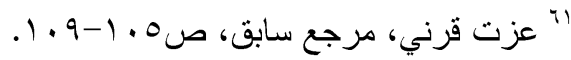

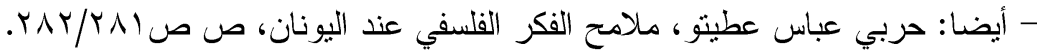

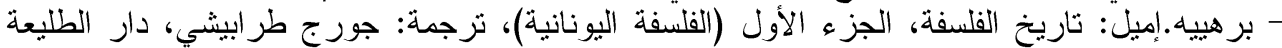

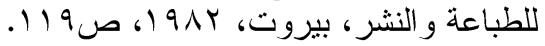
"َ ماذا تعني الديموقر اطية الأثينية؟ إنها بالدقة النظام السياسي لحكم طبقة التجار التي اتخذت موقاً وسطا

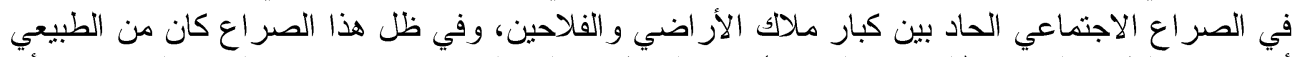

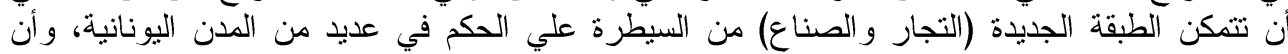

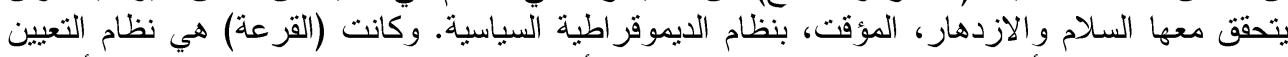

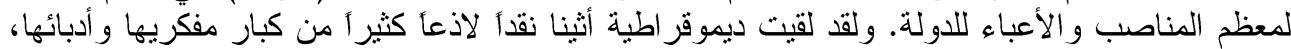

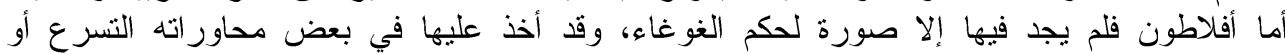

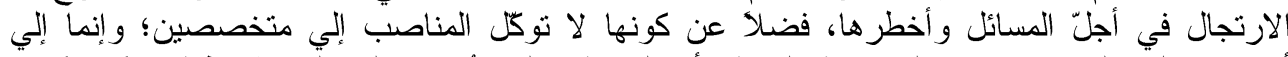

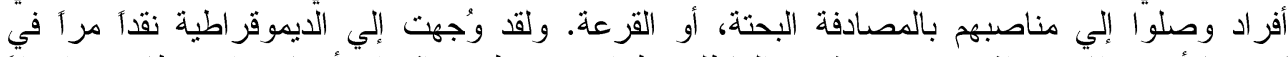

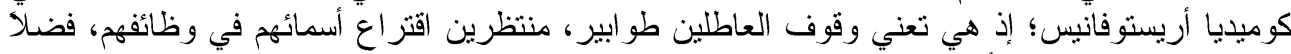

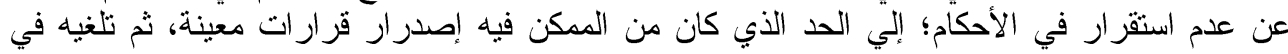

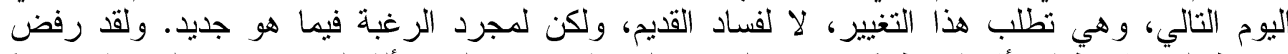

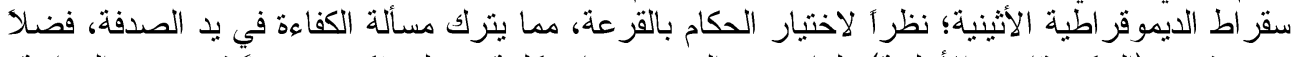

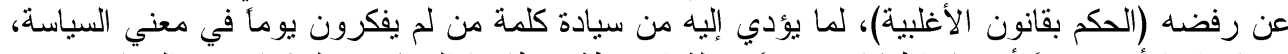

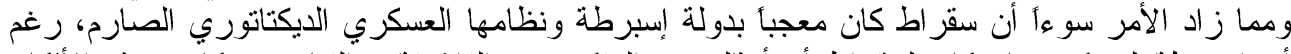

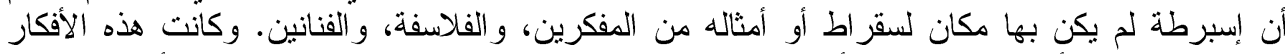
مصدر إزعاج للأثنيين، خاصنة وأنه اعتزم زرعها في نفوس المواطنين في مقابل الأفكار الفردية وذه الإن 
السوفسطائية، وقد أدت هذه الديموقر اطية إلي إعدامه في النهاية بالاقتر اع الذي صدر بأغلبية ضئيلة أثارت

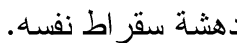
-انظر: ستون.آي.إف: محاكمة سقراط، ترجمة: نسيم مجلي، المجلس الأعلي للثقافة، القاهرة، ب...؟، صو 9.

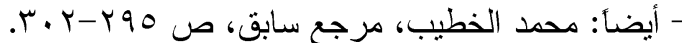

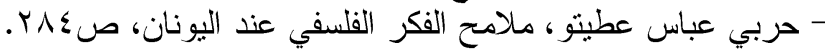

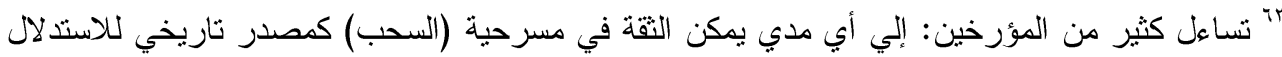

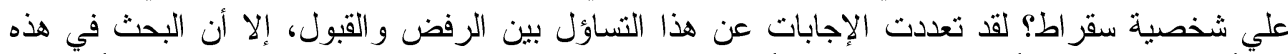

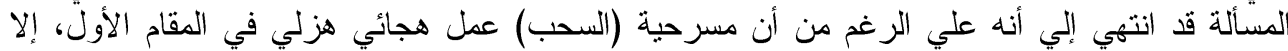

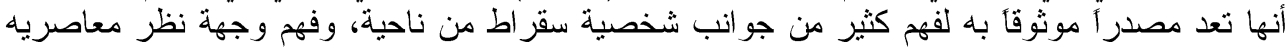

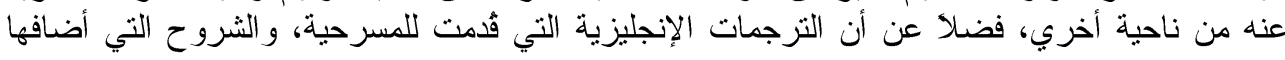

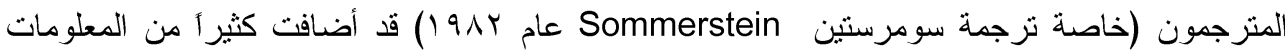
حول شخصية سقر اط، و التي تتاولها أفلاطون بعد ذللك بمزيد من الإيضاح في محاور اته. - انظر -

- El Murr.Dimitri: Socrates, Published in: Classics Oxford Bibliographies, Oxford, UK, r.17, P.r.

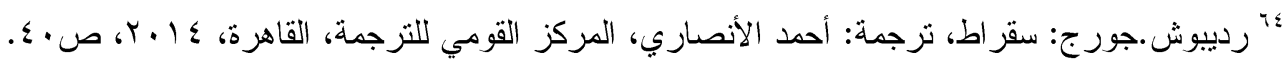

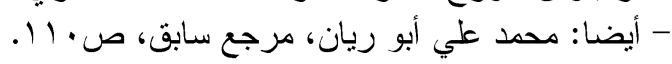

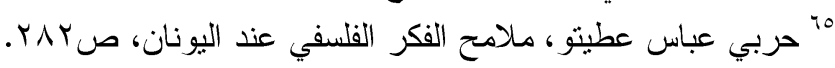

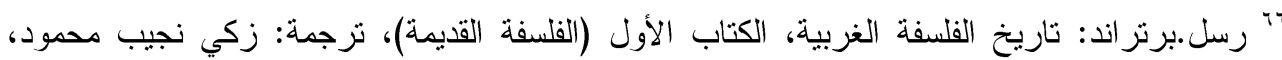

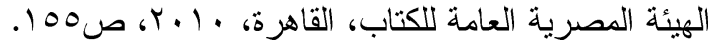

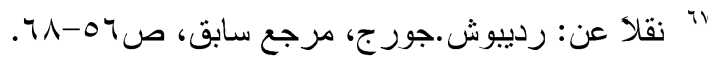

- Brickhouse.Thomas and Smith.Nicholas: Socratic Problem and Sources on Socrates, published in: The Blackwell Guide to Ancient Philosophy, Edited by: Shields.Christopher, Blackwell Publishers, U.S.A, r..r, P. ^.

"A-Brian.Duignan(ed): The History of Philosophy (Ancient Philosophy From $\uparrow \cdot$ BCE To ○. BCE), Encyclopedia Britannica, Inc., NewYork, Y.11, P. ₹r.

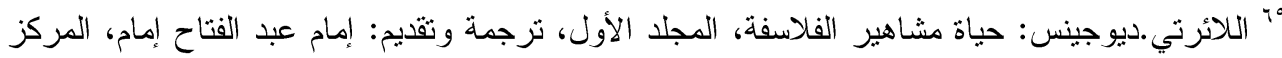

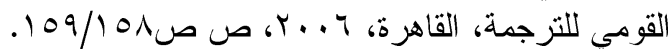

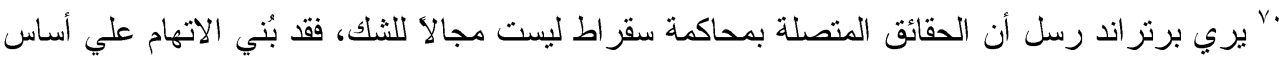

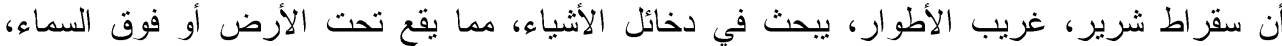

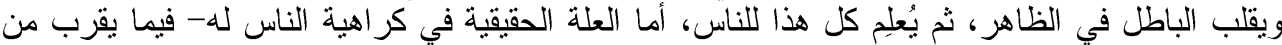

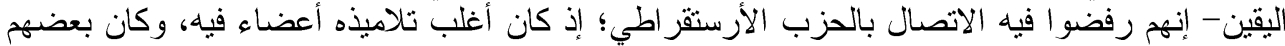

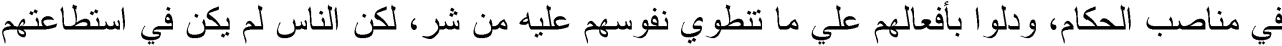

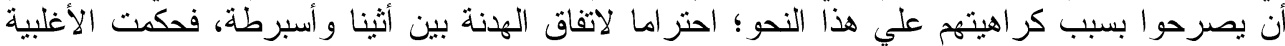

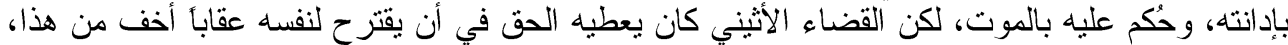

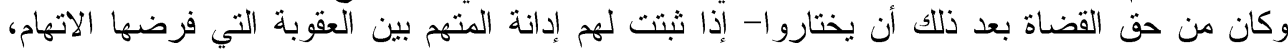

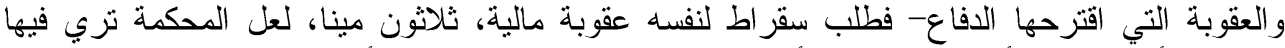

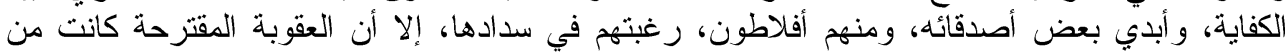

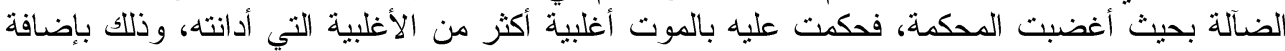

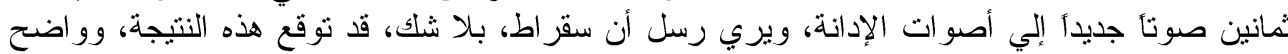

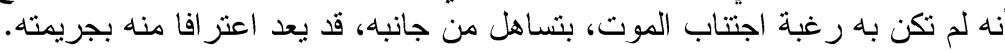

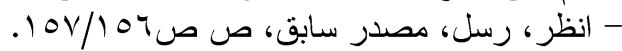




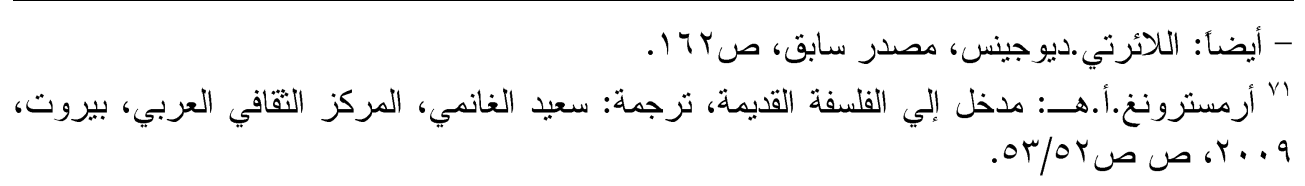

- Cheek.Lee: The Role of Existential Openness in the Apology and the Gorgias (Article), Published at: Georgia Political Science Association, r. 11, P.r.

-Cooper.John.M: Socrates, Published in: The Shorter Routledge Encyclopedia of Philosophy, Edited by: Craig.Edward, Routledge, London and NewYork, r... , PP. 9V / १YY.

صور لنا أفلاطون رفض سقراط لاقتر اح الفرار قبل تنفيذ عقوبة الإعدام في محاورة اقريطون، فلقد

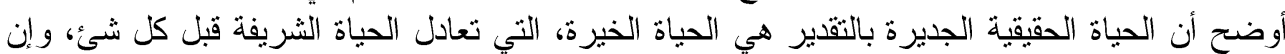

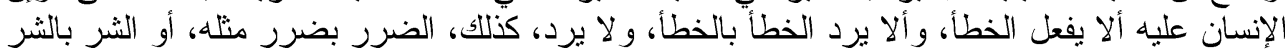

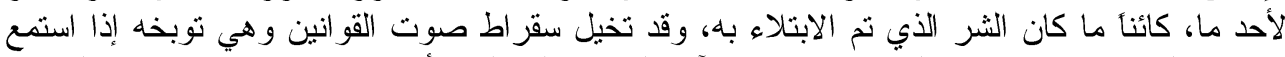

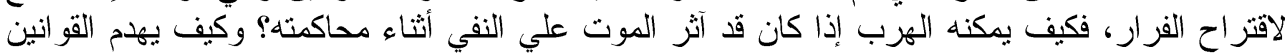

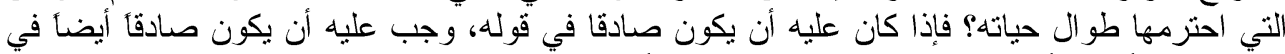

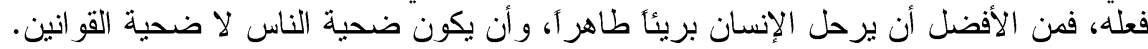

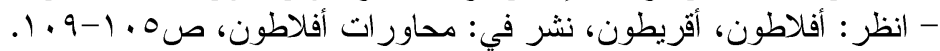

- Bonner.Kieran: Principles, Dialectic and The Common World of Friendship: Socrates and Crito in Conversation (Article), published in: HHS (History of the Human Sciences), Vol. $X X, r \cdot I r, P . r$.

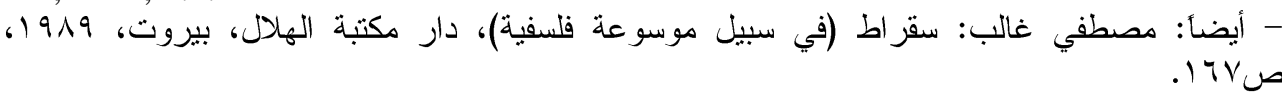

Kirkpatrick.Jennet: Exit out of Athens? Migration and Obligation in Plato's Crito (Article), Published in: Political Theory, Vol. $\leqslant$ r, r. 10, P.rov-ro9.

${ }^{\gamma}$ Flannery,Kevin.L: Rule of Law and The Virtue of Justice: The Socrates of Plato's Crito and A Pair of Later Moral Issues (Article), Published in: the Proceedings of the American Catholic Philosophical Association, Vol.9., r. IV, P. .'.

- Lévystone.David: What Rules and Laws does Socrates Obey? (Article), Published in: Journal of Philosophy, Vol.v०, Y..v, PP. $\leftleftarrows \cdots / \varepsilon \cdot 1$.

-Kirkpatrick.Jennet, Op.Cit, P. ${ }^{\circ}$.

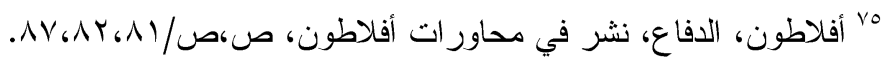

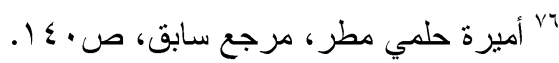

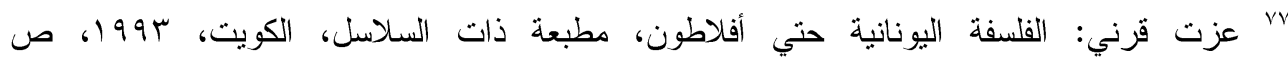

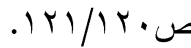

$$
\begin{aligned}
& \text { - أيضاً: محمد عبد الرحمن مرحبا: تاريخ الفلسفة اليونانية من بدايتها وحتي المرحلة الهلنسية، مؤسسة }
\end{aligned}
$$

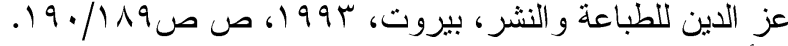

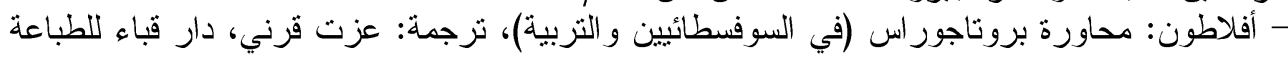

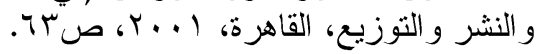

$$
\begin{aligned}
& \text { - كوبلستون.فردريك: تاريخ الفلسفة، الجزء الأهرة، الأول (اليونان، وروما)، ترجمة: إمام عبد الفتاح إمام، }
\end{aligned}
$$

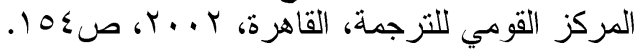

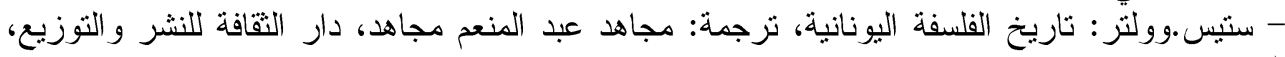

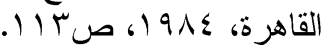

$$
\begin{aligned}
& \text { - تاتاركيفيتش.فو ادسواف: الفلسفة اليونانية، ترجمة: محمد عثمان مكي العجيل، كنوز للنشر و التوزيع، }
\end{aligned}
$$

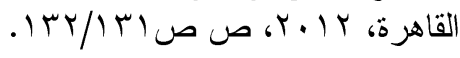

$$
\begin{aligned}
& \text {-Brian.Duignan(ed), Op.Cit, P.ruro. }
\end{aligned}
$$




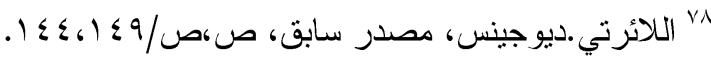
^و مصطفي النشار : مدخل لقر اءة الفكر الفلسفي عند اليونان، دار قباء للطباعة و النشر و التوزيع، القاهرة،

1- أبيقور الرسائل والحكم، دراسة وترجمة العمة: جلال الدين سعيد، الدار العربية للكتاب، (د.م)، (د.ت).

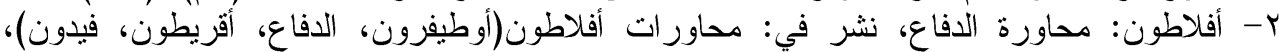

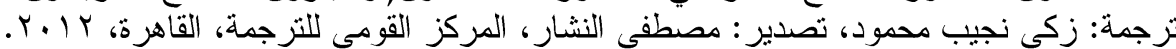

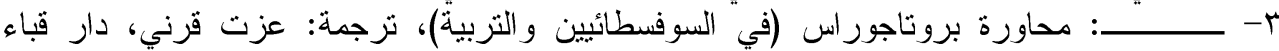

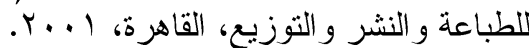

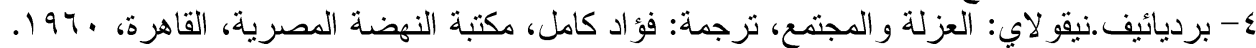

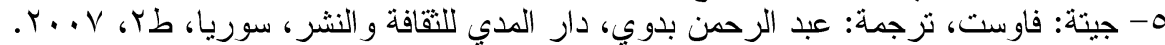

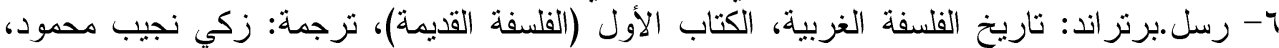

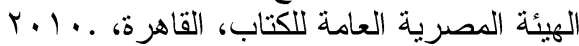
V- روسو .جان جاكئ هواجسة المس، المتنزه المنفرد بنفسه، ترجمة: بولس غانم، المنظمة العربية للترجمة،

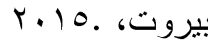
^- اللائرتي.ديوجينس: حياة مشاهير الفلاسفة، المجلد الأول، ترجمة وتقديم: إمام عبد الفتاح إمام، المركز

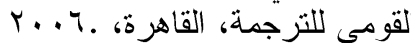
9- هايدجر .مارتن: الأنطولوجيا هيرمينوطيقا الواقعانية، ترجمة: عمارة الناصر، منشورات الجمل،

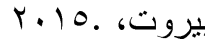

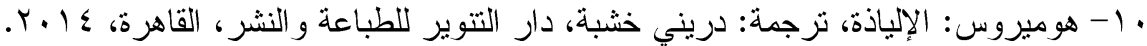

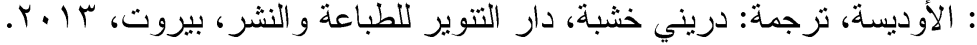

1- أميرة حلمي مطر : الفلسفة اليونانية تاريخها ومشكلاتها، دار قباء للطباعة و النشر و التوزيع، القاهرة،

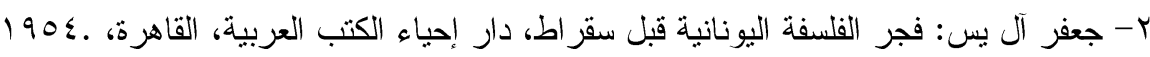
r- حربي عباس عطيتو : اتجاهات التفكير الفلسفي عند اليونان (العصر الهاللينستي)، مطبعة البحيرة،

r...v. دمنهور

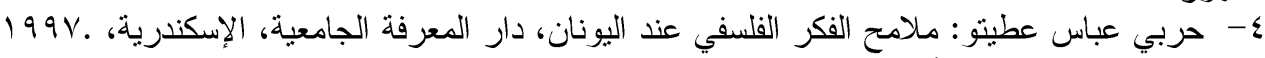

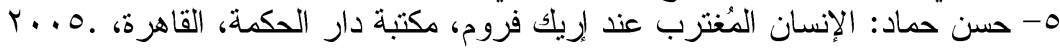

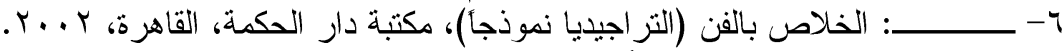

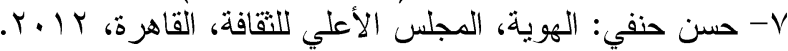

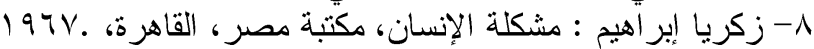

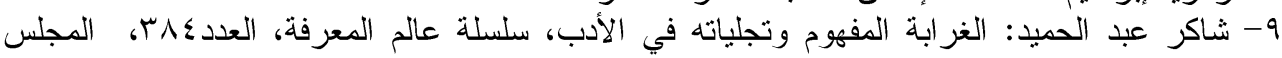

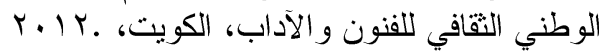
لمة الفن و الغرابة (مقدمة في تجليات الغريب في الفن والحياة)، الهيئة المصرية العامة

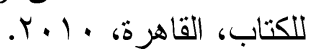

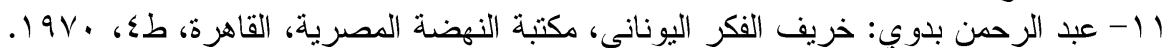
r ا- عبد اللطيف محمد خليفة: دراسات في سيكولوجية الاغتراب، دار غريب للطباعة و النشر، القاهرة،

س ا - عزت قرني: الفلسفة اليونانية حتي أفلاطون، مطبعة ذات السلاسل، الكويت، ب99 1. 
ع ا - فالح عبد الجبار : الاستلاب (هوبز، لوك، روسو، هيغل، فويرباخ، ماركس)، دار الفارابي، بيروت، .$r .11$ 10- مجاهد عبد المنعم مجاهد: الإنسان و الاغتراب، سعد الدين للطباعة والنشر و التوزيع، القاهرة،

1910

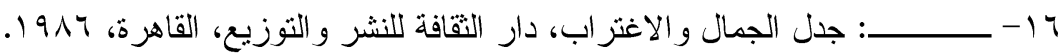

IV

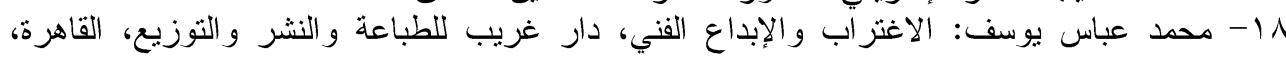

r...

9 أ- محمد عبد الرحمن مرحبا: تاريخ الفلسفة اليونانية من بدايتها وحتي المرحلة الهلنسية، مؤسسة عز

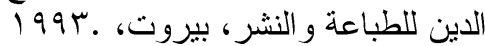

• ب- محمد علي أبو ريان: تاريخ الفكر الفلسفي (الفلسفة اليونانية)، دار الجامعات المصرية، الإسكندرية،

$19 \gamma r$. 190

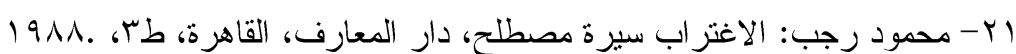

r r r مصطفي النشار: المصادر الثرقية للفلسفة اليونانية، دار قباء للطباعة و النشر و التوزيع، القاهرة،

$199 Y$.

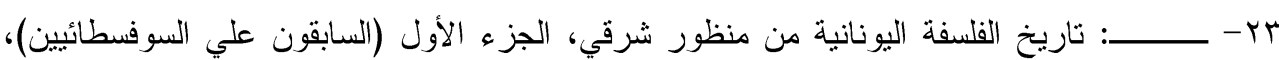

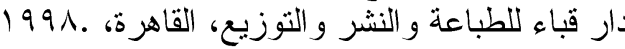

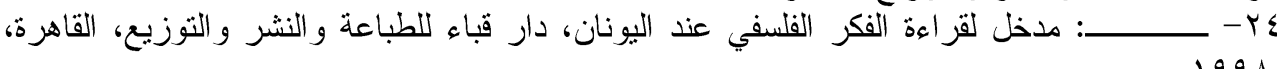

1991.

OY - مصطفي غالب: سقر اط (في سبيل موسو عة فلسفية)، دار مكتبة الهلال، بيروت، צr- يحبي سليم البشتاوي: أزمة الإنسان في الأدب المعاصر، دار دار ومكتبة الكندي للنشر و التوزيع، عمان،

$.+1 \leq$

VY أب- يمني طريف الخولي: العلم والاغتراب و الحرية (مقال في فلسفة العلم من الحتمية إلي اللاحتمية)،

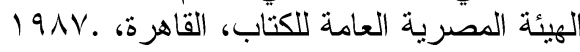

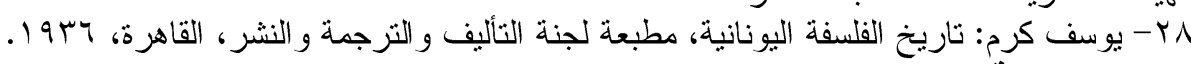

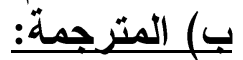

أ- أرمسترونغ.أ.هـ- مدخل إلي الفلسفة القديمة، ترجمة: سعيد الغانمي، المركز النقافي العربي، بيروت،

r- برهييه. إميل: تاريخ الفلسفة، الجزء الأول (الفلسفة اليونانية)، ترجمة: جورج طر ابيشي، دار الطلبعة

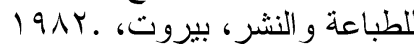
r- تاتاركيفيتش.فو ادسو اف: الفلسفة اليونانية، ترجمة: محمد عثمان مكي العجيل، كنوز للنشر و التوزيع،

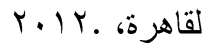

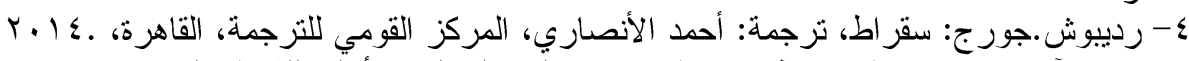

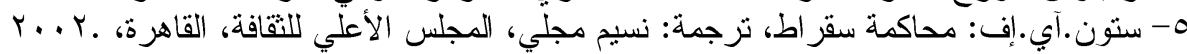

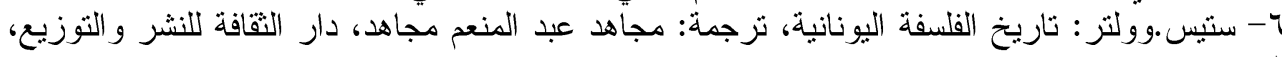

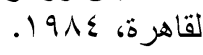
V- فاين.بول: هل اعتقد الإغريق بأساطيرهم؟ (بحث في الخيال المُّون)، ترجمة: جورج سليمان، هيئة

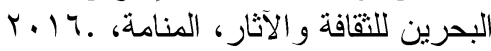
ر- فرنان.جان بيير: الأسطورة و الفكر عند اليونانيان (دراسات في علم النفس التاريخي)، ترجمة: جورج

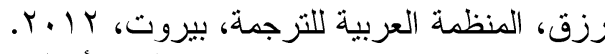

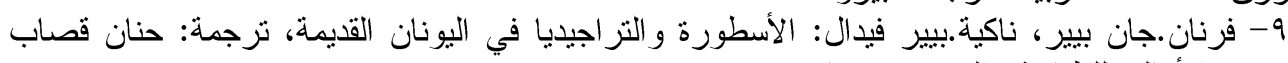

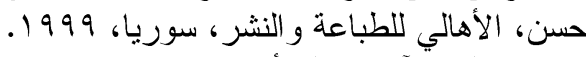

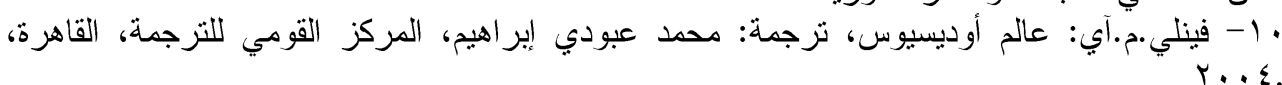




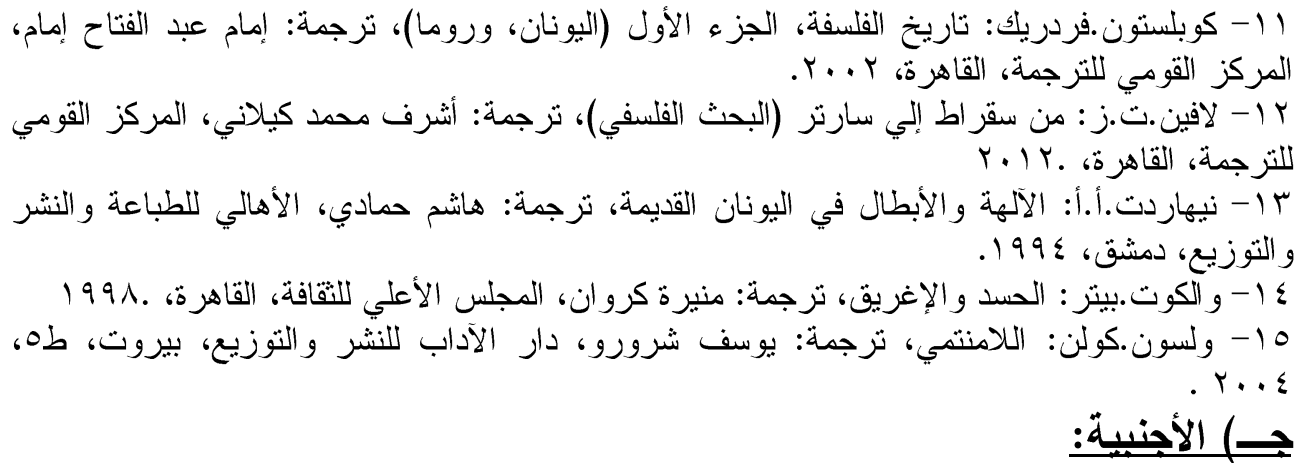

1- Brian.Duignan(ed): The History of Philosophy (Ancient Philosophy From 7 . BCE To ○. BCE), Encyclopedia Britannica, Inc., NewYork, $Y .11$.

r- Harrington.K.P,Herbert.C.T: Greek and Roman Mythology, Leach-Shewell and Sonborn Press, NewYork, $1 \wedge 9 \mathrm{~V}$.

ץ- Houle.M.M: Gods and Goodness in Greek Mythology, Enslow Publishers, U.S.A, ץ ...

乏- Sayers.Sean: Marx and Alienation (Essays on Hegelian Themes), Palgrave Macmillan, $\mathrm{UK}, \mathrm{r} \cdot 11$.

๑- Vernant.J.P: Myth and Society in Ancient Greece, Zone Book, NewYork, 199. .

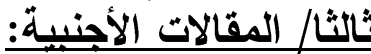

1- Bernburg.Jon: Anomie, Social Change and Crime. A Theoretical Examination of Institutional-Anomie Theory, British Journal of Criminology, September $r \ldots r$.

$r_{-}$Bjarnason.Thoroddur: Anomie Among European Adolescents (Conceptual and Empirical Clarification of a Multilevel Sociological Concept), Published in: Sociological Forum, Vol. $r \varepsilon$, No. ', March $r$.. .

r- Bonner.Kieran: Principles, Dialectic and The Common World of Friendship: Socrates and Crito in Conversation (Article), published in: HHS (History of the Human Sciences), Vol.XX, r. $r$ r.

¿-Brownlee.Timothy.L: Alienation and Recognition in Hegel's Phenomenology of Spirit (Article),Published in: Philosophical Forum, r.10.

- Cheek.Lee: The Role of Existential Openness in the Apology and the Gorgias (Article), Published at: Georgia Political Science Association, $r \cdot 11$.

'-Dicristin.Bruce: Durkheim's Theory of Anomie and Crime: A Clarification and Elaboration (Article), Anzsoc (Australian and New Zealand Journal of Criminology), Vol. $\leqslant 9$, Y. 17.

V- El Murr.Dimitri: Socrates, Published in: Classics Oxford Bibliographies, Oxford, UK, $r \cdot 17$.

^-Farahbod.Farzin: Work Alienation, Historical Backgrounds, Concepts, Reasons and Effects (Article), Published in: ISSN (Journal of Basic and Applied Scientific Research), r. Ir.

१-Flannery,Kevin.L: Rule of Law and The Virtue of Justice: The Socrates of Plato's Crito and A Pair of Later Moral Issues (Article), Published in: the Proceedings of the American Catholic Philosophical Association, Vol. $9 \cdot, r \cdot I V$.

1.- Kirkpatrick.Jennet: Exit out of Athens? Migration and Obligation in Plato's Crito (Article), Published in: Political Theory, Vol. $₹ r, r \cdot 10$.

11 - Lévystone.David: What Rules and Laws does Socrates Obey? (Article), Published in: Journal of Philosophy, Vol.vo, Y..V.

Ir- Mukherjee.S.R: On violence as the Negativity of the Durkheimian: between anomie, sacrifice and effervescence, Blackwell Publishing, Oxford, $r \ldots q$.

$1 \mathrm{r}$ - Obbink.Dirk: The Atheism of Epicurus, Barnard College, Columbia University, $19 \wedge 9$. 


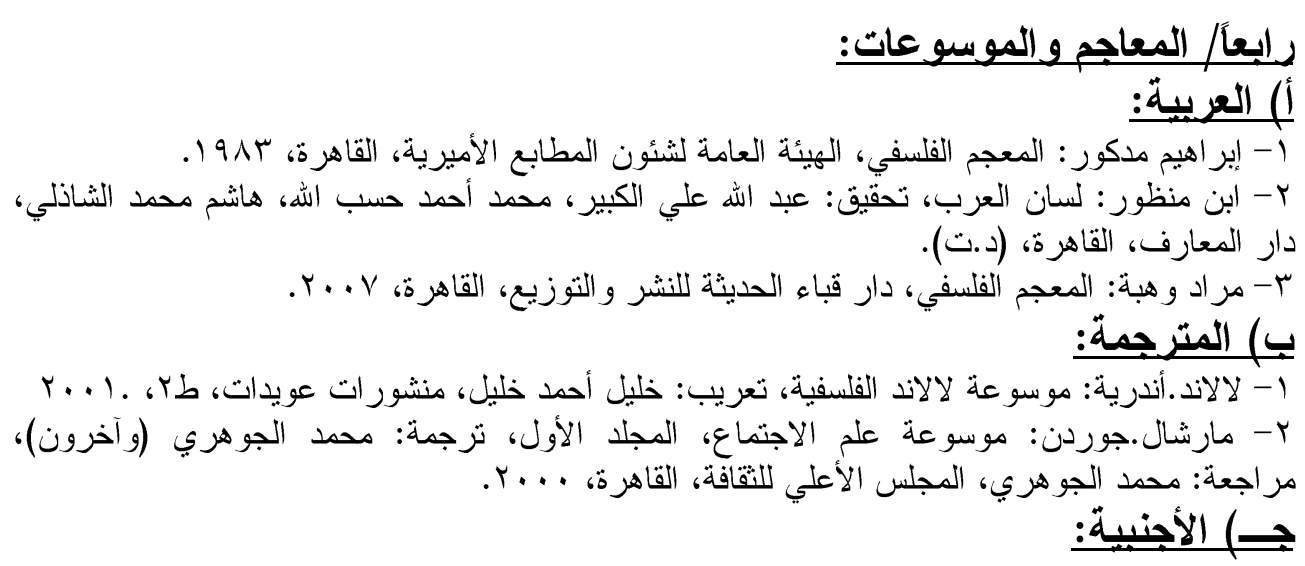

1- Bonnerjet,Biren: A Dictionary of Superstitions and Mythology, Folk Press, London, $194 r$.

r- Brickhouse.Thomas and Smith.Nicholas: Socratic Problem and Sources on Socrates, published in: The Blackwell Guide to Ancient Philosophy, Edited by: Shields.Christopher, Blackwell Publishers, U.S.A, $r \ldots r$.

r- Cooper.John.M: Socrates, Published in: The Shorter Routledge Encyclopedia of Philosophy, Edited by: Craig.Edward, Routledge, London and NewYork, Y $\cdots$. .

乏-Leopold.David: Alienation, Published online in: Stanford Encyclopedia of Philosophy, $r \cdot 1 \Lambda$.

- Wood.Aleen: Alienation, Published in: Routledge Encyclopedia of Philosophy, Routledge, London and NewYork, 1991 .

\section{خامساً / الرسائل العلمبة الأجنيية:}

1- Chooback.Nima: Marx's Theory of Alienation and the Capability Approach (A Comparative Study), Thesis Submitted to the requirements for the Degree of Master of Arts, The University of Western Ontario, Canada,,$\cdot 1$.

r- Hatley.Kathleen: The Development of the Concept of Alienation from Hegel to Marx (Its Relationship to the Perennial Philosophy), Thesis Submitted to the requirements for the Degree of Master of Science, Stilwell University, Oklahoma, $19 \mathrm{Vr}$.

r- Jackson.Sidney.J: The alienation of the individual from society: A social-psychological theory and cross-cultural comparison, Theses Submitted to the Requirements for the Degree of Doctor of Philosophy (Published), Iowa State University, Iowa, 19入r. 